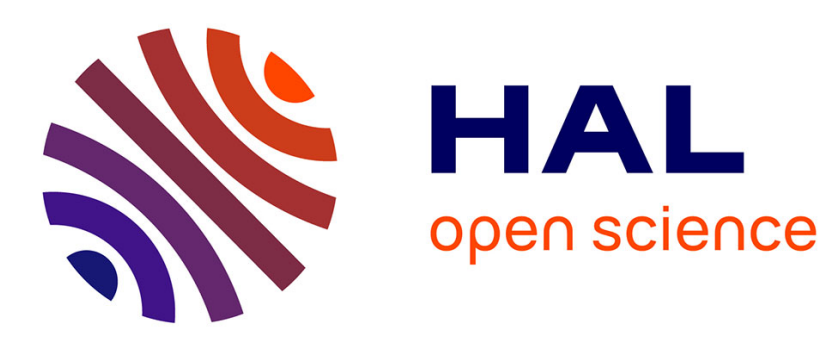

\title{
Protonation of $\mathrm{Cp}^{*} \mathrm{M}(\mathrm{dppe}) \mathrm{H}$ Hydrides: Peculiarities of the Osmium Congener
}

\author{
Pavel Dub, Oleg A Fillipov, Gleb A Silantyev, Natalia V Belkova, \\ Jean-Claude Daran, Lina M Epstein, Rinaldo Poli, Elena S Shubina
}

\section{- To cite this version:}

Pavel Dub, Oleg A Fillipov, Gleb A Silantyev, Natalia V Belkova, Jean-Claude Daran, et al.. Protonation of $\mathrm{Cp}^{*} \mathrm{M}($ dppe $) \mathrm{H}$ Hydrides: Peculiarities of the Osmium Congener. European Journal of Inorganic Chemistry, 2010, 2010 (10), pp.1489-1500. 10.1002/ejic.200901120 • hal-03177977

\section{HAL Id: hal-03177977 \\ https://hal.science/hal-03177977}

Submitted on 24 Mar 2021

HAL is a multi-disciplinary open access archive for the deposit and dissemination of scientific research documents, whether they are published or not. The documents may come from teaching and research institutions in France or abroad, or from public or private research centers.
L'archive ouverte pluridisciplinaire HAL, est destinée au dépôt et à la diffusion de documents scientifiques de niveau recherche, publiés ou non, émanant des établissements d'enseignement et de recherche français ou étrangers, des laboratoires publics ou privés. 


\title{
Protonation of $\mathrm{Cp} * \mathrm{M}(\mathrm{dppe}) \mathrm{H}$ hydrides: peculiarities of the osmium congener
}

\author{
Pavel A. Dub, ${ }^{[a, b]}$ Oleg A. Fillipov, ${ }^{[a]}$ Gleb A. Silantyev, ${ }^{[a]}$ Natalia V. Belkova, ${ }^{*[a]}$ \\ Jean-Claude Daran, ${ }^{[b]}$ Lina M. Epstein, ${ }^{[a]}$ Rinaldo Poli, ${ }^{*[b, c]}$ and Elena S. Shubina*[a]
}

Keywords: Osmium / Hydrido ligand / Proton transfer / Hydrogen bonding / DFT calculations

The interaction between $\mathrm{Cp} * \mathrm{OsH}(\mathrm{dppe})(\mathbf{1})$ and a series of proton donors (HA) of increasing strength (indole, $\mathrm{CFH}_{2} \mathrm{CH}_{2} \mathrm{OH}$ (MFE), $\mathrm{CF}_{3} \mathrm{CH}_{2} \mathrm{OH}$ (TFE), $\left(\mathrm{CF}_{3}\right)_{2} \mathrm{CHOH}$ (HFIP), p-nitrophenol, and $\left.\mathrm{HBF}_{4} \cdot \mathrm{Et}_{2} \mathrm{O}\right)$ has been investigated experimentally by variable temperature IR and NMR spectroscopies in solvents with different coordinating abilities (alkanes, dichloromethane and their mixtures) and computationally at the DFT/B3PW91 level using different models. Both the IR and NMR spectroscopic data for the interaction with weak proton donors are conform to the criteria of $\mathrm{M}-\mathrm{H} \cdots \mathrm{H}-\mathrm{A}$ bond formation. Theoretical calculations, however, indicate an asymmetric bifurcated interaction with a significant contribution from the metal atom, which is greater than that previously found for the corresponding $\mathrm{Fe}$ system. The basicity factor of $\mathbf{1}\left(E_{\mathrm{j}}=1.47\right)$ is greater than those of the $\mathrm{Ru}(1.39)$ and $\mathrm{Fe}$ (1.35) congeners, in agreement with previous studies on other compound families. The kinetic product of proton transfer, cis-

\begin{abstract}
$\left[\mathrm{Cp}^{*} \mathrm{Os}(\mathrm{H})_{2}(\mathrm{dppe})\right]^{+} \mathrm{X}^{-}$, which is selectively obtained at low temperatures, irreversibly rearranges to trans$\left[\mathrm{Cp} * \mathrm{Os}(\mathrm{H})_{2}(\mathrm{dppe})\right]^{+} \mathrm{X}^{-}$upon warming to $>230 \mathrm{~K}$. The latter compound with $\mathrm{X}=\mathrm{BF}_{4}$ has been crystallographically characterized. The activation enthalpy of the isomerization process $\left(\Delta H^{\ddagger}=21.5 \pm 1.0 \mathrm{kcal} \mathrm{mol}^{-1}\right)$, obtained from kinetics investigation by ${ }^{1} \mathrm{H}$ NMR in the $240-260 \mathrm{~K}$ range, is identical within experimental error to those previously reported for the $\mathrm{M}\left(\eta^{2}-\mathrm{H}_{2}\right)^{+} \mathrm{BF}_{4}^{-} \rightarrow$ trans $-\mathrm{M}(\mathrm{H})_{2}{ }^{+} \mathrm{BF}_{4}^{-}$isomerization process of the iron and ruthenium analogues. The activation entropy $\left(\Delta S^{\neq}\right.$ $=12 \pm 4$ e.u.), on the other hand, is greater than for the lighter metals, following the order $\mathrm{Fe}<\mathrm{Ru}<$ Os. The mechanism of proton transfer and trends in the energetics of the various steps upon changing the metal atom nature are discussed.
\end{abstract}

[a] A. N. Nesmeyanov Institute of Organoelement Compounds, Russian $\sqsupseteq \quad$ Academy of Sciences, 28 Vavilov Street, 119991 Moscow, Russia Fax: +7-499-1355085 E-mail: nataliabelk@ineos.ac.ru; shu@ineos.ac.ru

[b] LCC (Laboratoire de Chimie de Coordination), CNRS, 205 route de Narbonne, F-31077 Toulouse, France; Université de Toulouse, F31077 Toulouse, France

E-mail: rinaldo.poli@1cc-toulouse.fr

[c] Institut Universitaire de France, 103 bd Saint-Michel, 75005 Paris, France

Supporting information for this article is available on the WWW under http://www.eurjic.org/ or from the author.

\section{Introduction}

Proton transfer to transition metal hydrides continues to attract attention $^{[1,2]}$ because of its fundamental importance in many areas, from homogeneous catalysis ${ }^{[3,4]}$ to $\mathrm{H}_{2}$ biogenesis. ${ }^{[5,6]}$ It results in the formation of cationic dihydride and/or dihydrogen complexes. ${ }^{[7-10]}$ The latter may also be kinetic protonation products giving ultimately the dihydride. ${ }^{[11-15]}$ In the case of half-sandwich cyclopentadienyl metal dihydride complexes the hydride ligands could occupy different coordination sites, being in cisoid (as shown for instance in I and II of Chart 1) or transoid position (IV) and the specific cisoid case results in a possible dichotomy between classical (II) dihydride and nonclassical (III) dihydrogen complexes. Structure I was shown e.g. for compounds $\left[\mathrm{Cp}^{\prime} \mathrm{Mo}\left(\mathrm{PMe}_{3}\right)_{2} \mathrm{LH}_{2}\right]^{+}\left(\mathrm{L}=\mathrm{CO}, \mathrm{Cp}{ }^{\prime}=\mathrm{Cp}^{*} ;{ }^{[16]} \mathrm{L}=\mathrm{PMe}_{3}, \mathrm{Cp}^{\prime}=\right.$ $\left.\mathrm{Cp},{ }^{[17]} \quad \mathrm{Cp}^{*[18]}\right), \quad\left[\mathrm{CpW}\left(\mathrm{PMe}_{3}\right)_{2}(\mathrm{CO}) \mathrm{H}_{2}\right]^{+},{ }^{[19]} \quad$ and $\left[\mathrm{CpMo}(\mathrm{dppe})(\mathrm{CO}) \mathrm{H}_{2}\right]^{+}{ }^{+20]}$ For group 8 complexes of type $\left[\mathrm{Cp}^{\prime} \mathrm{ML}_{2} \mathrm{H}_{2}\right]^{+}$, structure $\mathbf{I V}$ is typical of all metals $\left(\mathrm{L}_{2}=2 \mathrm{PR}_{3}\right.$ or bidentate diphosphine), ${ }^{[7,8,12,15,21]}$ whereas structure II was only demonstrated spectroscopically at low temperature for a few osmium compounds. ${ }^{[21-23]}$ These structures are usually referred as trans and cis; this notation will be used herein as well. The cis (II) and dihydrogen complex (III) could be seen as resulting from protonation of the neutral precursors $\left(\mathrm{C}_{5} \mathrm{R}_{5}\right) \mathrm{MHL}_{2}$ on the same side (syn) as the hydride ligand, whereas the trans (IV) structure results from proton attack at the opposite side (anti).
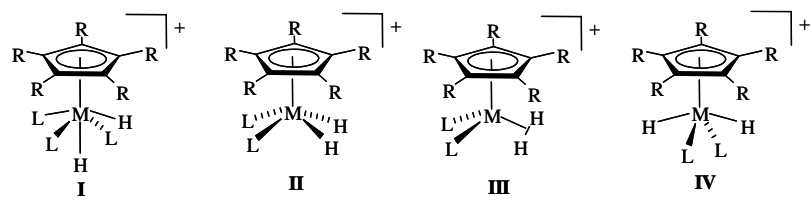

Chart 1.

The metal influence on the properties and relative stability of dihydrogen and dihydride tautomers of Group 8 metal hydrides is known for complexes of several types such as $\mathrm{MH}_{4} \mathrm{~L}_{3},\left[\mathrm{MH}_{3} \mathrm{~L}_{4}\right]^{+}$, $\left[\mathrm{MH}_{3}(\mathrm{PP})_{2}\right]^{+}, \quad\left[\mathrm{MCl}\left(\mathrm{H}_{2}\right)(\mathrm{PP})_{2}\right]^{+}, \quad\left[\mathrm{MH}\left(\mathrm{H}_{2}\right)\left(\mathrm{PP}_{3}\right)\right]^{+}, \quad$ and $\left[\mathrm{CpMH}_{2}(\mathrm{PP})\right]^{+}(\mathrm{L}=$ phosphines or monophosphites, $\mathrm{CO}$; $\mathrm{PP}=$ chelating phosphines; $\left.\mathrm{PP}_{3}=\mathrm{P}\left(\mathrm{CH}_{2} \mathrm{CH}_{2} \mathrm{PR}_{2}\right)_{3}\right){ }^{[24,}{ }^{25]}$ The relative stability of the dihydrogen form decreases when the metal is replaced successively by a heavier metal in the same group. The same trend was found for the $\left(\eta^{2}-\mathrm{H}_{2}\right)$ ligand acidity. A few exceptions to this general trend have been noted, which could be related to the strong $\mathrm{H}-\mathrm{H}$ interaction. ${ }^{[24,25]}$ The osmium analogues usually have the least tendency to form dihydrogen complexes. In some cases they give cationic cis-dihydride II (Chart 1) upon protonation without the observation of a dihydrogen complex 
intermediate. ${ }^{[21-23]}$ For example, the result of $\mathrm{CpMH(dppe)}$ protonation depends on the metal ( $\mathrm{Fe}, \mathrm{Ru}, \mathrm{Os})$ and temperature. In the case of iron the low temperature protonation by $\mathrm{HBF}_{4}$ yields $\left[\mathrm{CpFe}\left(\eta^{2}-\mathrm{H}_{2}\right)(\mathrm{dppe})\right]^{+}$, which remains non-classical up to room temperature but slowly loses $\left.\mathrm{H}_{2} .{ }^{[14,}{ }^{15}\right]$ For osmium the same reaction at $198 \mathrm{~K}$ yields mixture of cis- $\left[\mathrm{CpOs}(\mathrm{H})_{2}(\mathrm{dppe})\right]^{+}$and trans- $\left[\mathrm{CpOs}(\mathrm{H})_{2}(\mathrm{dppe})\right]^{+}$in a $1: 3$ ratio, which changes to $1: 70$ upon warming to room temperature. ${ }^{[21]}$ Protonation of the ruthenium congener was reported only at room temperature to yield a $1: 2$ mixture of $\left[\mathrm{CpRu}\left(\eta^{2}-\mathrm{H}_{2}\right)(\mathrm{dppe})\right]^{+}$and trans$\left[\mathrm{CpRuH}_{2} \text { (dppe) }\right]^{+} .{ }^{[26]}$

For the recently studied series of Group $8 \mathrm{Cp} * \mathrm{M}(\mathrm{dppe}) \mathrm{H}$ complexes $\left(\mathrm{M}=\mathrm{Fe},{ }^{[15,}{ }^{27,}{ }^{28]} \mathrm{Ru}^{[29]} \mathrm{Os}^{[23]}\right)$, the low temperature protonation by strong acids $\left(195 \mathrm{~K}, \mathrm{CD}_{2} \mathrm{Cl}_{2}\right)$ yields $\left(\eta^{2}-\mathrm{H}_{2}\right)(\mathrm{Fe}$, $\mathrm{Ru})$ or cis-(H)2 (Os) complexes as kinetic products of syn protonation. For all three metals they convert into the corresponding trans-dihydrides upon warming. The use of weak proton donors allowed establishing the following proton transfer mechanism for $\mathrm{M}=\mathrm{Fe}$ and $\mathrm{Ru}$ (Scheme 1):

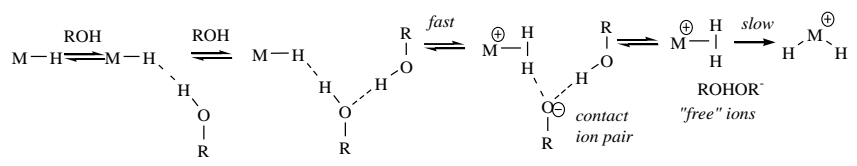

Scheme 1. Mechanism of proton transfer to $\mathrm{Cp}^{*} \mathrm{MH}(\mathrm{dppe})(\mathrm{M}=\mathrm{Fe}, \mathrm{Ru})$

After the reversible dihydrogen bond formation the proton transfer occurs with participation of a second proton donor molecule. The irreversible isomerization $\left[\mathrm{Cp} * \mathrm{M}\left(\eta^{2}-\mathrm{H}_{2}\right)(\mathrm{dppe})\right]^{+} \rightarrow$ trans- $\left[\mathrm{Cp} * \mathrm{M}(\mathrm{H})_{2}(\mathrm{dppe})\right]^{+}$occurs upon ion pair dissociation. The enthalpy of dihydrogen bond formation and proton transfer increases from iron to ruthenium, whereas the activation parameters for the subsequent isomerization are very similar. The theoretical study of the dihydrogen - dihydride transformation mechanism for $\mathrm{M}=\mathrm{Fe}$ showed that it involves a ligand reorganization without intermediates. ${ }^{[30]}$ Notably, no stationary point was found corresponding to a putative cis-dihydride isomer. The present work aims at shining more light on the mechanism of proton transfer to $\mathrm{Cp} * \mathrm{Os}(\mathrm{dppe}) \mathrm{H}$.

\section{Results}

Interaction with weak proton donors: characterisation of the hydrogen-bonded intermediate.

In order to investigate the mechanism of the protonation of $\mathrm{Cp} * \mathrm{OsH}(\mathrm{dppe}), \mathbf{1}$, in more details, its interaction with different proton donors was studied by IR $\left(v_{\mathrm{OH}}\right.$ and $\left.v_{\mathrm{OsH}}\right)$ and NMR spectroscopies in the 190-300 K temperature range. According to our well-established protocol, ${ }^{[31]}$ the following set of $\mathrm{OH}$ and $\mathrm{NH}$ proton donors was used: $\mathrm{CFH}_{2} \mathrm{CH}_{2} \mathrm{OH}$ (MFE), $\mathrm{CF}_{3} \mathrm{CH}_{2} \mathrm{OH}$ (TFE) and $\left(\mathrm{CF}_{3}\right)_{2} \mathrm{CHOH}$ (HFIP), indole. In the presence of excess hydride in any solvent used $\left(\mathrm{CH}_{2} \mathrm{Cl}_{2}\right.$, alkanes or their mixtures), the IR spectra of MFE and TFE in the $v_{\mathrm{OH}}$ region show a typical picture of hydrogen bond formation. The intensity decrease of the alcohol $\mathrm{vOH}^{\text {free }}$ band is accompanied by the appearance of a new broad low frequency $\mathrm{vOH}^{\text {bonded }}$ bands typical of hydrogen bonded $\mathrm{OH}$ (Table $1)$.

As expected, the interaction with the more fluorinated alcohol TFE - is stronger than with MFE, as indicated by the greater band shift $\Delta v_{\mathrm{OH}}=\mathrm{vOH}^{\text {free }}-\mathrm{VOH}^{\text {bonded }}$. The interaction enthalpies were obtained using Iogansen's empirical correlation (Equation 1). ${ }^{[32,33]}$ Analysis of the temperature dependence of the H-bond formation constants for TFE gives $\Delta H^{\circ}=-6.1 \mathrm{kcal} \mathrm{mol}^{-1}$ and $\Delta S^{\circ}=-19.7$ e.u. The basicity factor $E_{j}=1.47$ obtained by Equation 2 can be compared with those found for the $\mathrm{Ru}(1.39)^{[29]}$ and $\mathrm{Fe}(1.35)^{[27]}$ analogues. These data show the expected basicity increase on descending the group, similarly to the $\mathrm{PP}_{3} \mathrm{MH}_{2}$ hydride series $\left(\mathrm{PP}_{3}\right.$ $\left.=\mathrm{P}\left(\mathrm{CH}_{2} \mathrm{CH}_{2} \mathrm{PPh}_{2}\right)_{3}, \mathrm{M}=\mathrm{Fe}, \mathrm{Ru}, \mathrm{Os}\right) .{ }^{[34]}$ However, the $E_{\mathrm{j}}$ range is narrower for the $\mathrm{Cp} * \mathrm{MH}(\mathrm{dppe})$ series than for the $\mathrm{PP}_{3} \mathrm{MH}_{2}$ series (1.12-1.67).

Table 1. Parameters of the hydrogen-bonding between $\mathrm{Cp} * \mathrm{OsH}(\mathrm{dppe})$ and MFE or TFE in $\mathrm{CH}_{2} \mathrm{Cl}_{2}$.

\begin{tabular}{lllllll}
\hline ROH & $\mathrm{P}_{\mathrm{i}}^{[\mathrm{a}]}$ & $\begin{array}{l}v_{\mathrm{OH}(\text { free })}, \\
\mathrm{cm}^{-1}\end{array}$ & $\begin{array}{l}v_{\mathrm{OH} \text { (bonded) }} \\
\mathrm{cm}^{-1}\end{array}$ & $\begin{array}{l}\Delta v, \\
\mathrm{~cm}^{-1}\end{array}$ & $\begin{array}{l}\Delta H^{\mathrm{o}[\mathrm{b}]} \\
\mathrm{kcal} \mathrm{mol}^{-1}\end{array}$ & $\mathrm{E}_{\mathrm{j}}^{[\mathrm{c}]}$ \\
\hline MFE & 0.74 & 3614 & 3338 & 276 & -5.0 & 1.47 \\
TFE & 0.89 & 3592 & 3229 & 363 & -6.0 & 1.47 \\
\hline
\end{tabular}

[a] Acidity factors of proton donors. ${ }^{[35]}$ [b] Calculated by Equation 1, mean error $\pm 0.4 \mathrm{kcal} \mathrm{mol}^{-1}$ [c] Basicity factor as defined in Equation 2, $\Delta H_{11}^{\circ}=$ $-4.6 \mathrm{kcal} \mathrm{mol}^{-1}$ for $\mathrm{CH}_{2} \mathrm{Cl}_{2}{ }^{[35]}$

$$
\begin{aligned}
& \Delta \mathrm{H}=18 \Delta v /(\Delta v+720) \\
& \mathrm{E}_{\mathrm{j}}=\Delta \mathrm{H}_{\mathrm{ij}} /\left(\Delta \mathrm{H}_{11} \mathrm{P}_{\mathrm{i}}\right)
\end{aligned}
$$

The IR spectrum of $\mathbf{1}$ in the Os-H stretching vibration region was studied in the presence of proton donors in different solvents. The $v_{\text {MH }}$ band of the hydride complex $1\left(2033 \mathrm{~cm}^{-1}, \Delta v_{1 / 2}=56 \mathrm{~cm}^{-1}\right.$ at $200 \mathrm{~K})$ is quite symmetric as shown in Figure 1 and partially overlaps on the low frequency side with a dppe ligand overtone. Its intensity decreases as the temperature increases $(\varepsilon=84$ and $63 \mathrm{~L}$ $\mathrm{mol}^{-1} \mathrm{~cm}^{-1}$ at 200 and $250 \mathrm{~K}$, respectively). Titration of 1 by TFE in hexane at $200 \mathrm{~K}$ causes the $v_{\mathrm{OsH}}$ band intensity to increase when using up to 4 equiv of the proton donor. However, no $v_{\mathrm{OsH}}$ band shift was observed under these conditions. Further addition of the proton donor causes an intensity decrease, explained by the proton transfer (see Figure S1). When the same study was carried out in the more polar dichloromethane, only the $v_{\mathrm{O} \text { sH }}$ band decrease due to protonation was observed with any amount of proton donor. No low-frequency shifts/shoulders expected for a dihydrogen-bonded adducts were revealed. A similar behavior was observed for the $\mathrm{Ru}$ analogue in these solvents. ${ }^{[29]}$

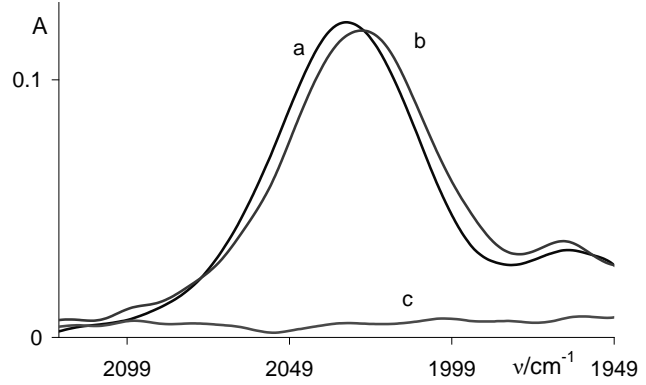

Figure 1. IR spectra ( $v_{\mathrm{OsH}}$ region) of $\mathrm{Cp}^{*} \mathrm{OsH}(\mathrm{dppe})(\mathbf{1})(0.017 \mathrm{M})(\mathrm{a}), \mathbf{1}$ in the presence of indole (5 equiv) (b). Methylcyclopentane-dichloromethane $2: 1 \mathrm{v} / \mathrm{v}$ mixture, $190 \mathrm{~K}$. Spectrum of indole $(0.085 \mathrm{M})(\mathrm{c})$ is shown for comparison.

In the case of the $\mathrm{Ru}$ system, use of a $2: 1 \mathrm{v} / \mathrm{v}$ hexane (or methylcyclopentane)-dichloromethane mixture revealed a lowfrequency $v_{\mathrm{MH}}$ shoulders in the presence of MFE or TFE, 
evidencing syn addition with formation of a dihydrogen-bonded adduct. In the case of osmium, on the other hand, only a band intensity increase and no low-frequency shoulder were observed under these conditions. However, a low-frequency shift (of $-5 \mathrm{~cm}^{-1}$ ) became observable in the presence of the weaker proton donor indole (5 equiv) (Figure 1), also suggesting syn addition of the proton donor for this metal.

The low temperature NMR study of $\mathbf{1}$ in the presence of excess TFE in $\mathrm{CD}_{2} \mathrm{Cl}_{2}$ shows the expected changes for dihydrogen bond formation: ${ }^{[31]}$ the hydride resonance shifts upfield $(\Delta \delta=-0.05$ and -0.07 with 2.7 and 4.5 equiv. TFE respectively, see Figure S2). The ${ }^{31} \mathrm{P}\left\{{ }^{1} \mathrm{H}\right\}$ resonance shifts by -0.4 and $-0.5 \mathrm{ppm}$. The $T_{1 \mathrm{~min}}$ value of the hydride resonance substantially decreases upon proton donor addition, being $270 \mathrm{~ms}$ at $230 \mathrm{~K}(500 \mathrm{MHz})$ in the presence of 2.7 equiv of TFE (vs. $850 \mathrm{~ms}$ at $220 \mathrm{~K}$ for $\mathbf{1}$ ). The presence of cis$\left[\mathrm{Cp} * \mathrm{Os}(\mathrm{H})_{2}(\mathrm{dppe})\right]^{+}$, cis- $\mathbf{1} \mathbf{H}^{+}(6 \%$ and $20 \%$ for 2.7 and 4.5 equiv of TFE), is evident from the appearance of a virtual triplet signal at $-13.32 \mathrm{ppm}$ in the ${ }^{1} \mathrm{H}$ NMR spectrum (having a $\mathrm{T}_{1}$ of ca. $270 \mathrm{~ms}$ at $200 \mathrm{~K})$. Much smaller $\Delta \delta$ values were found for the interaction between 1 and MFE ( 3 and 7 equiv): -0.005 and -0.011 for ${ }^{1} \mathrm{H}$ and 0.03 and -0.06 for ${ }^{31} \mathrm{P}\left\{{ }^{1} \mathrm{H}\right\}$ (see Figure S3). Both the IR and NMR spectroscopic data obtained for the interaction of $\mathrm{Cp} * \mathrm{OsH}(\mathrm{dppe})$ with proton donors as well as those obtained earlier for the iron and ruthenium congeners are conform to the criteria of $\mathrm{M}-\mathrm{H} \cdots \mathrm{H}-\mathrm{A}$ bond formation. ${ }^{[31]}$

\section{Interaction with p-nitrophenol - ion pairing in cis- $\left[\mathrm{Cp} * \mathrm{Os}(\mathrm{H})_{2}(\mathrm{dppe})\right]^{+} \mathbf{X}^{-}$}

The equilibrium resulting from the interaction between $\mathrm{Cp} * \mathrm{OsH}(\mathrm{dppe})$ and $p$-nitrophenol (PNP, $P_{i}=1.27$ ) was investigated with the aim to get data about ion pairs formed as the result of proton transfer. Following the approach developed in our laboratories, ${ }^{[28,29,36]} \mathrm{UV}$-visible spectra were recorded for $\mathrm{CH}_{2} \mathrm{Cl}_{2}$ solutions of PNP $(0.001 \mathrm{M})$ in the presence of $\mathbf{1}$ at ratios from 1:0.1 to $1: 2$ at $200 \mathrm{~K}$. As expected the spectra show wide overlapping bands resulting from various forms of phenol and the hydride complex (both free and hydrogen bonded) (Figure 2 and Scheme 2 ). The absence of free phenolate is signalled by the absence of a band at $430 \mathrm{~nm}$.

Band decomposition yields three bands with maxima at 312 , 346 , and $386 \mathrm{~nm}$. The first two are assigned to free PNP and to the dihydrogen bonded complex $[\mathrm{Cp} *(\mathrm{dppe}) \mathrm{OsH}] \cdots \mathrm{HOC}_{6} \mathrm{H}_{4} \mathrm{NO}_{2}$. The band at $386 \mathrm{~nm}$ is attributed to a hydrogen-bonded phenolate ion, since this is blue-shifted from the free $\mathrm{ArO}^{-}$band by $44 \mathrm{~nm}$. The anion appears to be present in the form of a homoconjugate ion on the basis of a titration experiment. Upon increasing the amount of $\mathbf{1}$ at constant PNP concentration at $200 \mathrm{~K}$, the bands at $346 \mathrm{~nm}$ and $386 \mathrm{~nm}$ grow in intensity whereas the free phenol band at $312 \mathrm{~nm}$ decreases (Figure 2, top). Plotting the intensity at $390 \mathrm{~nm} v s$ the $\mathrm{Cp} * \mathrm{OsH}$ (dppe) mole fraction (Figure 2, bottom) gives a break point for a mole fraction of 0.33 , indicating a $1: 2$ binding stoichiometry for the ionic species, cis-[Cp* $\left.(\mathrm{dppe}) \mathrm{Os}(\mathrm{H})_{2}\right]^{+-}$ [ArOHOAr]. The same ion pair composition was shown previously for the cationic dihydrogen complexes of iron and ruthenium, $\left[\mathrm{Cp} *(\mathrm{dppe}) \mathrm{M}\left(\eta^{2}-\mathrm{H}_{2}\right)\right]^{+}[\mathrm{ArOHOAr}]^{-}$. The $14 \mathrm{~nm}$ blueshift of this band relative to free [ArOHOAr] $]^{-}$suggests ${ }^{[37]}$ further hydrogen bonding of the homoconjugated anion with the cationic dihydrogen complex, $\left[\mathrm{Cp}^{*}(\mathrm{dppe}) \mathrm{OsH}_{2}\right]^{+\ldots}[\mathrm{ArOHOAr}]^{-}$. Note that on descending the group both bands attributed to the hydrogen bonded complex and ion pair shift slightly to longer wavelengths; the hydrogen bonded complex band appears at 340, 342 and 346 $\mathrm{nm}$ and that of the ion pair is at 380,384 and $386 \mathrm{~nm}$ for $\mathrm{Fe}, \mathrm{Ru}$ and Os, respectively. This is in agreement with an increase of hydride proton accepting ability and weakening of hydrogen bonding within the ion pair on going down the Group.
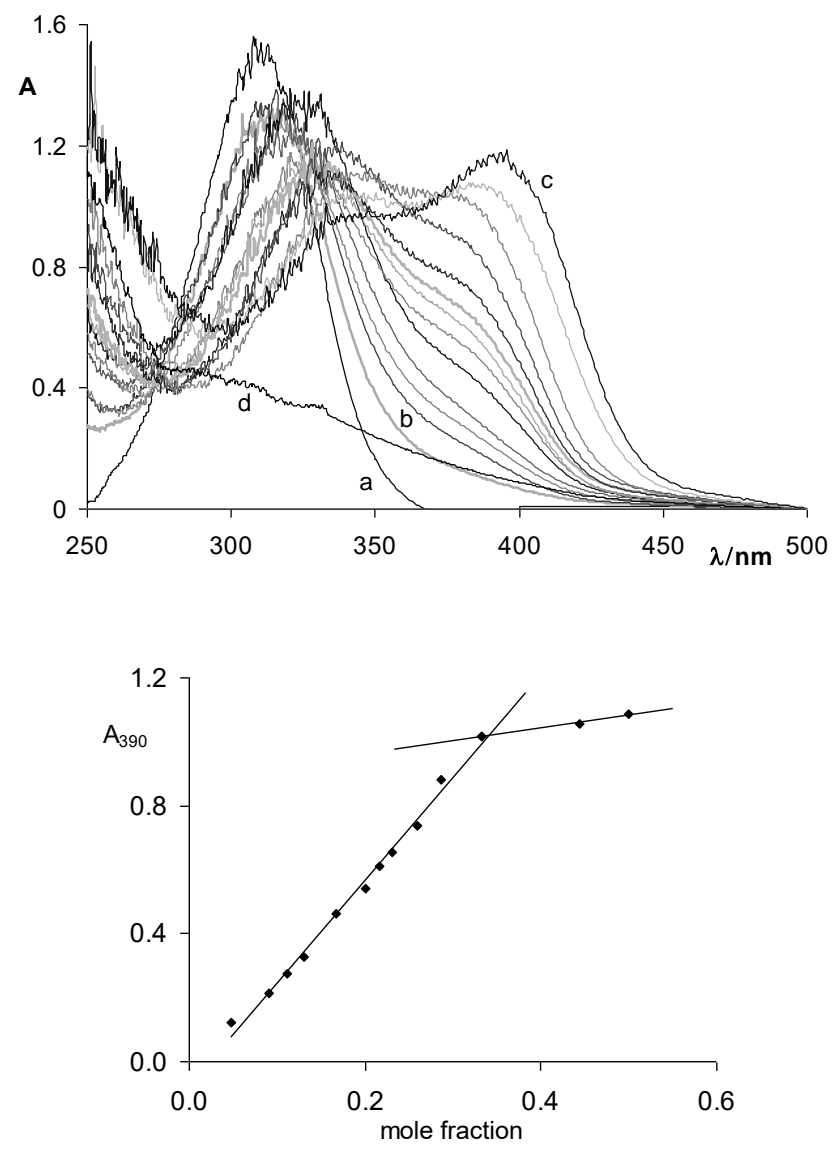

Figure 2. UV-visible spectra (top) of PNP (0.002 M, a) in the presence of 0.05 (b) to 1.0 (c) equiv $\mathrm{Cp} * \mathrm{OsH}(\mathrm{dppe})(\mathbf{1})$ and corresponding titration plot (bottom). $\mathrm{CH}_{2} \mathrm{Cl}_{2}, 200 \mathrm{~K}$. Mole fraction $=c(\mathbf{1}) /(c(\mathbf{1})+c(\mathrm{PNP}))$. The spectrum of $\mathbf{1}(0.0023 \mathrm{M}, \mathrm{d})$ is also given for comparison.

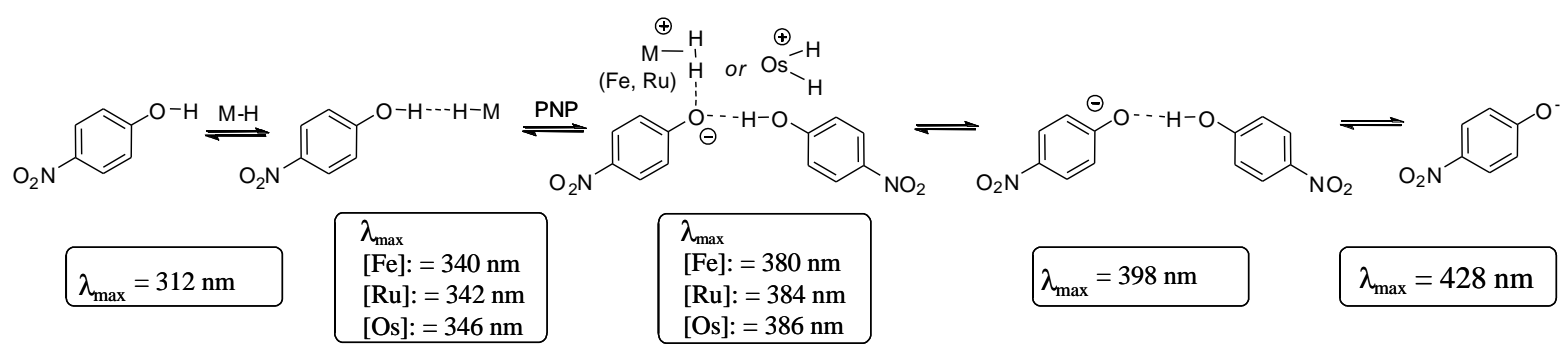

Scheme 2. Summary of UV-visible absorption frequencies of various forms of PNP and its conjugate anion. 


\section{Protonation by $\mathrm{HBF}_{4} \cdot \mathrm{Et}_{2} \mathrm{O}$ : characterisation of cis- and trans- $\left[\mathrm{Cp} * \mathbf{O s}(\mathrm{dppe}) \mathrm{H}_{2}\right]^{+}$}

We have shown recently ${ }^{[23]}$ that $c i s-\left[\mathrm{Cp} * \mathrm{Os}(\mathrm{dppe}) \mathrm{H}_{2}\right]^{+}$is the kinetic product $\left(193 \mathrm{~K}\right.$ ) when protonating 1 with $\mathrm{HBF}_{4} \cdot \mathrm{Et}_{2} \mathrm{O}$, then irreversibly transforming into the trans-isomer upon warming (above $233 \mathrm{~K}$ ). Both cis- and trans- $\mathbf{1 H}^{+}$were characterized by NMR-spectroscopy in $\mathrm{CD}_{2} \mathrm{Cl}_{2}$. In this contribution, we complete the characterisation of these complexes by an IR study and by structural analysis of trans $-\mathbf{1 H}^{+} \mathrm{BF}_{4}{ }^{-}$.

Addition of ca. 1 equiv $\mathrm{HBF}_{4} \cdot \mathrm{Et}_{2} \mathrm{O}$ to the solution of $\mathbf{1}$ in $\mathrm{CH}_{2} \mathrm{Cl}_{2}$ at $200 \mathrm{~K}$ causes the complete disappearance of the Os-H stretching band of 1 (Table 2) and the appearance of two new bands at 2126 and $2177 \mathrm{~cm}^{-1}$ belonging to $\mathrm{cis}-\mathbf{1} \mathbf{H}^{+}$in the IR spectrum (Table 2, Figure 3). These two bands were attributed to the symmetric $v^{\mathrm{s}}$ and asymmetric $v^{\text {as }} \mathrm{OsH}_{2}$ stretching vibrations on the basis of the theoretical calculations (Table S1). This spectrum remains essentially unchanged so long the temperature remains below 230 $\mathrm{K}$. At higher temperatures, slow conversion to the trans-dihydride complex (trans $-1 \mathbf{H}^{+}$) occurs, eventually yielding two new bands at 2053 and $2102 \mathrm{~cm}^{-1}$ (Figure 3, spectrum c).

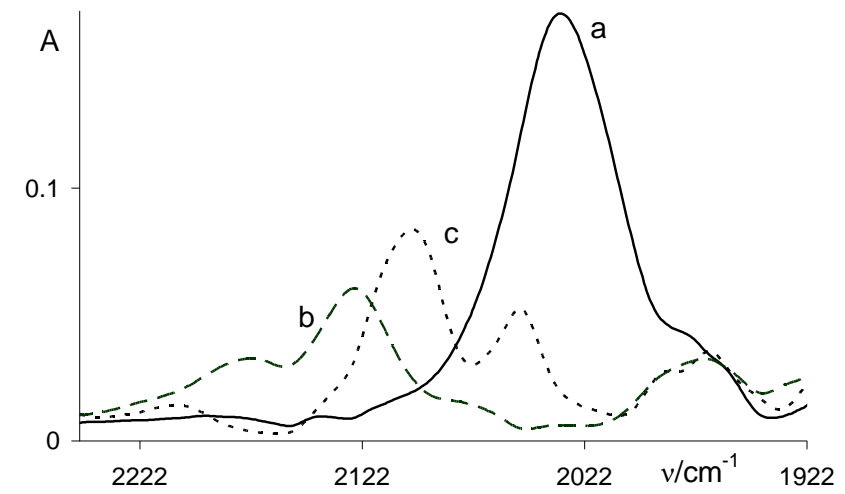

Figure 3. IR spectra ( $v_{\mathrm{OsH}}$ region) of $\mathrm{Cp} * \mathrm{Os}(\mathrm{dppe}) \mathrm{H}(\mathbf{1}, 0.017 \mathrm{M})(\mathrm{a})$; cis$\mathbf{1 H}^{+}$generated in situ ${ }^{[38]}$ by mixing $\mathbf{1}$ and ca. 1 equiv. $\mathrm{HBF}_{4} \cdot \mathrm{Et}_{2} \mathrm{O}(\mathrm{b})$ and trans $-1 \mathrm{H}^{+}$, obtained from (b) after warming to $298 \mathrm{~K}$ and cooling back (c). $\mathrm{CH}_{2} \mathrm{Cl}_{2}, 200 \mathrm{~K}, \mathrm{l}=1.2 \mathrm{~mm}$.

Table 2. IR spectroscopic parameters of the $v_{\mathrm{MH}}$ and $v_{\mathrm{MH} 2}$ bands of $\mathrm{Cp} * \mathrm{MH}(\mathrm{dppe})$ hydrides and their protonation products, $\left[\mathrm{Cp} * \mathrm{MH}_{2}(\mathrm{dppe})\right]^{+}$, in $\mathrm{CH}_{2} \mathrm{Cl}_{2}$ at $200 \mathrm{~K}$.

\begin{tabular}{|c|c|c|c|c|c|c|}
\hline \multirow{2}{*}{ M } & \multicolumn{2}{|l|}{ Cp*MH(dppe) } & \multicolumn{4}{|c|}{ trans $-\left[\mathrm{Cp} * \mathrm{M}(\mathrm{H})_{2}(\mathrm{dppe})\right]^{+}$} \\
\hline & $v_{\mathrm{MH}}\left(\Delta v_{1 / 2}\right)^{[\mathrm{a}]}$ & $\varepsilon^{[\mathrm{b}]}$ & $v_{\mathrm{MH} 2}^{\mathrm{s}}\left(\Delta v_{1 / 2}\right)^{[\mathrm{a}]}$ & $\varepsilon^{[\mathrm{b}]}$ & $v^{\mathrm{as}}{ }_{\mathrm{MH} 2}\left(\Delta v_{1 / 2}\right)^{[\mathrm{a}]}$ & $\varepsilon^{[\mathrm{b}]}$ \\
\hline $\mathrm{Fe}$ & $1844(48)$ & 12 & $1940(40)$ & 4 & & \\
\hline $\mathrm{Ru}$ & 1918 (58) & 34 & $2002(56)$ & 14 & $1968(26)$ & 8 \\
\hline \multirow[t]{2}{*}{ Os } & $2033(56)$ & 83 & $2102(40)$ & 41 & 2053 (24) & 25 \\
\hline & & & $2126(55)^{[\mathrm{c}]}$ & $16^{[\mathrm{c}]}$ & $2177(85)^{[\mathrm{c}]}$ & $29^{[\mathrm{c}]}$ \\
\hline
\end{tabular}

[a] in $\mathrm{cm}^{-1}[\mathrm{~b}]$ molar absorption coefficient in $\mathrm{L} \mathrm{mol}^{-1} \mathrm{~cm}^{-1}$ [c] cis $-\mathrm{H}_{2}$

Careful reinvestigation of the previously reported ${ }^{[29]}$ IR spectrum of trans-[Cp* $\left.\mathrm{Ru}(\mathrm{H})_{2}(\mathrm{dppe})\right]^{+}$complex revealed two $v_{\mathrm{RuH} 2}$ bands at 1968 and $2002 \mathrm{~cm}^{-1}$ (see Figure S4 and Tables 2 and S1), whereas only the stronger one was previously described. On the other hand the IR spectrum of trans-[Cp* $\left.\mathrm{Fe}(\mathrm{H})_{2}(\mathrm{dppe})\right]^{+}$complex features only one band at $1940 \mathrm{~cm}^{-1}$. This can be explained by the lower intensity of the $v^{\mathrm{s}} \mathrm{FeH} 2$ band and by the decrease of the difference between $v^{\mathrm{s}} \mathrm{MH} 2$ and $v^{\mathrm{as}}{ }_{\mathrm{MH} 2}$ (Table 2 and Table S1) on ascending the group $\left(\Delta v=v_{\mathrm{MH} 2}^{\mathrm{s}}-v^{\mathrm{as}} \mathrm{MH} 2=51 \mathrm{~cm}^{-1}\right.$ for Os and $35 \mathrm{~cm}^{-1}$ for $\left.\mathrm{Ru}\right)$ leading to bands superposition for $\mathrm{Fe}$. Another interesting feature is a decrease of the band shift upon protonation on descending the group. Taken as the difference between the starting hydride $v_{M}-\mathrm{H}$ band and the higher intensity $v_{\mathrm{MH} 2}$ band of the trans-dihydride, the band shift $\Delta v=100,86$ and $71 \mathrm{~cm}^{-1}$ for $\mathrm{M}=\mathrm{Fe}, \mathrm{Ru}$ and $\mathrm{Os}$, respectively.

The molecular structure of trans- $\left[\mathrm{Cp} * \mathrm{Os}(\mathrm{dppe})(\mathrm{H})_{2}\right]^{+} \mathrm{BF}_{4}^{-}$was determined by single crystal X-ray analysis (Figure 4); the main geometrical parameters are collected in Table 3. The two hydrides were located and fully refined with isotropic thermal parameter. The coordination geometry around osmium can be described as a distorted four-legged piano stool. The two hydride atoms are in transoid position with an $\mathrm{H}(1)-\mathrm{Os}(1)-\mathrm{H}(2)$ angle much larger than that for trans- $\left[\mathrm{Cp} * \mathrm{Fe}(\mathrm{dppe})(\mathrm{H})_{2}\right]^{+} \mathrm{BF}_{4}^{-}\left(133(3)^{\circ}\right.$ vs. $\left.110.5^{\circ}\right),{ }^{[15]}$ whereas the $\mathrm{Os}-\mathrm{H}$ bonds and $\mathrm{Fe}-\mathrm{H}$ bonds are identical within the

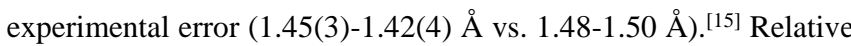
to the iron analogue, the $\mathrm{P}(1)-\mathrm{M}-\mathrm{P}(2)$ angle is smaller $\left(87.11(3)^{\circ}\right.$ vs. $\left.90.73(8)^{\circ}\right)$, whereas the Os-P and Os-CNT distances are slightly longer (2.2841(9)-2.2836(9) $\AA$ and 1.888(2) $\AA$ vs. 2.170(2)-2.166(2) ̊ and 1.728(6) ̊).

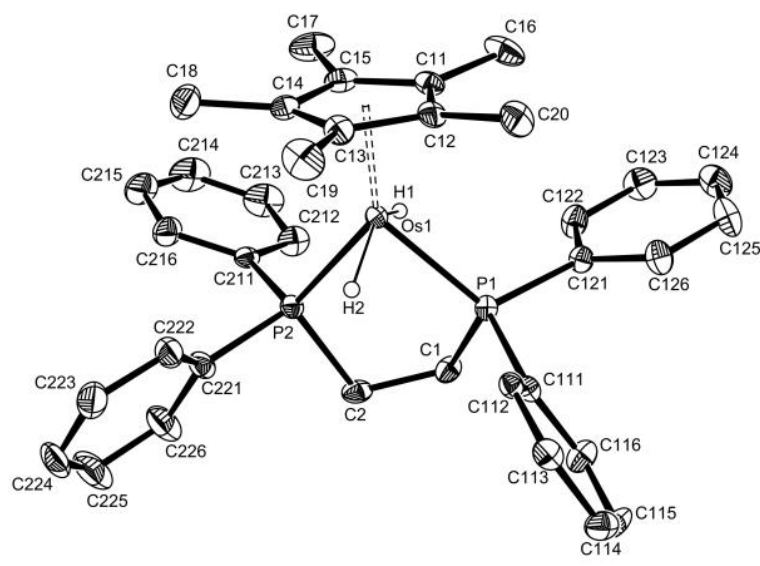

Figure 4. Molecular structure of trans $-\left[\mathrm{Cp}^{*} \mathrm{Os}(\mathrm{dppe})(\mathrm{H})_{2}\right]^{+} \mathrm{BF}_{4}^{-}(30 \%$ probability level).

\section{Kinetic study on the "cis-trans" isomerization}

The previously reported ${ }^{1} \mathrm{H}$ NMR study of the cis/trans isomerization of $\mathbf{1 H}^{+}$was limited to $250 \mathrm{~K}$, giving the rate constant $k=3.15 \pm 0.02 \cdot 10^{-4} \mathrm{~s}^{-1}$. ${ }^{[23]}$ We have now carried out a variable temperature study in order to obtain the activation parameters. ${ }^{[39]}$ An example of the ${ }^{1} \mathrm{H}$ NMR monitoring is shown in Figure 5.

The data obtained at each temperature gave an excellent fit to the first order rate law yielding the isomerization rate constants reported in Figure 6. The Eyring analysis of the rate constants (Figure S5) yields the activation parameters $\Delta H^{\ddagger}=21.5 \pm 1.0 \mathrm{kcal}$ $\mathrm{mol}^{-1}$ and $\Delta S^{\neq}=12 \pm 4$ e.u. The activation enthalpy value is identical, within experimental error, to those found for the iron $\left(\Delta H^{\ddagger}=21.6 \pm 0.8 \mathrm{kcal} \mathrm{mol}^{-1}\right)^{[30]}$ and ruthenium $\left(\Delta H^{\ddagger}=20.9 \pm 0.8\right.$ $\left.\mathrm{kcal} \mathrm{mol}{ }^{-1}\right)^{[29]} \mathrm{M}\left(\eta^{2}-\mathrm{H}_{2}\right)^{+} \rightarrow$ trans- $\mathrm{M}(\mathrm{H})_{2}{ }^{+}$isomerization process, whereas the entropy values tend to increase on descending the group $\left(\Delta S^{\neq}=5 \pm 3\right.$ e.u. for $\mathrm{Fe}$ and $\Delta S^{\neq}=9 \pm 3$ e.u. for $\left.\mathrm{Ru}\right)$ resulting in the increase of the isomerization rate constant in the order $k_{\mathrm{Fe}}<$ $k_{\mathrm{Ru}}<k_{\mathrm{O}}$ at any given temperature. 
Table 3. Key bond lengths ( $\AA$ ) and angles (deg) for hydride $\mathbf{1}$ and its protonation products $c i s-\mathbf{1 H}^{+}$and trans $-\mathbf{1 H}^{+}$according to the single crystal $\mathrm{X}$-ray data and the DFT B3PW91 calculations on model $\mathrm{Cp} * \mathrm{OsH}(\mathrm{dhpe})$ $\left(\mathbf{1}_{\mathbf{t}}\right)$ and real (1) complexes. ${ }^{[\mathrm{a}]}$
The computational analysis of hydrogen bonding and proton transfer was carried out at the DFT/B3PW91 level, using HFIP as proton donor and the model complex Cp*OsH(dhpe) $\left(\mathbf{1}_{\mathbf{t}}\right)$, where the phenyl rings of the dppe ligand are replaced by $\mathrm{H}$ atoms. A similar study on the $\mathrm{Fe}$ analogue was previously reported using either 1 or 2 HFIP molecules, although using a different method (B3LYP) and the simpler $\mathrm{CpFeH}$ (dhpe) model. ${ }^{[28]}$ Our study started with the analysis of the H-bonding and proton transfer to the syn site. The optimized geometries of the hydrogen bonded complexes $\mathrm{Cp} *($ dhpe $)$ OsH $\cdots(\text { HFIP })_{\mathrm{x}}(\mathrm{x}=1,2)$ and of the proton transfer product, cis$\left.\mathbf{1}_{\mathbf{t}} \mathbf{H}^{+\cdots} \cdot\left(\mathrm{CF}_{3}\right)_{2} \mathrm{CHO} \cdots \mathrm{H}^{\cdots} \cdot \mathrm{OCH}\left(\mathrm{CF}_{3}\right)_{2}\right]^{\prime}, \quad$ are depicted in Figure 7.

As expected the formation of syn-1t.HFIP entails the lengthening of the $\mathrm{O}-\mathrm{H}$ and $\mathrm{Os}-\mathrm{H}$ bonds relative to the isolated compounds by $\Delta r(\mathrm{OH})=0.024 \AA$ and $\Delta r(\mathrm{Os}-\mathrm{H})=0.006 \AA$. The
2.330

2.324

132.3

114.6

135.1

87.9

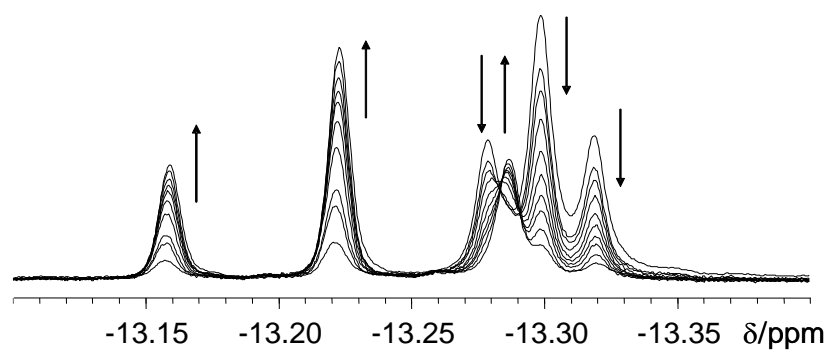

Figure 5. ${ }^{1} \mathrm{H}$ NMR (500 MHz) monitoring (hydride region) of the cis-1 $\mathbf{H}^{+}$ $\rightarrow$ trans $-\mathbf{1 H}^{+}$isomerization at $250 \mathrm{~K}, \mathrm{CD}_{2} \mathrm{Cl}_{2} . c\left(\right.$ cis $\left.-\mathbf{1 H}^{+}\right)=0.017 \mathrm{M}$.

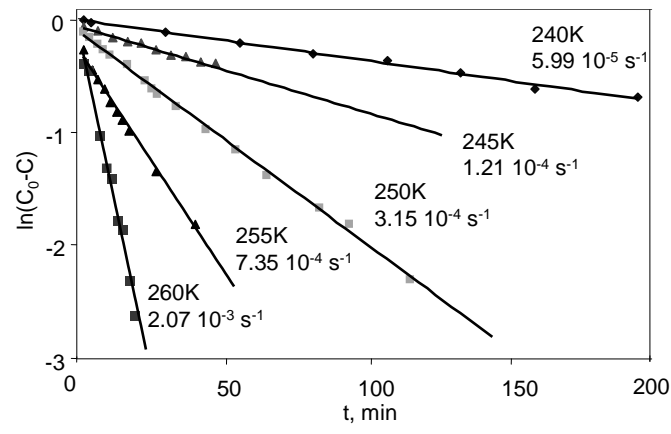

Figure 6. Logarithmic plots of the hydride resonance $(-13.17 \mathrm{ppm})$ appearance for trans-[Cp* Os $(\mathrm{dppe})\left(\mathrm{H}_{2}\right]^{+} \mathrm{BF}_{4}$. Temperatures and the corresponding rate constants are indicated near to the lines.

The isotope effect in the isomerization process was investigated using $\mathrm{CF}_{3} \mathrm{SO}_{3} \mathrm{X}(\mathrm{X}=\mathrm{H}, \mathrm{D})$ at $250 \mathrm{~K}$, yielding the rate constants $k_{\mathrm{H}}$ $=2.48 \pm 0.05 \cdot 10^{-4} \mathrm{~s}^{-1}$ and $k_{\mathrm{D}}=1.86 \pm 0.04 \cdot 10^{-4} \mathrm{~s}^{-1}$. The kinetic isotope effect $k_{\mathrm{HH}} / k_{\mathrm{HD}}=1.33$ compares to 1.24 previously reported for iron, ${ }^{[30]}$ suggesting a similar intramolecular mechanism for the two isomerization processes. No scrambling of the cis-1D $\mathbf{1 D}^{+}$ compound with cis- $\mathbf{1 H}^{+}$and $c i s-\left[\mathrm{Cp} * \mathrm{Os}(\mathrm{dppe})(\mathrm{D})_{2}\right]^{+}$was observed and the isomerization produced trans-10 ${ }^{+}$selectively, indicating that the initial protonation process is irreversible and that the isomerization is intramolecular.

\section{Computational study}

$(\mathrm{Os}) \mathrm{H} \cdots \mathrm{H}(\mathrm{O})$ distance is quite short, but the overall geometry of the Os- $\mathrm{H} \cdots \mathrm{HO}$ fragment $(\mathrm{Os} \cdots \mathrm{H}$ distance $2.924 \AA, \angle \mathrm{Os} \cdots \mathrm{H}-\mathrm{O}=$ $158^{\circ}, \angle \mathrm{H} \cdots \mathrm{H}-\mathrm{O}=152^{\circ}$ ) indicates an asymmetric bifurcated interaction with a contribution from the metal atom. Similar structural features were found for the hydrogen bonded adducts of complex $\mathrm{Cp}^{*} \mathrm{WH}_{3}(\mathrm{dppe}){ }^{[40]}$ The $\mathrm{Os} \cdots \mathrm{H}(\mathrm{O})$ and $(\mathrm{Os}) \mathrm{H} \cdots \mathrm{H}(\mathrm{O})$ distances shorten while the Os-H and $\mathrm{O}-\mathrm{H}$ bonds elongate upon binding of the second alcohol molecule in agreement with stronger binding in the $s y n-\mathbf{1}_{\mathbf{t}} \cdot(\mathrm{HFIP})_{2}$ adduct. The minimum for the syn1. HFIP adduct is found $10.7 \mathrm{kcal} \mathrm{mol}^{-1}$ below the isolated reactants, whereas addition of the second alcohol molecule brings it further down to $-21.3 \mathrm{kcal} \mathrm{mol}^{-1}$. The formation energy of the latter complex considerably exceeds the sum of the formation energies for the 1. HFIP adduct and the HFIP dimer $(-7.5 \mathrm{kcal}$ $\left.\mathrm{mol}^{-1}\right)$ due to a cooperative effect, which was calculated as $\Delta E_{\text {coop }}=$ $\Delta E\left(\mathbf{1}_{\mathbf{t}} \cdot(\mathrm{HFIP})_{2}\right)-\Delta \mathrm{E}(\mathbf{1} \cdot \mathrm{HFIP})-\Delta E\left((\mathrm{HFIP})_{2}\right)=-4.5 \mathrm{kcal} \mathrm{mol}^{-1}$. As expected ${ }^{[41]}$ consideration of the solvent by means of single point CPCM calculations lowers all the formation energies, the syn$\mathbf{1}_{\mathbf{t}} \cdot(\mathrm{HFIP})_{2}$ adduct being found only $-3.5 \mathrm{kcal} \mathrm{mol}^{-1}$ below the reactants in $\mathrm{CH}_{2} \mathrm{Cl}_{2}$ (see the energy profile in Figure S6).

Proton transfer was only investigated starting from the 1:2 adduct, syn-1 $\mathbf{1} \cdot($ HFIP) 2 , because when using only 1 HFIP molecule the proton transfer product did not afford a local minimum and reverted back to the H-bonded adduct, like for the previously published Fe system. ${ }^{[28]}$ The proton transfer transition state, syn-TS (Figure 7), features an almost fully formed Os-H bond, with a distance between the hydride ligand and the incoming proton $(1.315 \AA)$ far above that typical of $\left(\eta^{2}-\mathrm{H}_{2}\right)$ complexes. The most stable configuration of the cis- $\mathbf{1}_{\mathbf{t}} \mathbf{H}^{+\cdots} \cdot\left(\mathrm{CF}_{3}\right)_{2} \mathrm{CHO} \cdots \mathrm{H} \cdots \mathrm{O}-$ $\left.\mathrm{CH}\left(\mathrm{CF}_{3}\right)_{2}\right]^{-}$ion pair $\left(\operatorname{syn}-\mathbf{1}_{\mathbf{t}} \mathbf{I P}\right)$ features a quite symmetrical cationanion arrangement with two (Os) $\mathrm{H} \cdots \mathrm{O}$ hydrogen bonds (Figure 7). The distance between the two hydride ligands is $1.552 \AA$. Thus, formation of the cis-dihydride complex occurs via the direct syn protonation of the metal atom assisted by the interaction with the hydride ligand. No minimum for an $\left(\eta^{2}-\mathrm{H}_{2}\right)$ complex could be found. The transition state $s y n$-TS is above $\operatorname{syn}-\mathbf{1}_{\mathbf{t}} \cdot(\mathrm{HFIP})_{2}$ by 13.8 $\mathrm{kcal} \mathrm{\textrm {mol } ^ { - 1 }}$ in the gas phase and $10.2 \mathrm{kcal} \mathrm{mol}^{-1}$ in dichloromethane. The product ion pair is $4.0 \mathrm{kcal} \mathrm{mol}^{-1}$ higher than syn-1. $\cdot(\mathrm{HFIP})_{2}$ adduct in the gas phase and $0.5 \mathrm{kcal}^{\mathrm{mol}^{-1}}$ lower in dichloromethane. Thus, the syn proton transfer is rendered favourable by the solvent effect in $\mathrm{CH}_{2} \mathrm{Cl}_{2}$. The full energetic profile for hydrogen bonding and proton transfer in the gas phase and in $\mathrm{CH}_{2} \mathrm{Cl}_{2}$ solution is available in the Supporting Information (Figure S6). 


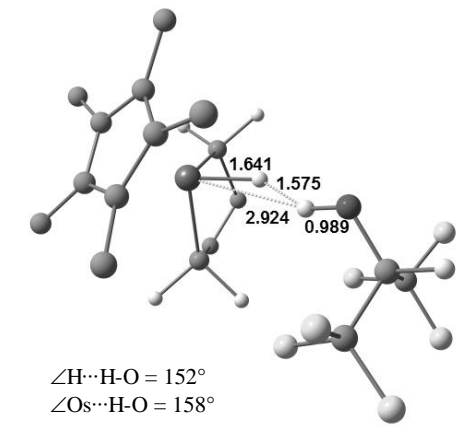

syn-1, HFIP

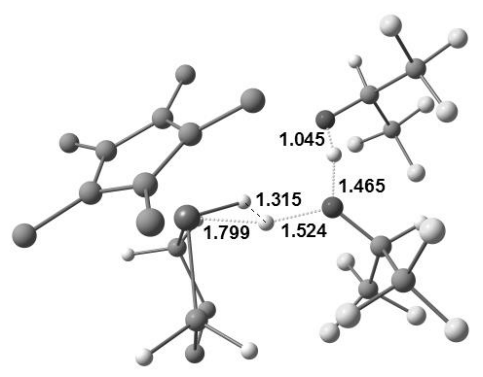

syn-TS

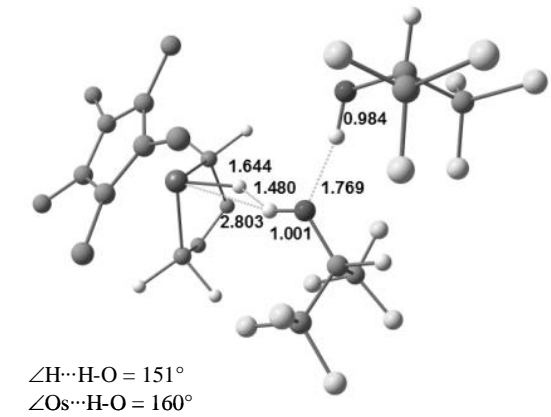

syn-1 $\mathbf{1}_{\mathbf{t}} \cdot(\mathrm{HFIP})_{2}$

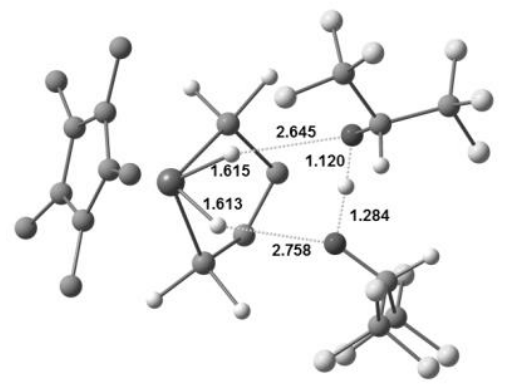

syn-1,IP

Figure 7. Optimized geometries of the hydrogen bonded, transition state, and final ion pair complexes related to the syn proton donor addition to $\mathbf{1}_{\mathbf{t}}$, with selected bond distances in $\AA$. Hydrogen atoms of the $\mathrm{Cp}^{*}$ ligand and of the ethylene backbone are removed for clarity.

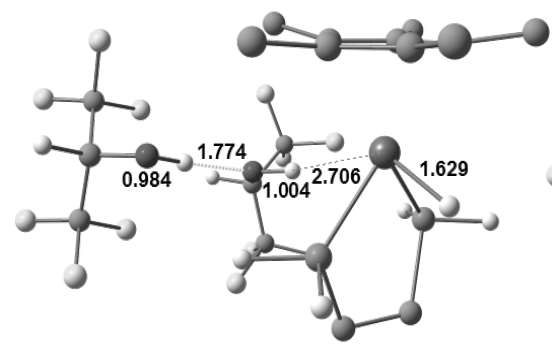

anti-1: $\cdot(\text { HFIP })_{2}$

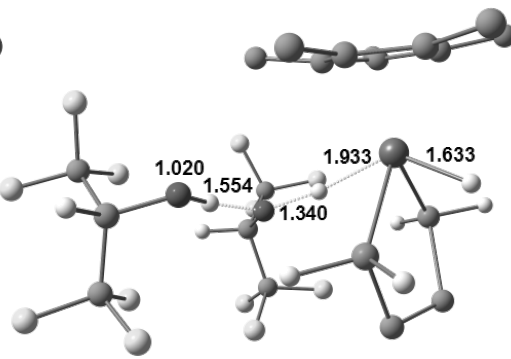

anti-TS

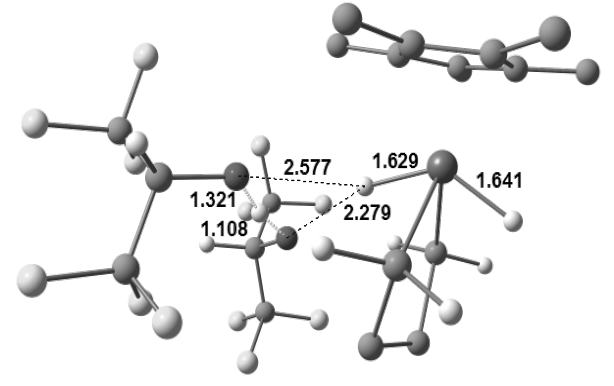

anti-1,IP

Figure 8. Optimized geometries of the hydrogen bonded, transition state, and final ion pair complexes related to the anti proton donor addition to $\mathbf{1}_{\mathbf{t}}$, with selected bond distances in $\AA$. Hydrogen atoms of the $\mathrm{Cp}^{*}$ ligand and of the ethylene backbone are removed for clarity.

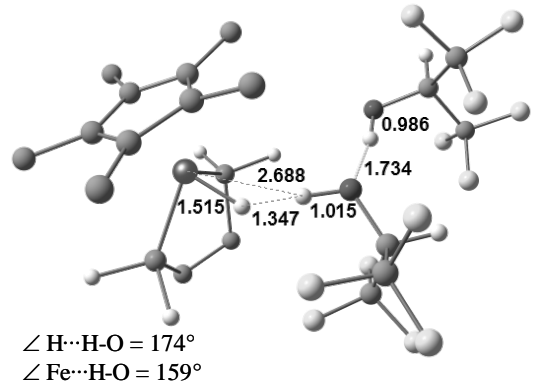

syn-2 $\mathbf{2}_{\mathbf{t}}(\mathrm{HFIP})_{2}$

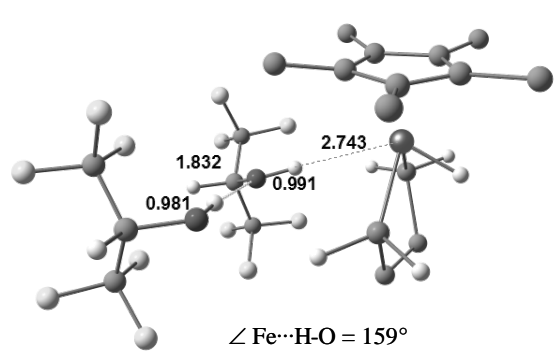

anti-2. $\cdot \mathbf{t}($ HFIP)

Figure 9. Optimized geometries of the hydrogen bonded complexes between $\mathrm{Cp} * \mathrm{FeH}(\mathrm{dhpe})\left(\mathbf{2}_{\mathrm{t}}\right)$ and two HFIP molecules, with selected bond distances in $\AA$ A. Hydrogen atoms of the $\mathrm{Cp} *$ ligand and of the ethylene backbone are removed for clarity.

The anti addition has only been studied for the more favourable 1:2 adduct, anti-1 $\mathbf{1}_{\mathbf{t}} \cdot(\mathrm{HFIP})_{2}$. As already found for the $\mathrm{Fe}$ analogue, ${ }^{[28]}$ this hydrogen-bonded adduct is less energetically favourable than the corresponding syn-1 $\cdot(\mathrm{HFIP})_{2}$. Its optimized geometry is shown in Figure 8 and its relative energy is included in Figure S6. The most relevant structural change is the shortening of 
the Os-H distance $(\Delta r(\mathrm{Os}-\mathrm{H})=-0.006 \AA)$. The anti protonation to yield trans $-\mathbf{1}_{\mathbf{t}} \mathbf{H}^{+\cdots}\left[\mathrm{R}^{\mathrm{F}} \mathrm{O} \cdots \mathrm{H}^{\cdots} \mathrm{OR}^{\mathrm{F}}\right]^{-}$features a transition state, anti-TS at $6.7 \mathrm{kcal} \mathrm{mol}^{-1}$ (in the gas phase) and $4.8 \mathrm{kcal} \mathrm{mol}^{-1}$ (in dichloromethane) above the corresponding metal-bound hydrogen bonded adduct, anti-1. $\cdot($ HFIP)2. Since the energetically preferred adduct is the dihydrogen bonded complex $s y n-\mathbf{1}_{\mathbf{t}} \cdot(\mathrm{HFIP})_{2}$, the latter can be regarded as the system "resting state". Hence, the proton transfer barrier becomes almost identical for the two pathways in dichloromethane (Figure S6).

For comparison, the two protonation pathways for the iron analogue were reinvestigated using the same computational level (B3PW91) and model [Cp*FeH(dhpe)] (2t) as for the Os system. The complete energy profiles for hydrogen bond formation and proton transfer, for both syn and anti additions, are provided in the Supporting Information (Figure S7). In spite of the lower $E_{j}, \mathbf{2}_{\mathbf{t}}$ gave slightly greater formation energies for the more stable syn$\mathbf{2}_{\mathbf{t}} \cdot(\mathrm{HFIP})_{2}$ adduct (Figure 9), $-22.4 \mathrm{kcal} \mathrm{mol}^{-1}$ in gas phase and -4.2 kcal $\mathrm{mol}^{-1}$ in $\mathrm{CH}_{2} \mathrm{Cl}_{2}$ relative to the isolated reactants, than the osmium analogue. The transition state for the syn protonation to yield the nonclassical kinetic protonation product, $\left[\mathrm{Cp} * \mathrm{Fe}\left(\eta^{2}\right.\right.$ $\left.\mathrm{H}_{2}\right)($ dhpe $\left.)\right]^{+\cdots}\left[\mathrm{R}^{\mathrm{F}} \mathrm{O}^{\cdots} \mathrm{H}^{\cdots} \mathrm{OR}^{\mathrm{F}}\right]^{-}$, syn-2 $\mathbf{t} \mathbf{I P}$, is above $\mathbf{2}_{\mathbf{t}} \cdot(\mathrm{HFIP})_{2}$ by 7.6 $\mathrm{kcal} \mathrm{mol}^{-1}$ in the gas phase and by $4.9 \mathrm{kcal} \mathrm{mol}^{-1}$ in dichloromethane, both being $c a$. half those of the related osmium system. On the other hand, the anti protonation to yield trans$\mathbf{2}_{\mathrm{t}} \mathrm{H}^{+\cdots}\left[\mathrm{R}^{\mathrm{F}} \mathrm{O} \cdots \mathrm{H}^{\cdots} \mathrm{OR}^{\mathrm{F}}\right]^{-}$, anti-2.2 $\mathrm{IP}$, is characterized by a higher activation barrier, reaching $12.3 \mathrm{kcal} \mathrm{mol}^{-1}$ in the gas phase and 9.7 $\mathrm{kcal} \mathrm{\textrm {mol } ^ { - 1 }}$ in dichloromethane relative to the corresponding anti$\mathbf{2}_{\mathbf{t}} \cdot(\mathrm{HFIP})_{2}$ local minimum (Figure S7), which corresponds to 20.2 $\mathrm{kcal} \mathrm{mol}^{-1}$ and $18.0 \mathrm{kcal} \mathrm{mol}^{-1}$, respectively, from the "resting state" syn-2. $\cdot(\text { HFIP) })_{2}$ (Figure S7).

The last point addressed by the computational study is the cis/trans isomerization mechanism for $\mathbf{1 H}^{+}$. This study was carried out on both the model $\left[\mathrm{Cp}^{*} \mathrm{OsH}_{2}(\mathrm{dhpe})\right]^{+}\left(\mathbf{1}_{\mathbf{t}} \mathbf{H}^{+}\right)$and the full $\left[\mathrm{Cp}^{*} \mathrm{OsH}_{2}(\mathrm{dppe})\right]^{+}$system, without consideration of the counterion. The optimized geometries of the model and full trans systems are in close correspondence with the experimentally observed structure (Table 3), the only major discrepancy being the Os-H distances which are notoriously underestimated in X-ray structural determinations. It is also notable that the experimental bond distances are better matched by the model system, although the discrepancy between model and full systems is small. The bond angles are quite close to the experiment for both systems. For comparison, the calculations were also carried out for the neutral precursor $\mathbf{1}$ (and for the model $\mathbf{1}_{\mathbf{t}}$ ), and compared with those of the previously reported ${ }^{[23]} \mathrm{X}$-ray structure in Table 3.

The model cation $\mathbf{1}_{\mathbf{t}} \mathbf{H}^{+}$gives nearly the same gas-phase energy $\left(E^{\mathrm{g}}\right)$ for the two isomers (just $0.8 \mathrm{kcal} \mathrm{mol}^{-1}$ in favour of cis- $\mathbf{1}_{\mathbf{t}} \mathbf{H}^{+}$), but the trans isomer becomes preferred by $6 \mathrm{kcal} \mathrm{mol}^{-1}$ for the full system $\mathbf{1 H}^{+}$, in agreement with the essentially quantitative isomerization. For comparison, the energy difference between the syn and anti protonation products for the $\mathrm{Ru}$ and $\mathrm{Fe}$ systems, $\left[\mathrm{Cp} * \mathrm{M}\left(\eta^{2}-\mathrm{H}_{2}\right)(\mathrm{dppe})\right]^{+}$and trans-[Cp* $\left.\mathrm{M}(\mathrm{dppe})(\mathrm{H})_{2}\right]^{+}$, is $4.9 \mathrm{kcal}$ $\mathrm{mol}^{-1}$ and $3.1 \mathrm{kcal} \mathrm{mol}^{-1}$, respectively, in favor of the anti isomer. The optimized geometries of these four complexes, reported here for the first time, are available in the SI. The proton affinity of these hydrides, calculated as $-\Delta H(298 \mathrm{~K})$ for the kinetically controlled syn protonation reactions 3 and 4 , is $258.6 \mathrm{kcal} \mathrm{mol}^{-1}$ for $\mathrm{Fe}, 257.3 \mathrm{kcal} \mathrm{mol}^{-1}$ for Ru and $263.4 \mathrm{kcal} \mathrm{mol}^{-1}$ for Os, placing the basicity of the Os complex higher than that of the $\mathrm{Fe}$ and $\mathrm{Ru}$ analogues in agreement with experiment. ${ }^{[42]}$

$[\mathrm{Cp} * \mathrm{M}(\mathrm{dppe}) \mathrm{H}]+\mathrm{H}^{+} \rightarrow\left[\mathrm{Cp} * \mathrm{M}\left(\eta^{2}-\mathrm{H}_{2}\right)(\mathrm{dppe})\right]^{+}$
$[\mathrm{Cp} * \mathrm{Os}(\mathrm{dppe}) \mathrm{H}]+\mathrm{H}^{+} \rightarrow$ cis-[Cp*Os(dppe $\left.)(\mathrm{H})_{2}\right]^{+}$

The transition state for the cis/trans isomerization of $\mathbf{1}_{\mathbf{t}} \mathbf{H}^{+}$ displays a similar geometry to that previously reported for the related non-classical complex of iron (Figure S8) and is located at $25.5 \mathrm{kcal} \mathrm{mol}^{-1}$ above cis-1 $\mathbf{t} \mathbf{H}^{+}$in the gas phase $\left(25.1 \mathrm{kcal} \mathrm{mol}^{-1}\right.$ in dichloromethane). ${ }^{[30]}$ The isomerization proceeds in a single step by migration of one hydride ligand from one side to the other of the metal coordination sphere with concomitant tilt of the phosphine ligands. The isomerization barrier is slightly lower than that reported for the $\left[\mathrm{Cp} * \mathrm{Fe}\left(\eta^{2}-\mathrm{H}_{2}\right)(\mathrm{dhpe})\right]^{+}$isomerization in the gas phase $\left(28.9 \mathrm{kcal} \mathrm{mol}^{-1}\right) .^{[30]}$ This is in agreement with the slow rate measured experimentally for the osmium system (see above), similar to that of the corresponding Fe system. ${ }^{[30]}$

\section{Discussion}

The overall process of proton transfer to $\mathrm{Cp}^{*} \mathrm{OsH}(\mathrm{dppe})$ (1) can be rationalized as shown in Scheme 3. It parallels the mechanism established for the protonation of the Cp*MH(dppe) complexes of $\mathrm{Fe}$ and $\mathrm{Ru}$ (Scheme 1), with a kinetically controlled syn addition followed by slow isomerization to the thermodynamically more stable trans isomer, which corresponds to the expected product of anti addition.

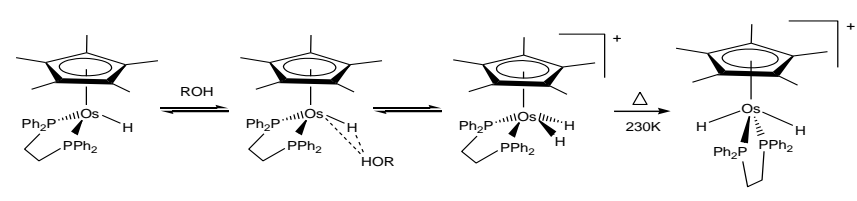

Scheme 3. Proposed mechanism of interaction between $\mathbf{1}$ and ROH proton donors.

The first step for all three metals is formation of a hydrogenbonded adduct with two proton donor molecules, since a 1:1 adduct does not have sufficient thermodynamic drive to complete the proton transfer step. Also common to the three metals is the site preference, the syn adduct being more stable than direct bonding to the metal site opposite to the hydride ligand. The hydride basicity in hydrogen bonding $\left(E_{\mathrm{j}}\right)$ increases on going down the group in agreement with expectations based on previous studies on other compound families (see Introduction). However, the range is narrower (1.35-1.47 on going from Fe to Os) than for the only other investigated family of Group 8 hydride complexes, $\mathrm{PP}_{3} \mathrm{MH}_{2}$ (1.12-1.67 range). ${ }^{[34]}$

A striking difference between the $\mathrm{PP}_{3} \mathrm{MH}_{2}$ and $\mathrm{Cp} * \mathrm{MH}$ (dppe) families is that dihydrogen bonding always leads to a nonclassical (dihydrogen complex) product for the former, whereas a change occurs in the latter: nonclassical product for $\mathrm{Fe}$ and $\mathrm{Ru}$; classical cis dihydride for Os. The geometrical analysis of the dihydrogen bonded adducts reveals an asymmetric bifurcated structure with the increasing impact of the $\mathrm{M} \cdots \mathrm{HO}$ interaction on going from iron to osmium (see Scheme 4). Consequently, the increasing importance of the direct metal participation in hydrogen bonding for the osmium system leads the proton transfer toward the direct formation of the classical $\mathrm{cis}-\mathbf{1} \mathbf{H}^{+}$, without involvement of a nonclassical intermediate. Despite its classical nature, cis-1 $\mathbf{H}^{+}$exists as an ion pair stabilized by hydrogen bonding with the homoconjugated $\left[\mathrm{R}^{\mathrm{F}} \mathrm{O} \cdots \mathrm{H}^{\cdots} \cdots \mathrm{OR}^{\mathrm{F}}\right]^{-}$anion similarly to the $\left[\mathrm{Cp} *(\mathrm{dppe}) \mathrm{M}\left(\eta^{2}-\mathrm{H}_{2}\right)\right]^{+}\left[\mathrm{R}^{\mathrm{F}} \mathrm{O} \cdots \mathrm{H}^{\cdots} \cdot \mathrm{OR}^{\mathrm{F}}\right]^{-}$ion pairs of $\mathrm{Fe}^{[28]}$ and Ru. ${ }^{[29]}$ 


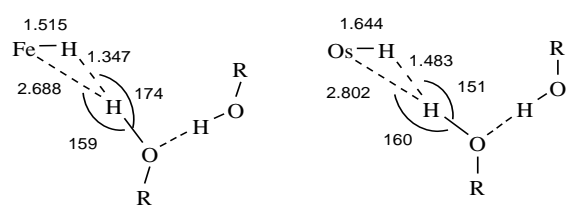

Scheme 4. Comparison of H-bonding parameters for syn$\mathrm{Cp} * \mathrm{MH}($ dhpe $) \cdot(\mathrm{HFIP})_{2}$ with $\mathrm{M}=\mathrm{Fe}$ and Os.

A similar trend had been previously reported for the $\left[\mathrm{Cp}^{*} \mathrm{MH}_{3}\right.$ (dppe) $)(\mathrm{M}=\mathrm{Mo}, \mathrm{W})$ pair of compounds. ${ }^{[0]}$ Although in neither case could a nonclassical intermediate of kinetically controlled protonation at a hydride site be experimentally observed ${ }^{[40,}{ }^{43]}$ calculations on the simplified $\left[\mathrm{CpMH}_{3}(\mathrm{dhpe})\right]$ models revealed a distinct local minimum for a dihydrogen complex $\left[\mathrm{CpMH}_{2}\left(\mathrm{H}_{2}\right)(\mathrm{dhpe})\right]^{+}$in the molybdenum case but none along the proton transfer pathway for the tungsten system. ${ }^{[40]}$ The maximum energy point for the preferred protonation pathway in the $\left[\mathrm{Cp} * \mathrm{WH}_{3}(\mathrm{dppe})\right]$ system has a dihydrogen character, with a $\mathrm{H} \cdots \mathrm{H}$ distance of $1.102 \AA .{ }^{[40]}$ For the presently investigated [Cp*OsH(dhpe)] complex, on the other hand, the $\mathrm{H} \cdots \mathrm{H}$ distance is much longer (1.315 $\AA$ in syn-TS, see Figure 7). On the basis of these distances, it is arguable that assistance by the hydride ligand for the direct proton transfer to the metal is greater for $\mathrm{CpWH}_{3}(\mathrm{dppe})^{[40]}$ than for compound $\mathbf{1}$.

It is interesting to understand what factors orient the proton transfer directly toward the metal (with a greater or smaller assistance by a hydride ligand) to form a classical product, or produce a well-defined non-classical local minimum. Whenever lone pairs are available on the metal site, they can compete with the high-energy electrons in the $\mathrm{M}-\mathrm{H}$ bond(s) as hydrogen bonding sites and the resulting interaction may have component from both types of electron density (bifurcation). For the same structural type, it seems clear from the results obtained so far that the electron density increase associated to a change of metal from the lighter to the heavier member of the same group increases the aptitude of the metal lone pairs to serve as proton acceptors to a greater extent relative to the $\mathrm{M}-\mathrm{H}$ bonding electrons. However, the details of the coordination sphere play also an important role for systems based on the same metal, as shown by proton transfer to the metal for $\mathbf{1}$ and to the hydride site for $\mathrm{OsH}_{2}\left(\mathrm{PP}_{3}\right)$.

For the specific $\mathrm{Cp} * \mathrm{MH}(\mathrm{dppe})$ family, comparison of the two barriers for the syn and anti protonations, the second one leading directly to the trans protonation product, leads to interesting considerations. The calculated barriers relative to the "resting state" syn-[Cp*MH(dhpe)].(HFIP) 2 for the $\mathrm{Fe}$ and Os systems in dichloromethane solution are compared in Figure 10. The relative energies of the isomeric protonation products shown by these calculations are incorrect (the trans product is more stable in the real system) but correct trends were obtained by running calculations on the full system, as shown above in the Results section. The interesting comparisons concern the barriers toward syn and anti protonation for the same metal (syn much faster than anti for the Fe system; similar barriers for the Os system), and the barriers for the same type of process (syn or anti) as the metal changes from $\mathrm{Fe}$ to Os (syn: faster for Fe than for Os; anti: slower for $\mathrm{Fe}$ than for Os). The anti pathway is easier to analyze because it gives the same product for both metals, whereas the syn pathway gives a classical dihydride product for Os and a dihydrogen complex for Fe. For the anti protonation, a lower barrier of the Os system is easily rationalized by invoking the greater metal basicity and the more diffuse character of the metal lone pairs, yielding greater thermodynamic stability to the protonation product and a more product-like character to the transition state. In both cases, the metal changes formal oxidation state from II to IV during the process. For the syn attack, on the other hand, the Fe complex protonation yields a non-classical product with little involvement of the metal lone pair at the transition state level and the metal formal oxidation state remains II throughout the process. The low metal rehybridization required for this process leads to a very low activation barrier. Syn protonation of the osmium system leads instead to a classical product with a change of formal oxidation state and a metal rehybridization, entailing a reaction barrier similar to that of the anti pathway. It is important to recollect that, although the sterically encumbered complex 1 shows a kinetically preferred syn protonation pathway leading to $c i s-\mathbf{1 H}^{+}$, less sterically encumbered complexes of the same family yield a mixture of cis and trans isomers under kinetically controlled conditions, ${ }^{[21,22]}$ in agreement with similar barriers for the protonation of both sites.

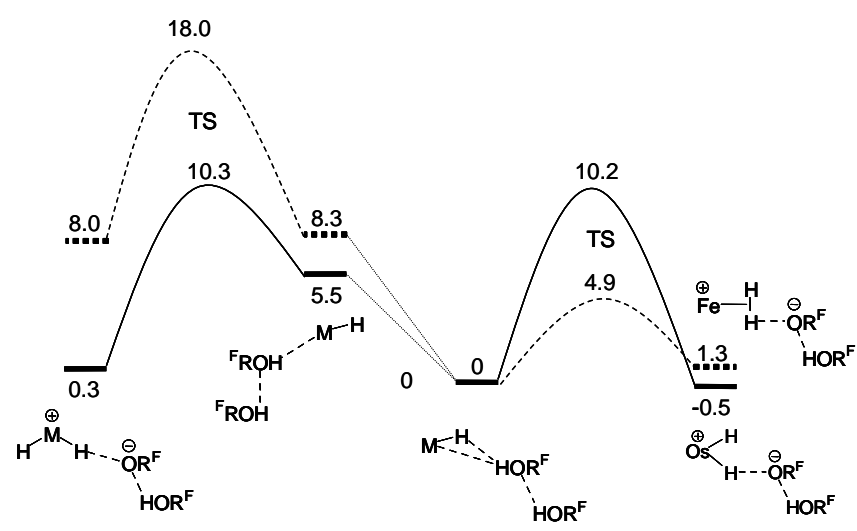

Figure 10. Energy profiles for syn (right) and anti (left) proton transfer to $\mathrm{Cp} * \mathrm{MH}(\mathrm{dhpe})$ in dichloromethane (Os - solid lines, Fe - dashed lines). Energies (in kcal $\mathrm{mol}^{-1}$ ) are relative to the "resting state", syn$\mathrm{Cp} * \mathrm{MH}($ dhpe $) \cdot(\mathrm{HFIP})_{2}$.

\section{Conclusions}

This work has revealed a large metal atom participation in the "dihydrogen bonding" to $\mathrm{Cp} * \mathrm{OsH}(\mathrm{dppe})$ and has confirmed that direct proton transfer to a metal lone pair may be a favored process in the presence of a hydride ligand, although the latter provides assistance to this process. In this case the proton approaches the metal along a trajectory featuring a fleeting proton-hydride contact. As the result, the classical dihydride complex cis$\left[\mathrm{Cp} *(\mathrm{dppe}) \mathrm{Os}(\mathrm{H})_{2}\right]^{+}$is formed at low temperatures. Its fate, however, is similar to that of lighter non-classical congeners, the $\left[\mathrm{Cp} *(\mathrm{dppe}) \mathrm{M}\left(\eta^{2}-\mathrm{H}_{2}\right)\right]^{+}$complexes of iron and ruthenium, with transformation into the thermodynamically more stable trans$\left[\mathrm{Cp} *(\mathrm{dppe}) \mathrm{M}(\mathrm{H})_{2}\right]^{+}$.

\section{Experimental Section}

The hydride 1 was prepared as previously described. ${ }^{[23]}$ All samples were prepared under a dry argon atmosphere using standard Schlenk techniques. The solvents used were purified by refluxing over $\mathrm{Na}$ (hexane, methylcyclohexane) or $\mathrm{CaH}_{2}\left(\mathrm{CH}_{2} \mathrm{Cl}_{2}\right)$ and distilled prior to use under a dry argon atmosphere. The NMR solvents (Aldrich) were degassed by three freeze-pump-thaw cycles, and then vacuum transferred at room temperature.

The IR measurements were performed on an "Infralum 801" FT-IR spectrometer using $\mathrm{CaF}_{2}$ cells of $0.04-0.22 \mathrm{~cm}$ path length. The UV measurements were performed on Specord M-40 and Varian Cary 5 spectrophotometers. Low-temperature 
measurements were carried out using a Carl Zeiss Jena cryostat under a stream of liquid nitrogen. The accuracy of the experimental temperature adjustment was $\pm 1 \mathrm{~K}$. The cryostat modification allows operating under an inert atmosphere and a reagents transfer (premixed either at low or at room temperature) directly into the cell precooled to the required temperature.

The ${ }^{1} \mathrm{H}$ and ${ }^{31} \mathrm{P}\left\{{ }^{1} \mathrm{H}\right\}$ data were collected with a Bruker AV500 spectrometer, operating at $500.3 \mathrm{MHz}$ and $202.5 \mathrm{MHz}$, respectively. The temperature was calibrated using a methanol chemical shift thermometer; the accuracy and stability was $\pm 1 \mathrm{~K}$. All samples were allowed to equilibrate at every temperature for at least $3 \mathrm{~min}$. The spectra were calibrated with the residual solvent resonance $\left({ }^{1} \mathrm{H}\right)$ and with external $85 \%$ $\mathrm{H}_{3} \mathrm{PO}_{4}\left({ }^{31} \mathrm{P}\right)$. The conventional inversion-recovery method $(180-\tau-90)$ was used to determine the variable-temperature longitudinal relaxation time $T_{1}$. Standard Bruker software was used for the calculation of the longitudinal relaxation time.

Crystallographic study. trans-[Cp* $\left.\mathrm{Os}(\mathrm{dppe})(\mathrm{H})_{2}\right]^{+} \mathrm{BF}_{4}^{-}$was crystallized from dichloromethane by slow evaporation. A single crystal was mounted under inert perfluoropolyether at the tip of a glass fibre and cooled in the cryostream of a Bruker APEX2 CCD diffractometer. Data were collected using monochromatic MoKa radiation $(\lambda=0.71073)$. The structure was solved by direct methods (SIR97) ${ }^{[44]}$ and refined by least-squares procedures on $F^{2}$ using SHELXL-97. ${ }^{[45]}$ All $\mathrm{H}$ atoms attached to carbon were introduced in calculation in idealised positions and treated as riding models. The absolute structure was determined by refining the Flack's parameter. ${ }^{[46}$ The drawing of the molecules was realised with the help of ORTEP32. ${ }^{[47]}$ Crystal data and refinement parameters are shown in Table 4.

The crystallographic data have been deposited with the Cambridge Crystallographic Data Center (CCDC 754974). Copies of this information may be obtained free of charge from: The Director, CCDC, 12 Union Road, Cambridge, CB2 1EZ, UK (Fax: +44-1223-336033; e-mail: deposit@ ccdc.cam.ac.uk or http://www.ccdc.cam.ac.uk).

Table 4. Crystal data and structure refinement parameters for trans$\left[\mathrm{Cp} * \mathrm{Os}(\mathrm{dppe})(\mathrm{H})_{2}\right]^{+} \mathrm{BF}_{4}^{-}$

\begin{tabular}{|c|c|}
\hline Empirical formula & $\mathrm{C}_{36} \mathrm{H}_{41}$ Os $\mathrm{P}_{2}, \mathrm{~B} \mathrm{~F}_{4}$ \\
\hline Formula weight & 812.64 \\
\hline Temperature, $\mathrm{K}$ & $180(2)$ \\
\hline Wavelength, $\AA$ & 0.71073 \\
\hline Crystal system & Monoclinic \\
\hline Space group & $\mathrm{P} 2(1)$ \\
\hline $\mathrm{a}, \AA$ & $11.0513(7)$ \\
\hline $\mathrm{b}, \AA$ & $13.8528(8)$ \\
\hline $\mathrm{c}, \AA$ & $11.9523(7)$ \\
\hline$\alpha,{ }^{\circ}$ & 90 \\
\hline$\beta,^{\circ}$ & $113.272(3)$ \\
\hline$\gamma,{ }^{\circ}$ & 90 \\
\hline Volume, $\AA^{3}$ & $1680.92(17)$ \\
\hline $\mathrm{Z}$ & 2 \\
\hline $\mathrm{D}$ (calcd), $\mathrm{Mg} / \mathrm{m}^{3}$ & 1.606 \\
\hline Abs. coeff., $\mathrm{mm}^{-1}$ & 3.935 \\
\hline $\mathrm{F}(000)$ & 808 \\
\hline Crystal size, $\mathrm{mm}^{3}$ & $0.123 \times 0.099 \times 0.079$ \\
\hline Theta range, ${ }^{\circ}$ & 2.49 to $29.20^{\circ}$. \\
\hline Reflts collected & 45979 \\
\hline Unique reflts [R(int)] & $8865(0.0439)$ \\
\hline Completeness, $\%$, & $99.7 \%$ \\
\hline Abs. correction & Multi-scan \\
\hline Max. / min. transmission & 1.0 and 0.788 \\
\hline Refinement method & $\mathrm{F}^{2}$ \\
\hline Data / restr. / param. & $8865 / 1 / 410$ \\
\hline Goodness-of-fit on $\mathrm{F}^{2}$ & 0.978 \\
\hline $\mathrm{R}, \mathrm{wR} 2[\mathrm{I}>2 \mathrm{~s}(\mathrm{I})]$ & $0.0263,0.0395$ \\
\hline R, wR2 (all data) & $0.0367,0.0415$ \\
\hline Resid. density, e. $\AA^{-3}$ & $0.733 /-0.528$ \\
\hline Absolute structure & $-0.005(4)$ \\
\hline
\end{tabular}

Computational details. Calculations were performed with the Gaussian $03^{[48]}$ package at the DFT/B3PW91 level. ${ }^{[49-51]}$ Effective core potentials (ECP) were used to represent the innermost electrons of the osmium, ruthenium and iron atoms as well as the electron core of the phosphorous atoms. ${ }^{[52,53]}$ The basis set for the Os, Ru, Fe and $\mathrm{P}$ atoms was that associated with the pseudopotential, ${ }^{[52,53]}$ with a standard double- $\zeta$ LANL2DZ contraction, supplemented in the case of $\mathrm{P}$ with a set of d-polarization functions. ${ }^{[54]}$ The carbon and hydrogen atoms of the $\mathrm{Cp}^{*}$ and dhpe ligands together with the atoms of the proton donor molecules $(\mathrm{C}, \mathrm{F}, \mathrm{H})$ that are not involved in hydrogen bonds were described with a $6-31 \mathrm{G}$ basis set. ${ }^{[55]}$ The phenyl substituents in case of dppe ligand were also described with 6-31G basis set. The hydridic hydrogen atom and the hydrogen and oxygen atoms of the proton donor molecules involved in hydrogen bonding were described with a $6-31 \mathrm{G}(\mathrm{d}, \mathrm{p})$ set of basis functions. ${ }^{[56]}$

The structures of the reactants, intermediates, transition states, and products were fully optimized without any symmetry restriction. Transition states were identified by having one imaginary frequency in the Hessian matrix. IRC calculations were carried out in both directions starting from the located transition states. No scaling factor was applied to the calculated frequencies since the optimization was run in the gas phase and the IR spectra were measured in solution.

Solvent effects were taken into account by using the CPCM continuum representation of the solvent, ${ }^{[57,58]}$ using standard options. ${ }^{\left[{ }^{[4]}\right.}$ The solvation free energies were computed in dichloromethane $(\varepsilon=8.93)$ using the gas phase optimized geometries.

Supporting Information (see footnote on the first page of this article): IR and NMR spectra, $v_{\mathrm{MH}}$ and $v_{\mathrm{MH} 2}$ frequencies calculated and xyz coordinates of all optimized structures.

\section{Acknowledgments}

Support by the Russian Foundation for Basic Research (RFBR, project 08 03-00464) and the Division of Chemistry and Material Sciences of Russian Academy of Sciences is gratefully acknowledged. We also thank the Centre National de la Recherche Scientifique (CNRS) and the RFBR for support through a France-Russia bilateral PICS grant, which is continuing within the framework of a GDRE (groupe de recherche européen). OAF thanks the Russian Federation President grant (MK-380.2008.3) for an individual support and RP thanks the Centre Interuniversitaire de Calcul de Toulouse (CICT, project CALMIP) for granting free computational time.

[1] M. Besora, A. Lledos and F. Maseras, Chem. Soc. Rev. 2009, 38, 957-966.

[2] G. J. Kubas, Chem. Rev. 2007, 107, 4152-4205.

[3] C. Bianchini and M. Peruzzini in Recent Advances in Hydride Chemistry, Vol. (Ed.: R. Poli and M. Peruzzini), Elsevier Science, Amsterdam, 2001, pp. 271-297.

[4] L. A. Oro and E. Sola in Recent Advances in Hydride Chemistry, Vol. (Ed.: R. Poli and M. Peruzzini), Elsevier Science, Amsterdam, 2001, pp. 299-327.

[5] R. A. Henderson in Recent Advances in Hydride Chemistry, Vol. (Ed.: R. Poli and M. Peruzzini), Elsevier Science, Amsterdam, 2001, pp. 419-461.

[6] J. F. Capon, F. Gloaguen, F. Y. Petillon, P. Schollhammer and J. Talarmin, Eur. J. Inorg. Chem. 2008, 4671-4681.

[7] P. G. Jessop and R. H. Morris, Coord. Chem. Rev. 1992, 121, 155284.

[8] D. M. Heinekey and W. J. Oldham, Jr., Chem. Rev. 1993, 93, 913926.

[9] G. J. Kubas, Metal Dihydrogen and $\sigma$-Bond Complexes, Kluwer Academic/Plenum Press, New York, 2001, pp.

[10] N. K. Szymczak and D. R. Tyler, Coord. Chem. Rev. 2008, 252, 212 230.

[11] G. Parkin and J. E. Bercaw, J. Chem. Soc., Chem. Commun. 1989, 255-257.

[12] M. S. Chinn and D. M. Heinekey, J. Am. Chem. Soc. 1990, 112 5166-5175

[13] G. Jia, A. J. Lough and R. H. Morris, Organometallics 1992, 11, $161-171$.

[14] P. Hamon, L. Toupet, J.-R. Hamon and C. Lapinte, Organometallics 1992, 11, 1429-1431. 
[15] J. R. Hamon, P. Hamon, L. Toupet, K. Costuas and J. Y. Saillard, C. R. Chimie 2002, 5, 89-98.

[16] P. A. Dub, N. V. Belkova, O. A. Filippov, J.-C. Daran, L. M. Epstein, A. Lledós, E. S. Shubina and R. Poli, Chem. Eur. J. doi: 10.1002/chem.200901613.

[17] J. C. Fettinger, H.-B. Kraatz, R. Poli, E. A. Quadrelli and R. C. Torralba, Organometallics 1998, 17, 5767-5775.

[18] M. Baya, P. A. Dub, J. Houghton, J.-C. Daran, R. Poli, N. V. Belkova, E. S. Shubina, L. M. Epstein and A. Lledós, Inorg. Chem. 2009, 48, 209-220.

[19] M. L. H. Green, A. K. Hughes, P. Lincoln, J. J. Martin-Polo, P. Mountford, A. Sella, L.-L. Wong, J. A. Bandy, T. W. Banks, K. Prout and D. J. Watkin, J. Chem. Soc., Dalton Trans. 1992, $2063-$ 2069.

[20] T.-Y. Cheng, D. J. Szalda, J. Zhang and R. M. Bullock, Inorg. Chem. 2006, 45, 4712-4720.

[21] G. Jia, W. S. Ng, J. Yao, C.-P. Lau and Y. Chen, Organometallics 1996, 15, 5039-5045.

[22] J. D. Egbert, R. M. Bullock and D. M. Heinekey, Organometallics 2007, 26, 2291-2295.

[23] P. A. Dub, N. V. Belkova, K. A. Lyssenko, G. A. Silantyev, L. M. Epstein, E. S. Shubina, J.-C. Daran and R. Poli, Organometallics 2008, 27, 3307-3311.

[24] G. C. Jia and C. P. Lau, Coord. Chem. Rev. 1999, 192, 83-108.

[25] R. H. Morris, Coord. Chem. Rev. 2008, 252, 2381-2394.

[26] F. M. Conroy-Lewis and S. J. Simpson, J. Chem. Soc., Chem Commun. 1987, 1675-1676.

[27] N. V. Belkova, P. O. Revin, L. M. Epstein, E. V. Vorontsov, V. I. Bakhmutov, E. S. Shubina, E. Collange and R. Poli, J. Am. Chem. Soc. 2003, 125, 11106-11115.

[28] N. V. Belkova, E. Collange, P. Dub, L. M. Epstein, D. A. Lemenovskii, A. Lledós, O. Maresca, F. Maseras, R. Poli, P. O. Revin, E. S. Shubina and E. V. Vorontsov, Chem. Eur. J. 2005, 11, 873-888.

[29] N. V. Belkova, P. A. Dub, M. Baya and J. Houghton, Inorg. Chim. Acta 2007, 360, 149-162.

[30] M. Baya, O. Maresca, R. Poli, Y. Coppel, F. Maseras, A. Lledós, N. V. Belkova, P. A. Dub, L. M. Epstein and E. S. Shubina, Inorg. Chem. 2006, 45, 10248-10262.

[31] L. M. Epstein, N. V. Belkova and E. S. Shubina in Recent Advances in Hydride Chemistry, Vol. (Ed.: M. Peruzzini and R. Poli), Elsevier, Amsterdam, 2001, pp. 391-418.

[32] A. V. Iogansen, Theor. Experim. Khim., 1971, 7, 312-317.

[33] A. V. Iogansen, Spectrochim. Acta, Part A 1999, 55, 1585-1612.

[34] E. Gutsul, N. Belkova, M. Sverdlov, L. Epstein, E. Shubina, V. Bakhmutov, T. Gribanova, R. Minyaev, C. Bianchini, M. Peruzzini and F. Zanobini, Chem. Eur. J. 2003, 9, 2219-2228.

[35] A. V. Iogansen, Theor. Experim. Khim., 1971, 7, 302-311.

[36] E. Gutsul, N. Belkova, G. Babakhina, L. Epstein, E. Shubina, C. Bianchini, M. Peruzzini and F. Zanobini, Russ. Chem. Bull. 2003, 52 , 1204-1206.

[37] For the parameters of the UV-visible bands of the free and homoconjugated PNP anion (the latter obtained by mixing equimolar amounts of PNP and potassium $p$-nitrophenolate in the presence of excess [18]crown-6), see ref. [28].

[38] Some amount (ca. 8\%) of trans-[Cp*Os(dppe) $\left.\mathrm{H}_{2}\right]^{+}$was initially present in the solution in addition to major cis $-\mathbf{1 H}^{+}$compound due to the occasional warming of the sample during the transfer to the cryostat at $200 \mathrm{~K}$. subtraction of normalized spectrum $\mathbf{c}\left(\right.$ trans $\left.-1 \mathbf{H}^{+}\right)$ from the initially obtained spectrum (mixture of cis and trans species) gave spectrum of $\mathrm{cis}-\mathbf{1} \mathbf{H}^{+}$which is shown on the Figure.

[39] The cis-trans isomerization reaction for $\left[\mathrm{Cp}^{*} \mathrm{OsH}_{2}(\mathrm{dppe})\right]^{+} \mathrm{BF}_{4}^{-}$could be studied by IR monitoring of the increase of the $v_{\mathrm{OsH}}$ band of trans$\mathbf{1 H}^{+}$at $2102 \mathrm{~cm}^{-1}$. In this way the rate constant $k_{250 \mathrm{~K}}=3.43 \pm$
$0.03 \cdot 10^{-4} \mathrm{~s}^{-1}$ was obtained by plotting $\ln \left(\mathrm{A}_{0}-\mathrm{A}_{\mathrm{t}}\right)$ versus time $t$ (compare to $3.15 \pm 0.02 \cdot 10^{-4} \mathrm{~s}^{-1}$ from NMR at $250 \mathrm{~K}$ ).

[40] N. V. Belkova, M. Besora, M. Baya, P. A. Dub, L. M. Epstein, A. Lledós, R. Poli, P. O. Revin and E. Shubina, Chem. Eur. J. 2008, 14, 9921-9934.

[41] N. Belkova, M. Besora, L. Epstein, A. Lledós, F. Maseras and E. Shubina, J. Am. Chem. Soc. 2003, 125, 7715-7725.

[42] The proton affinities of the model [Cp*MH(dhpe)] systems, on the other hand, do not provide the correct basicity order: $255.5 \mathrm{kca}$ $\mathrm{mol}^{-1}$ for $\mathbf{1}_{\mathrm{t}}$ with respect to $\mathrm{cis}-\mathbf{1}_{\mathbf{t}} \mathbf{H}^{+}, 258.7$ and $257.1 \mathrm{kcal} \mathrm{mol}^{-1}$ for the $\mathrm{Fe}$ and $\mathrm{Ru}$ systems, ${ }^{[28,29]}$ respectively, relative to the model nonclassical $\left[\mathrm{Cp} * \mathrm{M}\left(\eta^{2}-\mathrm{H}_{2}\right)(\mathrm{dhpe})\right]^{+}$complexes.

[43] B. Pleune, R. Poli and J. C. Fettinger, Organometallics 1997, 16, 1581-1594.

[44] A. Altomare, M. Burla, M. Camalli, G. Cascarano, C. Giacovazzo, A. Guagliardi, A. Moliterni, G. Polidori and R. Spagna, J. Appl. Cryst. 1999, 32, 115-119.

[45] G. M. Sheldrick, SHELXL97. Program for Crystal Structure refinement, University of Göttingen, Göttingen, Germany, 1997, pp.

[46] H. D. Flack, Acta Cryst. 1983, A39, 876-881.

[47] L. J. Farrugia, J. Appl. Crystallogr. 1997, 32, 565.

[48] M. J. Frisch, G. W. Trucks, H. B. Schlegel, G. E. Scuseria, M. A Robb, J. R. Cheeseman, J. Montgomery, J. A., T. Vreven, K. N. Kudin, J. C. Burant, J. M. Millam, S. S. Iyengar, J. Tomasi, V. Barone, B. Mennucci, M. Cossi, G. Scalmani, N. Rega, G. A. Petersson, H. Nakatsuji, M. Hada, M. Ehara, K. Toyota, R. Fukuda, J. Hasegawa, M. Ishida, T. Nakajima, Y. Honda, O. Kitao, H. Nakai, M. Klene, X. Li, J. E. Knox, H. P. Hratchian, J. B. Cross, C. Adamo, J. Jaramillo, R. Gomperts, R. E. Stratmann, O. Yazyev, A. J. Austin, R. Cammi, C. Pomelli, J. W. Ochterski, P. Y. Ayala, K. Morokuma, G. A. Voth, P. Salvador, J. J. Dannenberg, V. G. Zakrzewski, S. Dapprich, A. D. Daniels, M. C. Strain, O. Farkas, D. K. Malick, A D. Rabuck, K. Raghavachari, J. B. Foresman, J. V. Ortiz, Q. Cui, A. G. Baboul, S. Clifford, J. Cioslowski, B. B. Stefanov, G. Liu, A Liashenko, P. Piskorz, I. Komaromi, R. L. Martin, D. J. Fox, T. Keith, M. A. Al-Laham, C. Y. Peng, A. Nanayakkara, M. Challacombe, P. M. W. Gill, B. Johnson, W. Chen, M. W. Wong, C. Gonzalez and J. A. Pople, Gaussian 03, Revision D.01, Gaussian, Inc., Wallingford CT, 2004, pp.

[49] J. P. Perdew, Physical Review B-Condensed Matter 1986, 33, 8822 8824.

[50] J. P. Perdew in Vol. (Ed.: P. Ziesche and H. Eschrig), Akademie Verlag, Berlin, 1991, pp. 11.

[51] A. D. Becke, J. Chem. Phys. 1993, 98, 5648-5652.

[52] P. J. Hay and W. R. Wadt, J. Chem. Phys. 1985, 82, 270-283.

[53] W. R. Wadt and P. J. Hay, J. Chem. Phys. 1985, 82, 284-298.

[54] A. Höllwarth, M. Böhme, S. Dapprich, A. Ehlers, A. Gobbi, V. Jonas, K. Kohler, R. Stegmann, A. Veldkamp and G. Frenking, Chem. Phys. Lett. 1993, 208, 237-240.

[55] W. Hehre, R. Ditchfie and J. Pople, J. Chem. Phys. 1972, 56, $2257-$ 2261.

[56] P. Harihara and J. Pople, Theor. Chim. Acta 1973, 28, 213-222.

[57] V. Barone and M. Cossi, J. Phys. Chem. A 1998, 102, 1995-2001.

[58] M. Cossi, N. Rega, G. Scalmani and V. Barone, J. Comput. Chem. 2003, 24, 669-681.

Received: ((will be filled in by the editorial staff)) Published online: ((will be filled in by the editorial staff)) 


\section{Entry for the Table of Contents}

Metal Hydrides Protonation

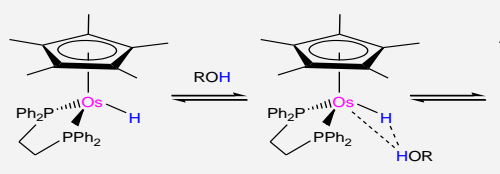

Large metal atom participation in the "dihydrogen bonding" to $\mathrm{Cp} * \mathrm{OsH}(\mathrm{dppe})$ makes the direct proton transfer to a metal a favored process in the presence of a hydride ligand, yielding cis$\left[\mathrm{Cp}^{*}(\mathrm{dppe}) \mathrm{Os}(\mathrm{H})_{2}\right]^{+}$at low temperatures.
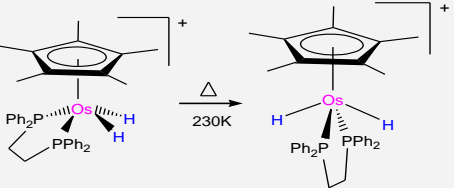

Similarly to lighter non-classical congeners, the $\left[\mathrm{Cp} *(\mathrm{dppe}) \mathrm{M}\left(\eta^{2}-\mathrm{H}_{2}\right)\right]^{+}$ complexes of iron and ruthenium, it transforms into the thermodynamically more stable trans-[Cp*(dppe $\left.) \mathrm{M}(\mathrm{H})_{2}\right]^{+}$ upon warming.

P. A. Dub, O. A. Fillipov, G. A.

Silantyev, N. V. Belkova,* J.-C. Daran, L. M. Epstein, R. Poli,* and E. S. Shubina* ... Page No. - Page No.

Protonation of $\mathrm{Cp} * \mathrm{M}(\mathrm{dppe}) \mathrm{H}$ hydrides: peculiarities of the osmium congener

Keywords: Osmium / Hydrido ligand / Proton transfer / Hydrogen bonding / DFT calculations 


\section{Protonation of $\mathrm{Cp} * \mathrm{M}(\mathrm{dppe}) \mathrm{H}$ hydrides: peculiarities of the osmium congener}

Pavel A. Dub, ${ }^{[a, b]}$ Oleg A. Fillipov, ${ }^{[a]}$ Gleb A. Silantyev, ${ }^{[a]}$ Natalia V. Belkova, ${ }^{*[a]}$ Jean-Claude Daran, ${ }^{[b]}$ Lina M. Epstein, ${ }^{[a]}$ Rinaldo Poli, ${ }^{*[b, c]}$ and Elena S. Shubina*[a]

\section{Supporting Information}

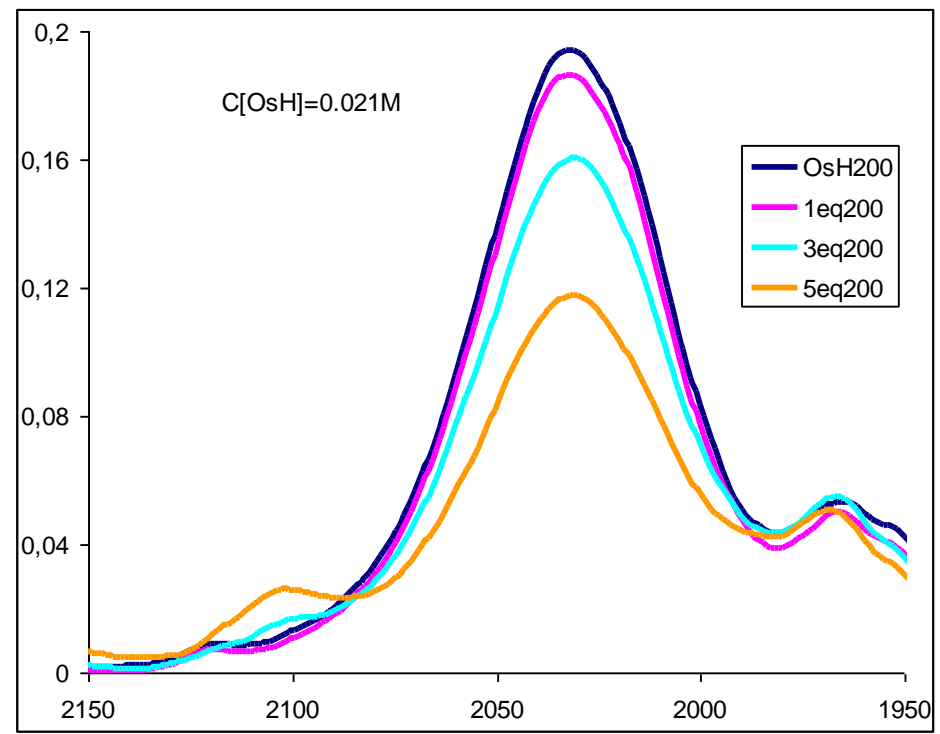

Figure S1. IR spectra of $\mathrm{Cp}^{*} \mathrm{Os}(\mathrm{dppe}) \mathrm{H}(\mathbf{1})$ in the presence of increasing amount of TFE. Hexane- $\mathrm{CH}_{2} \mathrm{Cl}_{2} 2: 1 \mathrm{v} / \mathrm{v}$ mixture, $200 \mathrm{~K}$.
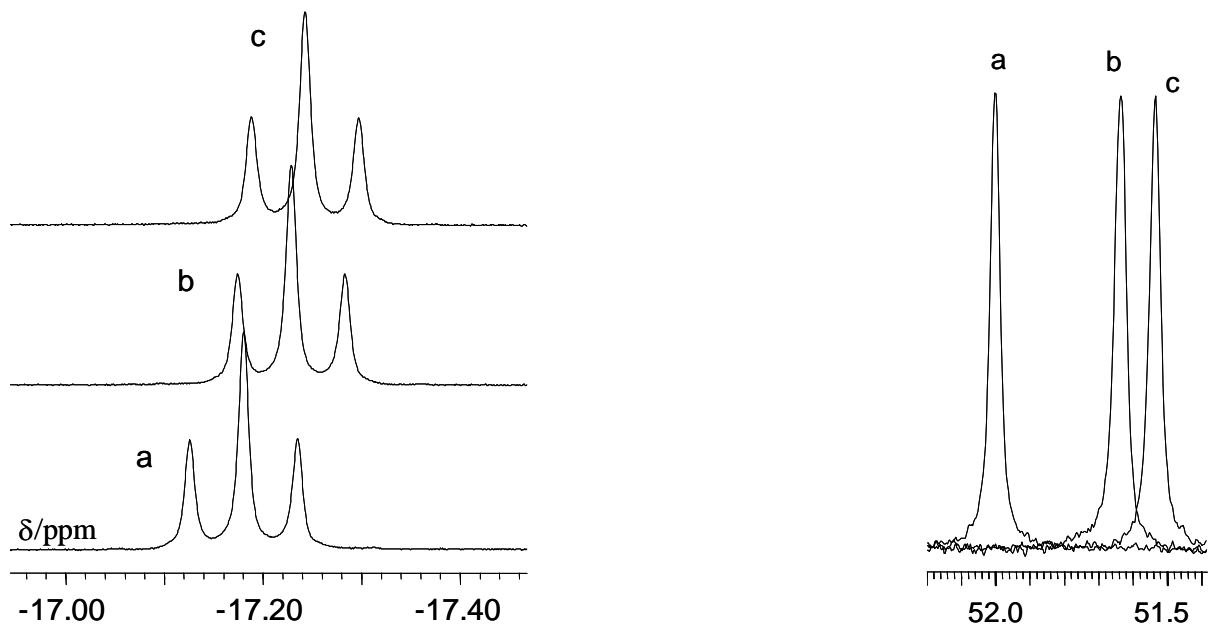

Figure S2. ${ }^{1} \mathrm{H}$ NMR (500 MHz, hydride region) and ${ }^{31} \mathrm{P}\left\{{ }^{1} \mathrm{H}\right\}(202.5 \mathrm{MHz})$ spectrum of $\mathbf{1}$ (a), $\mathbf{1}$ in the presence of 2.7 (b) and 4.5 (c) equiv TFE. $\mathrm{CD}_{2} \mathrm{Cl}_{2}, 200 \mathrm{~K}, c(\mathbf{1})=3.3 \cdot 10^{-2} \mathrm{M}$. 

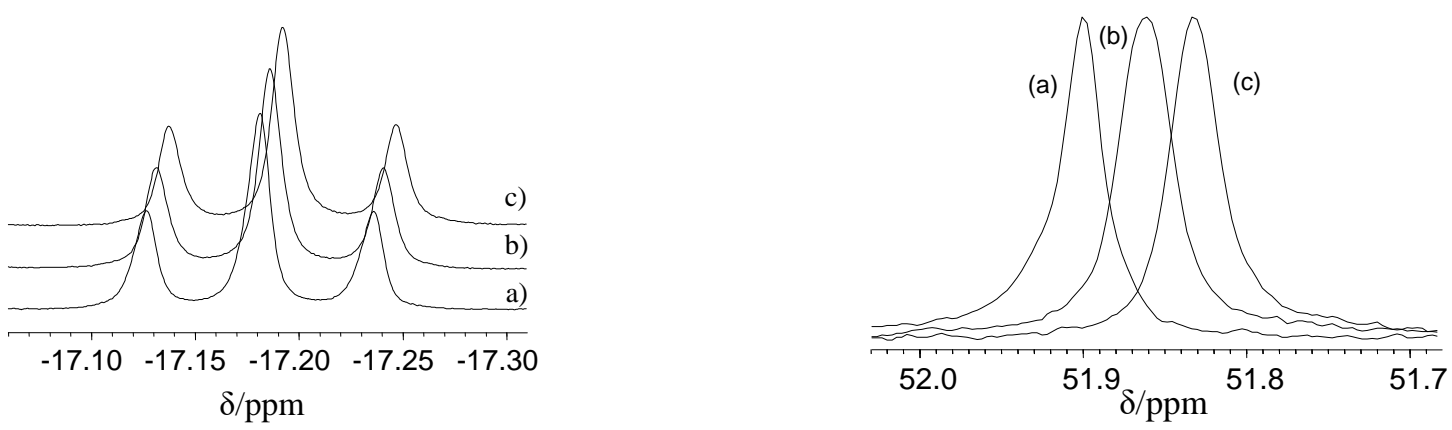

Figure S3. ${ }^{1} \mathrm{H}(500 \mathrm{MHz})$ (hydride region, left) and ${ }^{31} \mathrm{P}\left\{{ }^{1} \mathrm{H}\right\}$ NMR $(202.5 \mathrm{MHz}$, right) NMR spectra of $\mathbf{1}$ (a), $\mathbf{1}$ in the presence of 3 equiv (b) or 7 equiv $\mathrm{MFE}$ (c). $\mathrm{CD}_{2} \mathrm{Cl}_{2}, 200 \mathrm{~K} . c(\mathbf{1})=$ $3.3 \cdot 10^{-2} \mathrm{M}$.

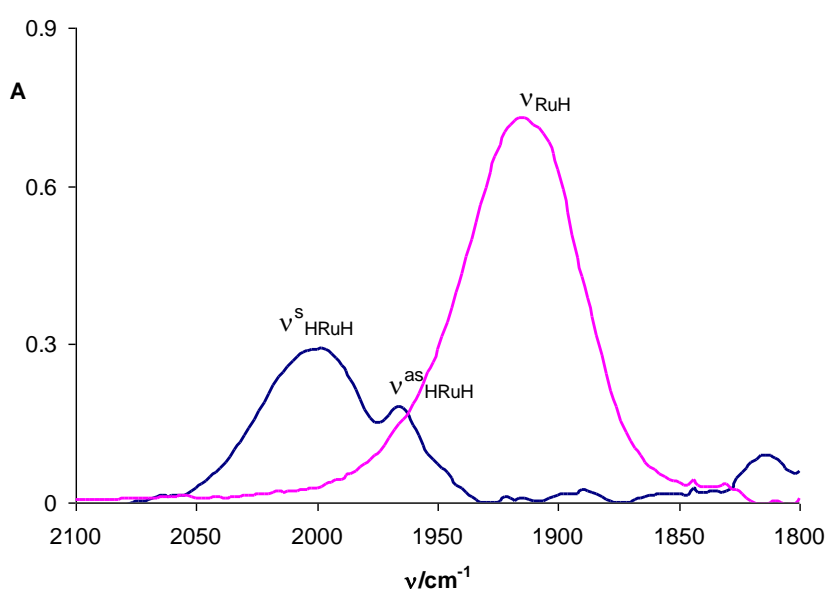

Figure S4. IR spectra ( $v_{\mathrm{RuH}}$ region) of $\mathrm{Cp} * \mathrm{Ru}(\mathrm{dppe}) \mathrm{H}(0.026 \mathrm{M})$ and trans$\left[\mathrm{Cp} * \mathrm{Ru}(\mathrm{dppe})(\mathrm{H})_{2}\right]^{+} \mathrm{BF}_{4}^{-}$after the subtraction of $\mathrm{Cp} * \mathrm{RuHCl}(\mathrm{dppe}) . \mathrm{CH}_{2} \mathrm{Cl}_{2}, 200 \mathrm{~K}, 1=1.2 \mathrm{~mm}$. 
Table S1. Frequencies $\left(\nu_{\mathrm{MH}}\right.$ or $\nu_{\mathrm{MH} 2}$ in $\left.\mathrm{cm}^{-1}\right)$ and intensities $\left(A\right.$ in $\left.10^{4} \mathrm{~L} \mathrm{~mol}^{-1} \mathrm{~cm}^{-2}\right)$ of $\mathrm{MH}$ stretching vibrations calculated for $\left[\mathrm{Cp}^{*} \mathrm{MH}(\mathrm{dppe})\right.$ and trans- $\left[\mathrm{Cp} * \mathrm{M}(\mathrm{H})_{2}(\mathrm{dppe})\right]^{+}$and their dhpe models.

\begin{tabular}{|c|c|c|c|c|c|c|}
\hline & \multicolumn{2}{|c|}{$[\mathrm{Cp} * \mathrm{MH}(\mathrm{dhpe})]$} & \multicolumn{4}{|c|}{ trans $-\left[\mathrm{Cp} * \mathrm{M}(\mathrm{H})_{2}(\mathrm{dhpe})\right]^{+}$} \\
\hline $\mathrm{M}$ & $v_{\mathrm{MH}}$ & A & $v^{\mathrm{s}} \mathrm{MH} 2$ & A & $v^{\mathrm{as}}{ }_{\mathrm{MH} 2}$ & A \\
\hline $\mathrm{Fe}$ & 1867 & 1.14 & 1990 & 0.63 & 2005 & 0.16 \\
\hline $\mathrm{Ru}$ & 1971 & 1.38 & 2005 & 0.78 & 1970 & 0.12 \\
\hline \multirow[t]{3}{*}{ Os } & 2093 & 0.84 & 2117 & 0.49 & 2065 & 0.05 \\
\hline & & & $2155^{\mathrm{a}}$ & $0.25^{\mathrm{a}}$ & $2187^{\mathrm{a}}$ & $0.001^{\mathrm{a}}$ \\
\hline & \multicolumn{2}{|c|}{$[\mathrm{Cp} * \mathrm{MH}(\mathrm{dppe})]$} & \multicolumn{4}{|c|}{ trans $-\left[\mathrm{Cp} * \mathrm{M}(\mathrm{H})_{2}(\mathrm{dppe})\right]^{+}$} \\
\hline $\mathrm{M}$ & $v_{\mathrm{MH}}$ & A & $v^{\mathrm{s}} \mathrm{MH} 2$ & A & $v^{\mathrm{as}} \mathrm{MH}_{2}$ & A \\
\hline $\mathrm{Fe}$ & 1920 & 1.12 & 2022 & 0.40 & 2062 & 0.18 \\
\hline $\mathrm{Ru}$ & 2007 & 1.31 & 2069 & 0.55 & 2034 & 0.31 \\
\hline \multirow[t]{2}{*}{ Os } & 2141 & 0.82 & 2169 & 0.41 & 2122 & 0.14 \\
\hline & & & $2129^{\mathrm{b}}$ & $0.12^{\mathrm{b}}$ & $2257^{\mathrm{b}}$ & $0.18^{\mathrm{b}}$ \\
\hline
\end{tabular}

${ }^{\mathrm{a}}$ cis-[Cp*Os $\left.(\mathrm{H})_{2}(\mathrm{dhpe})\right]^{+} \quad{ }^{\mathrm{b}}$ cis- $\left[\mathrm{Cp} * \mathrm{Os}(\mathrm{H})_{2}(\mathrm{dppe})\right]^{+}$

The calculated frequencies of the Os-H stretching vibrations match the experimental observations (Table 2, main text) with experimental to calculated ratio of $>0.97$

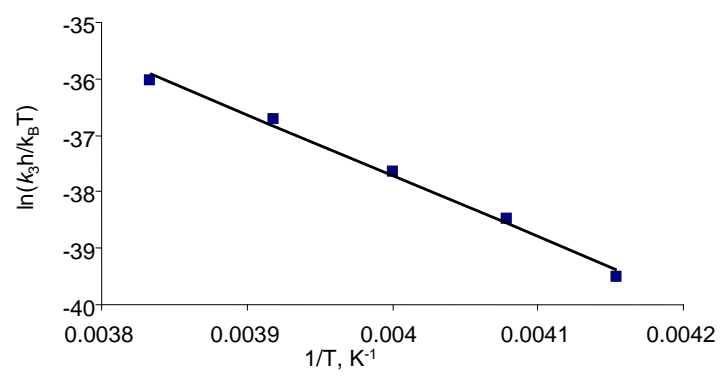

Figure S5. Eyring plot for the isomerization rate constant $k_{3}$.
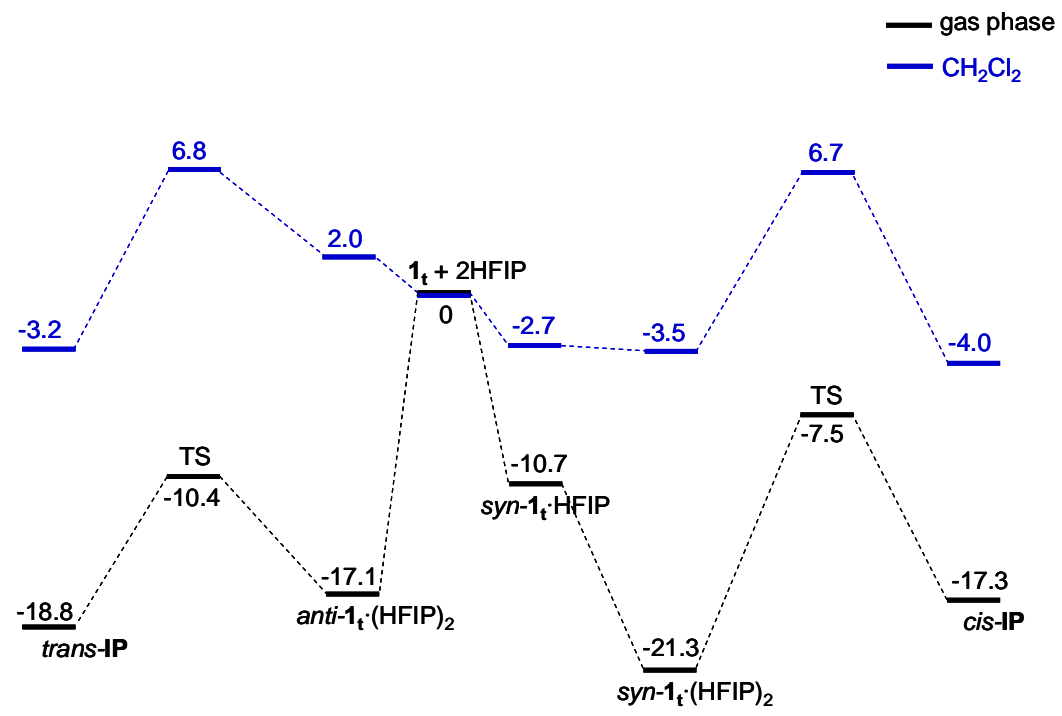

Figure S6. Energy profile for the hydrogen bonding and proton transfer between $\mathrm{Cp}{ }^{*} \mathrm{OsH}(\mathrm{dhpe})\left(\mathbf{1}_{\mathbf{t}}\right)$ and HFIP. Energies (in $\mathrm{kcal} \mathrm{mol}{ }^{-1}$ ) are relative to isolated $\mathbf{1}_{\mathbf{t}}$ and HFIP. 


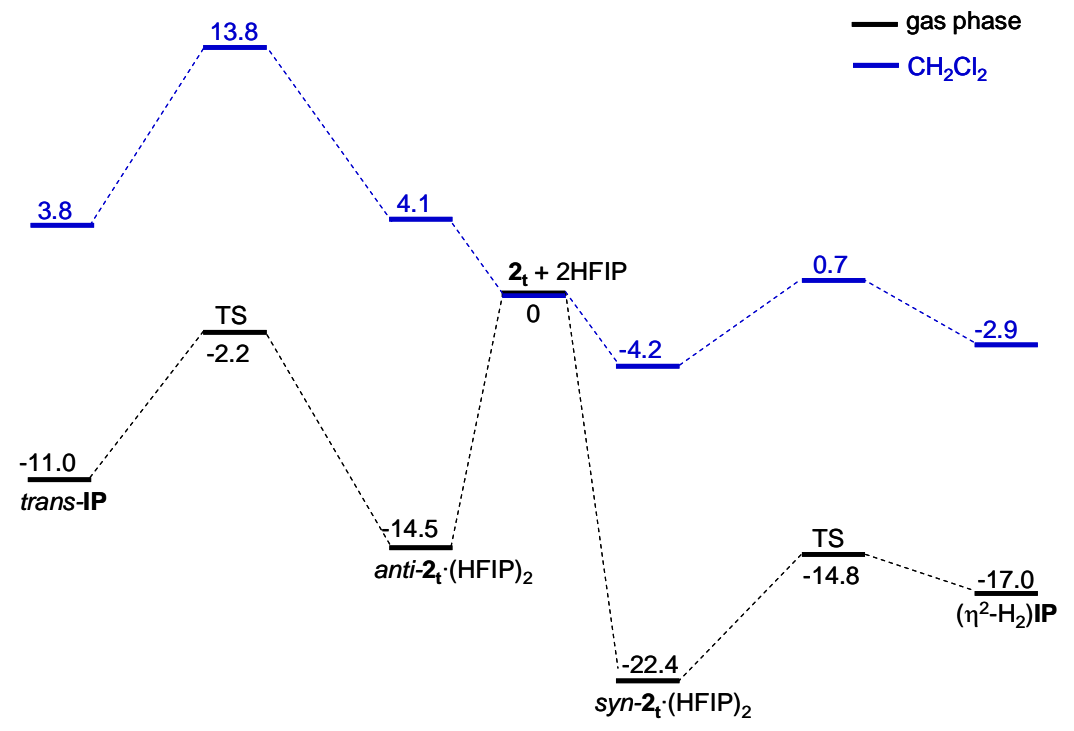

Figure S7. Energy profile for the hydrogen bonding and proton transfer between $\mathrm{Cp} * \mathrm{FeH}(\mathrm{dhpe})\left(\mathbf{2}_{\mathbf{t}}\right)$ and two molecules of HFIP. Energies (in $\mathrm{kcal} \mathrm{mol}^{-1}$ ) are relative to isolated $\mathbf{2}_{\mathbf{t}}$ and HFIP.

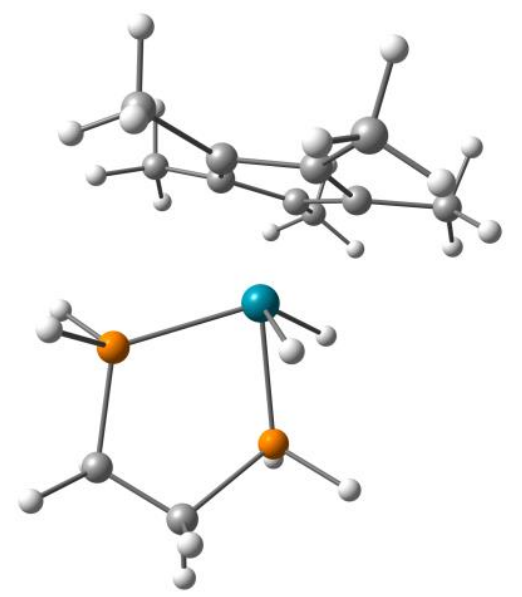

Figure S8. Transition state for the cis- to trans-[Cp* $\left.\mathrm{OsH}_{2}(\mathrm{dhpe})\right]^{+}$isomerization. 
Table S2. xyz coordinates of all optimized structures.

a. free species

$\mathrm{Cp} * \mathrm{Os}(\mathrm{dhpe}) \mathrm{H}$

$6-0.701866000$

$6 \quad 0.738462000$

$6 \quad 0.995275000$

$6-0.257414000$

$76 \quad 0.119736000$

$15-1.041088000$

$6-1.349079000$

$1-0.574603000$

$-2.371887000$

$-0.165768000$

$-1.508857000$

$-2.271549000$

$-0.419523000$

$15 \quad 0.410559000$

0.688763000

1.685104000

$-0.250272000$

1.425980000

2.320980000

3.143676000

2.474202000

2.393062000

1.729042000

1.454607000

1.788066000

2.732328000

$-1.409956000$

$-2.392933000$

$-1.561197000$

$-0.841816000$

$-2.778512000$

$-2.990328000$

$-3.182587000$

$-3.334276000$

$-0.468263000$

0.388196000

$-0.614131000$

$-1.350735000$

\section{$\mathrm{E}=-575.694341100$}

$-1.465036000 \quad-0.068221000$

$-1.434719000 \quad 1.232639000$

$-1.614837000$

$-1.775658000$

$-1.664275000$

0.325326000

1.902852000

3.447689000

2.513067000

1.649580000

3.644186000

4.325025000

3.264402000

4.303033000

1.961939000

4.084449000

2.351371000

1.900303000

0.988760000

$-2.097466000$

$-1.663920000$

$-3.185015000$

$-1.707564000$

$-1.817285000$

$-1.250730000$

$-2.877580000$

$-1.497405000$

$-1.380720000$

$-0.909446000$

$-2.389796000$

$-0.808088000$

$-1.444278000$

$-0.945393000$

$-2.464356000$

$-0.913966000$

$-1.940015000$

$-1.614822000$

$-3.015005000$

$-1.419078000$

Cp*Fe(dhpe)H $\quad \mathrm{E}=-608.008435119$

$6-1.352514000-1.493640000$

$6-0.737410000-1.467676000$

$-0.737410000$

$\begin{array}{ll}6 & 0.702749000\end{array}$

$6 \quad 0.959386000$

$6-0.300227000$

$26-0.052114000$

$15-1.095168000$

$6-1.067500000$

$-0.662251000$

$-2.489388000$

0.102427000

$-1.011328000$

$-2.021295000$

$-0.027728000$

$15 \quad 0.249699000$

1.049541000

1.495331000
$-1.467676000$

$-1.529044000$

$-1.615851000$

$-1.568436000$

0.191928000

1.655244000

3.353986000

1.992231000

1.584427000

3.405381000

4.159496000

3.457548000

4.200098000

1.717267000

3.577720000

1.878956000
1.059334000

$-0.349893000$

$-1.061207000$

0.001235000

$-1.109538000$

$-0.067980000$

$-2.324921000$

$-1.585872000$

$-0.704821000$

0.497678000

1.728263000

1.522125000

0.361219000

2.057789000

2.799624000

$-0.724248000$

$-0.964922000$

$-0.389944000$

$-1.007611000$

$-1.983807000$

2.163538000

3.058836000

2.450098000

1.867236000

2.549638000

2.457075000

2.959326000

3.290788000

$-0.361987000$

$-1.313341000$

$-0.428229000$

0.416981000

$-2.517816000$

$-2.700172000$

$-2.901861000$

$-0.031758000$

1.256218000

1.068335000

$-0.342707000$

$-1.032444000$

0.109049000

$-1.055935000$

$-0.232024000$

$-2.382236000$

$-1.401377000$

0.766116000

$-0.972183000$

0.300971000

1.508715000

1.575545000

0.241673000

2.267372000
0.890500000

$-3.115751000$
$-0.565906000$

1.133386000

2.302676000

3.088550000

2.560654000

2.327785000

1.724399000

1.402728000

1.910115000

2.681611000

$-1.442680000$

$-2.425297000$

$-1.597929000$

$-0.870533000$

$-2.822337000$

$-3.072837000$

$-3.182242000$

$-3.396083000$

$-0.499330000$

0.317138000

$-0.543692000$

$-1.432748000$

1.918324000

0.918256000

$-1.780585000$

$-1.301419000$

$-2.844429000$

$-1.334109000$

$-1.634416000$

$-1.114452000$

$-2.683177000$

$-1.198950000$

$-1.465077000$

$-0.987102000$

$-2.489137000$

$-0.928454000$

$-1.534631000$

$-1.044736000$

$-2.571329000$

$-1.036770000$

$-1.722337000$

$-1.260950000$

$-2.782471000$

$-1.256157000$

HFIP E=-789.322984605

$8 \quad 8.651224000-0.489130000$

8.651224000

8.667873000

9.681354000

8.012521000

7.983615000

8.740218000

6.724782000

7.876791000

6.669555000

8.188750000

8.638545000

9.188096000

0.489130000

$-1.254165000$

$-0.954647000$

$-1.665335000$

$-1.628287000$

$-1.204940000$

$-2.989282000$

$-0.668170000$

$-2.203249000$

$-0.033010000$

1.012363000

HFIP dimer $\quad E=-1578.65797852$

$8 \quad 8.572624000 \quad 0.522208000$

$6 \quad 8.642900000$

9.669220000

7.978296000

$-0.815121000$

$-1.184050000$

$-0.969306000$

7.994484000

$-1.658378000$

8.733858000

6.706284000

$-1.554208000$

$-1.265286000$

7.964410000

6.646238000

8.118607000

8.611662000

12.507522000

12.006526000

12.380212000

12.504930000

10.599253000

9.384742000

$-2.996469000$

$-0.645061000$

$-2.242095000$

$-0.106104000$

2.280392000

1.577621000

2.146781000

0.145832000

1.588444000

0.969663000

3.607583000

1.721946000

2.220522000

$-0.660488000$

0.077733000

2.748580000

$-0.468634000$

$-0.981747000$

$-0.390555000$

$-1.083449000$

$-1.980051000$

2.156825000

3.065890000

2.430243000 


\section{b. $\left[\mathrm{Cp} * \mathrm{Os}(\mathrm{dhpe}) \mathrm{H}_{2}\right]^{+}$: minima and isomerisation TS}

\begin{tabular}{|c|c|}
\hline & $\mathrm{p} * \mathrm{Os}(\mathrm{c}$ \\
\hline & -1.553338000 \\
\hline & -0.763314000 \\
\hline & 0.599327000 \\
\hline & 0.646390000 \\
\hline & -0.686899000 \\
\hline & -0.917942000 \\
\hline & -0.276499000 \\
\hline & -0.058372000 \\
\hline & 0.966956000 \\
\hline & -1.087295000 \\
\hline & 0.547420000 \\
\hline & 0.565487000 \\
\hline & -1.054404000 \\
\hline & 0.440297000 \\
\hline & -0.279476000 \\
\hline & 1.616884000 \\
\hline & 0.654258000 \\
\hline & -1.270823000 \\
\hline & -2.257594000 \\
\hline & 1.875516000 \\
\hline & 2.631273000 \\
\hline & 2.327775000 \\
\hline & 1.655029000 \\
\hline & 1.767108000 \\
\hline & 1.479887000 \\
\hline & 2.199215000 \\
\hline & 2.559233000 \\
\hline & -1.211530000 \\
\hline & -2.280476000 \\
\hline & -1.024407000 \\
\hline & -0.679014000 \\
\hline & -2.953844000 \\
\hline & -3.476914000 \\
\hline & -2.944149000 \\
\hline & -3.539664000 \\
\hline & -1.035648000 \\
\hline & -0.432557000 \\
\hline & -0.857671000 \\
\hline & -2.086861000 \\
\hline & \\
\hline
\end{tabular}

$$
\begin{array}{cc} 
& \multicolumn{2}{c}{E=-576.112439335} \\
-1.831078000 & 0.143226000 \\
-1.678359000 & 1.355553000 \\
-1.361747000 & 0.962341000 \\
-1.281128000 & -0.470073000 \\
-1.559615000 & -0.988647000 \\
0.324721000 & 0.272062000 \\
2.006398000 & -1.193384000 \\
3.652836000 & -0.340799000 \\
1.835176000 & -1.872966000 \\
2.327762000 & -2.313978000 \\
3.411635000 & 1.048228000 \\
4.317126000 & -0.947385000 \\
4.105005000 & -0.261798000 \\
4.287696000 & 1.695531000 \\
1.922732000 & 1.826628000 \\
3.180111000 & 0.971294000 \\
1.549754000 & 2.836462000 \\
2.500857000 & 2.664818000 \\
0.786309000 & -0.511015000
\end{array}
$$

$-1.094986000$

$-0.492470000$

$-2.070920000$

$-0.620369000$

$-1.267779000$

$-1.300189000$

$-0.789460000$

$-1.520191000$

$-2.260364000$

1.890534000

$-0.885423000$

$-2.264947000$

2.874067000

2.046816000

$-0.627539000$

$-2.033506000$

1.493706000

2.738293000

$-1.854816000$

2.874474000

$-3.097589000$

$-1.461077000$

2.932342000

3.502199000

$-2.350510000$

0.071874000

$-1.984135000$

$-0.814456000$

$-3.447054000$

0.027082000

$-2.057126000$

$-1.777763000$

0.945997000

$-1.156709000$

$-2.427497000$

$-2.825313000$

$-3.095315000$

$-2.703259000$

$-1.557040000$

$-2.626189000$

0.639754000

1.132399000

\section{trans $-\left[\mathrm{Cp} * \mathrm{Os}(\mathrm{dhpe}) \mathrm{H}_{2}\right]^{+} \quad \mathrm{E}=-576.113676016$}

$\begin{array}{lccc}6 & -1.398718000 & -1.615802000 & -0.028443000 \\ 6 & -0.777535000 & -1.605032000 & 1.295255000 \\ 6 & 0.659024000 & -1.606055000 & 1.113487000 \\ 6 & 0.927688000 & -1.608264000 & -0.307217000 \\ 6 & -0.336504000 & -1.619536000 & -1.015353000 \\ 76 & -0.270506000 & 0.317777000 & 0.215761000 \\ 15 & -1.109242000 & 1.967297000 & -1.166484000 \\ 6 & -1.023317000 & 3.599248000 & -0.250484000 \\ 1 & -0.476256000 & 2.237033000 & -2.410873000 \\ 1 & -2.460964000 & 1.926272000 & -1.604193000 \\ 6 & 0.206579000 & 3.653776000 & 0.678199000 \\ 1 & -1.012619000 & 4.433891000 & -0.958834000 \\ 1 & -1.949049000 & 3.672599000 & 0.333769000 \\ 1 & 0.123274000 & 4.485577000 & 1.385084000\end{array}$

$\begin{array}{lr}15 & 0.435901000 \\ 1 & 1.122472000 \\ 1 & 1.785239000 \\ 1 & -0.219472000 \\ 1 & 1.034184000 \\ 6 & 2.277981000 \\ 1 & 3.056576000 \\ 1 & 2.535576000 \\ 1 & 2.308385000 \\ 6 & 1.681677000 \\ 1 & 1.328896000 \\ 1 & 1.907160000 \\ 1 & 2.620098000 \\ 6 & -1.491857000 \\ 1 & -2.502603000 \\ 1 & -1.574727000 \\ 1 & -0.962216000 \\ 6 & -2.854028000 \\ 1 & -3.149306000 \\ 1 & -3.083277000 \\ 1 & -3.481363000 \\ 6 & -0.504133000 \\ 1 & 0.281622000 \\ 1 & -0.457939000 \\ 1 & -1.468241000 \\ 1 & -1.621800000\end{array}$

2.036388000 3.806344000 2.116677000 2.251189000 1.001749000 $-1.735532000$ $-1.265680000$ $-2.797393000$ $-1.285430000$ $-1.743077000$ $-1.329058000$ $-2.804060000$ $-1.245895000$ $-1.784467000$ $-1.371549000$ $-2.853022000$ $-1.303207000$ $-1.817489000$ $-1.380220000$ $-2.890095000$ $-1.373290000$ $-1.788331000$ $-1.275563000$ $-2.852942000$ $-1.408038000$ 0.902644000
1.596844000 0.093691000 2.036210000 2.840294000 $-0.507921000$ $-0.936597000$ $-0.331366000$ $-1.043747000$ $-1.931246000$ 2.195129000 3.142794000 2.364666000 1.936507000 2.597086000 2.564765000 2.834237000 3.423187000 $-0.308652000$ $-1.265989000$ $-0.350354000$ 0.467714000 $-2.491688000$ $-3.052505000$ $-2.755528000$ $-2.837897000$ 0.932366000 cis-trans isomerisation TS

$6 \quad-1.768570000 \quad 0.061719000$

$6-1.336986000$

$6-1.371848000$

$6-1.735604000$

$6-1.941457000$

$\begin{array}{ll}76 & 0.254813000\end{array}$

$15 \quad 2.135156000$

$6 \quad 3.689912000$

12.464025000

$1 \quad 2.203336000$

$6 \quad 3.624839000$

14.565407000

$1 \quad 3.725722000$

14.335483000

$15 \quad 1.883932000$

$1 \quad 3.852911000$

$1 \quad 1.781175000$

$1 \quad 1.993722000$

1

6

1

1

1
6

1

1
1

1
6

6

1

1

1
6
1

0.145486000

$-2.050175000$

$-1.416004000$

$-1.894923000$

$-3.095529000$

$-2.547123000$

$-2.260363000$

$-3.642658000$

$-2.245040000$

$-2.020462000$

$-3.080168000$

$-1.817360000$

$-1.427746000$

$-1.200669000$

$-0.544341000$

$-0.811007000$
1.249855000

0.976430000

$-0.381681000$

$-0.981236000$

$-0.362079000$

$-1.679507000$

$-0.769532000$

$-2.231096000$

$-2.869609000$

0.643081000

$-1.322851000$

$-0.739285000$

1.320900000

1.300217000

0.627273000

2.231275000

2.238263000

$-1.809106000$

$-0.049589000$

0.616213000

$-1.067180000$

0.221707000

$-2.323839000$

$-3.054623000$

$-2.250183000$

$-2.720581000$

$-1.066065000$

$-0.943795000$

$-2.138567000$

$-0.649680000$

2.607618000

3.263152000

2.556277000
$E=-576.071762005$

$-1.208215000$

$-0.514728000$

0.936201000

1.112229000

$-0.230724000$

$-0.163591000$

0.094316000

$-0.374641000$

1.367502000

$-0.676974000$

0.218236000

$-0.018252000$

$-1.469599000$

$-0.264167000$

0.035253000

1.290427000

1.109357000

$-1.033934000$

0.563735000

$-2.671573000$

$-3.261184000$

$-3.036128000$

$-2.868271000$

$-0.489502000$

0.270568000

$-0.483690000$

$-1.461604000$

2.409983000

2.670594000

2.361364000

3.228050000

$-1.129447000$

$-0.549597000$

$-2.149374000$ 
$-2.182849000$

$-1.201960000$

$-2.164443000$

$-0.842985000$

$-0.504330000$

0.770372000

3.095756000

1.999182000

2.483422000

1.554531000

2.791562000

$-0.725188000$

$-1.175446000$

2.011753000

2.223697000

2.943398000

1.725323000

$-1.658741000$

\section{c. Hydrogen bonded complexes of $1_{t}$ with HFIP}

\begin{tabular}{|c|c|c|c|}
\hline & . & & \\
\hline 6 & -7.686253000 & -0.997126000 & -10.749461000 \\
\hline 6 & -6.955207000 & -0.142603000 & -11.653007000 \\
\hline & -7.571200000 & -0.259016000 & -12.972002000 \\
\hline 6 & -8.687018000 & -1.159144000 & -12.862718000 \\
\hline & -8.770175000 & -1.616049000 & -11.476439000 \\
\hline 76 & -9.116145000 & 0.642478000 & -11.536559000 \\
\hline 15 & -11.317112000 & 0.934030000 & -11.957820000 \\
\hline 6 & -11.769745000 & 2.747032000 & -12.200089000 \\
\hline & -11.902863000 & 0.333478000 & -13.124762000 \\
\hline 1 & -12.365460000 & 0.549961000 & 58159000 \\
\hline 6 & -10.582719000 & 3.482076000 & -12.839696000 \\
\hline 1 & -12.682588000 & 2.839412000 & -12.798615000 \\
\hline 1 & -11.978042000 & 3.150848000 & -11.201272000 \\
\hline 1 & -10.661794000 & 4.567638000 & 94000 \\
\hline 15 & -8.981248000 & 2.835617000 & 67000 \\
\hline 1 & -10.532347000 & 3.266506000 & 1630000 \\
\hline 1 & -8.031021000 & 3.274473000 & 96000 \\
\hline 1 & -8.717540000 & 263000 & 6000 \\
\hline 1 & -9.578595000 & 1.121290000 & 88000 \\
\hline 6 & -9.519381000 & 7570000 & 15000 \\
\hline & -9.569375000 & -0.961313000 & 63000 \\
\hline 1 & -9.101896000 & -2.614182000 & 97000 \\
\hline 1 & -10.5465 & 4000 & 000 \\
\hline & -7.028534000 & 0.333343000 & 235000 \\
\hline 1 & -6.590258000 & 1.321590000 & 68000 \\
\hline & -6.240306000 & 3993000 & 21000 \\
\hline 1 & -7.809687000 & 0.447134000 & 747000 \\
\hline 6 & -5.6 & 373000 & 36000 \\
\hline & -5.582305000 & 0.843850000 & 52000 \\
\hline 1 & -4.808945000 & -0.121079000 & 13000 \\
\hline 1 & -5.5 & 288000 & 38000 \\
\hline & -7.307966000 & -1.300343000 & 82000 \\
\hline 1 & -8.183070000 & -1.552436000 & 02000 \\
\hline 1 & -6.618892000 & -2.156088000 & 31000 \\
\hline 1 & -6.816291000 & -0.452910000 & 1000 \\
\hline 6 & -9.66102 & 851000 & 096000 \\
\hline 1 & -10.613105000 & -2.734801000 & -11.502885000 \\
\hline 1 & -9.186132000 & -3.690214000 & 07000 \\
\hline 1 & -9.890294000 & -2.567915000 & 83000 \\
\hline 2 & -8.725322000 & 1.483390000 & 356000 \\
\hline 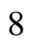 & -8.518743000 & 1.404488000 & 97000 \\
\hline U & -8.086803000 & 2.608117000 & 3854000 \\
\hline 1 & -7.885000000 & 2.425655000 & 23000 \\
\hline 6 & -6.761354000 & 3.071501000 & 566000 \\
\hline & -9.184002000 & 3.669802000 & 640000 \\
\hline 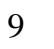 & -10.276060000 & 3.236912000 & -6.569139000 \\
\hline y & -9.618948000 & 3.927358000 & -8.581839000 \\
\hline 9 & -8.772630000 & 4.872197000 & -6.744192000 \\
\hline 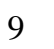 & -6.880275000 & 3.476823000 & -9.168773000 \\
\hline & -6.208185000 & 4.121069000 & -7.139699000 \\
\hline & -5848778000 & 2.031856000 & -7820589000 \\
\hline
\end{tabular}

syn-Cp*OsH(dhpe)·HFIP $\quad \mathrm{E}=-1365.03438009$

$-0.259016000-12.972002000$

$-1.616049000-11.476439000$

$.642478000-11.536559000$

957820000

$0.333478000-13.124762000$

$0.549961000-11.058159000$

$839412000-12.798615000$

$3.150848000-11.201272000$

$567638000-12.714194000$

$3.274473000-13.055096000$

$3.879263000-11.134006000$

$1.121290000-10.036388000$

$-2.614182000-14.387497000$

$-1.885564000-13.675135000$

$-0.303993000 \quad-14.659421000$

$0.447134000-14.991747000$

$0.544373000-11.361036000$

$-9.333982000$

8.729602000

$-9.302831000$

$-8.852611000$

$-11.502885000$

$-9.903383000$

$-8.763356000$

$-6.188023000$

$-7.850566000$

$-8.581839000$

$-6.744192000$

$-7.139699000$

$-7.820589000$
syn-Cp*OsH(dhpe) $\cdot(\mathrm{HFIP})_{2} \quad \mathrm{E}=-2154.37417594$

$6 \quad-7.394308000 \quad-0.659831000 \quad-10.480307000$

$\begin{array}{lllll}6 & -6.837931000 & -0.004565000 & -11.635437000\end{array}$

$\begin{array}{llll}6 & -7.640860000 & -0.377111000 & -12.796242000\end{array}$

$\begin{array}{llll}6 & -8.704041000 & -1.231479000 & -12.336870000\end{array}$

$\begin{array}{lllll}6 & -8.566240000 & -1.402935000 & -10.892585000\end{array}$

$\begin{array}{lllll}76 & -8.982386000 & 0.791808000 & -11.342284000\end{array}$

$\begin{array}{llll}15 & -11.209631000 & 1.050722000 & -11.634205000\end{array}$

$\begin{array}{llll}6 & -11.670354000 & 2.828624000 & -12.048472000\end{array}$

$\begin{array}{lllll}1 & -11.884179000 & 0.327117000 & -12.674700000\end{array}$

$\begin{array}{lllll}1 & -12.180764000 & 0.783639000 & -10.615040000\end{array}$

$\begin{array}{lllll}6 & -10.547950000 & 3.456192000 & -12.887818000\end{array}$

$\begin{array}{llll}1 & -12.638496000 & 2.867829000 & -12.559483000\end{array}$

$\begin{array}{llll}1 & -11.771125000 & 3.352932000 & -11.089902000\end{array}$

$\begin{array}{lllll}1 & -10.611884000 & 4.549722000 & -12.898961000\end{array}$

$\begin{array}{llll}15 & -8.882948000 & 2.888165000 & -12.203949000\end{array}$

$\begin{array}{llll}1 & -10.601726000 & 3.101263000 & -13.924712000\end{array}$

$\begin{array}{llll}1 & -8.035182000 & 3.150629000 & -13.328568000\end{array}$

$\begin{array}{llll}1 & -8.504004000 & 4.048677000 & -11.458445000\end{array}$

$\begin{array}{llll}1 & -9.375856000 & 1.476122000 & -9.900270000\end{array}$

$\begin{array}{llll}6 & -9.685524000 & -1.958819000 & -13.200881000\end{array}$

$\begin{array}{llll}1 & -9.885665000 & -1.417296000 & -14.130493000\end{array}$

$\begin{array}{llll}1 & -9.302533000 & -2.952834000 & -13.469783000\end{array}$

$\begin{array}{llll}1 & -10.643352000 & -2.103869000 & -12.690712000\end{array}$

$\begin{array}{llll}6 & -7.308534000 & -0.053658000 & -14.218816000\end{array}$

$\begin{array}{lllll}1 & -6.907674000 & 0.960169000 & -14.320343000\end{array}$

$\begin{array}{llll}1 & -6.550919000 & -0.746134000 & -14.612404000\end{array}$

$\begin{array}{llll}1 & -8.190112000 & -0.125791000 & -14.862671000\end{array}$

$\begin{array}{lllll}6 & -5.543496000 & 0.746781000 & -11.677293000\end{array}$

$\begin{array}{lllll}1 & -5.359041000 & 1.283791000 & -10.743197000\end{array}$

$1 \quad-4.700368000 \quad 0.060563000 \quad-11.841937000$

$\begin{array}{llll}1 & -5.530750000 & 1.482071000 & -12.487463000\end{array}$

$\begin{array}{lllll}1 & -6.773987000 & -0.707762000 & -9.120441000\end{array}$

$1 \quad-7.518171000 \quad-0.867562000 \quad-8.337999000$

$1 \quad-6.056705000 \quad-1.539057000 \quad-9.069047000$

$\begin{array}{llll}1 & -6.233745000 & 0.210447000 & -8.879337000\end{array}$

$6 \quad-9.337551000 \quad-2.361507000 \quad-10.039257000$

$1 \quad-10.353399000 \quad-2.508233000 \quad-10.418628000$

$1 \quad-8.849767000 \quad-3.346862000 \quad-10.010546000$

$\begin{array}{llll}1 & -9.422924000 & -2.000149000 & -9.010497000\end{array}$

$\begin{array}{lllll}1 & -8.455302000 & 1.910759000 & -8.826553000\end{array}$

$\begin{array}{lllll}8 & -8.207824000 & 1.975524000 & -7.858843000\end{array}$

$\begin{array}{lllll}6 & -7.847364000 & 3.263616000 & -7.447240000\end{array}$

$\begin{array}{llll}1 & -7.654134000 & 3.214029000 & -6.372712000\end{array}$

$\begin{array}{llll}6 & -6.538133000 & 3.688180000 & -8.105425000\end{array}$

$\begin{array}{llll}6 & -8.987889000 & 4.261758000 & -7.634162000\end{array}$

$\begin{array}{llll}9 & -10.144478000 & 3.762735000 & -7.075899000\end{array}$

$\begin{array}{llll}9 & -9.256508000 & 4.526649000 & -8.967895000\end{array}$

$9 \quad-8.708431000 \quad 5.467671000 \quad-7.019933000$

$9 \quad-6.629845000 \quad 3.737524000 \quad-9.485693000$

$\begin{array}{llll}9 & -6.119742000 & 4.929710000 & -7.666746000\end{array}$

$\begin{array}{llll}9 & -5.546642000 & 2.778152000 & -7.795815000\end{array}$

$\begin{array}{llll}9 & -9.320768000 & 2.209146000 & -4.701422000\end{array}$

$\begin{array}{lllll}9 & -11.076415000 & 0.853737000 & -4.471883000\end{array}$

$\begin{array}{llll}6 & -9.715064000 & 0.942178000 & -4.289361000\end{array}$

$\begin{array}{llll}9 & -9.467687000 & 0.853101000 & -2.932461000\end{array}$

$6 \quad-9.012405000 \quad-0.158749000 \quad-5.082181000$

$\begin{array}{llll}8 & -9.328012000 & -0.081150000 & -6.437935000\end{array}$

$\begin{array}{llll}1 & -8.954148000 & 0.734284000 & -6.842988000\end{array}$

$\begin{array}{llll}1 & -9.405588000 & -1.108225000 & -4.705547000\end{array}$

$6 \quad-7.502866000 \quad-0.198704000 \quad-4.851203000$

$9 \quad-6.939674000 \quad-1.207439000 \quad-5.604092000$

$9 \quad-7.184632000 \quad-0.441157000 \quad-3.528725000$ 
anti-Cp*OsH(dhpe $) \cdot(\mathrm{HFIP})_{2} \quad \mathrm{E}=-2154.36761761$

6

$0.405189000-11.038251000$

$0.119835000-12.278116000$

$-1.147168000-12.788889000$

$-9.579769000 \quad-1.622536000 \quad-11.879897000$

$\begin{array}{lll}-9.703744000 & -0.676108000 & -10.786702000\end{array}$

$\begin{array}{llll}-10.346016000 & 0.407009000 & -12.652758000\end{array}$ $\begin{array}{llll}-12.527197000 & 0.086087000 & -13.178297000\end{array}$ $-13.241617000$ $-13.049931000$ $-13.482656000$ $-12.192668000$ $-14.141834000$ $-13.537193000$ $-12.420399000$ $-10.462242000$ $-12.172604000$ $-9.663987000$ $-10.209708000$ $-11.114481000$ $-10.248440000$ $-10.426023000$ $-9.623655000$ $-11.213532000$ $-7.903785000$ $-7.477952000$

$-7.077924000$ $-8.590029000$ $-6.939604000$ $-6.963175000$ $-5.979935000$ $-6.954379000$ $-8.436306000$ $-9.307645000$ $-7.636639000$ $-8.099840000$ $-10.486722000$ $-11.390415000$ $-9.888483000$ $-10.800834000$ $-10.349393000$ $-9.950952000$

$-10.694213000$ $-10.055391000$ $-11.011847000$ $-11.928319000$ $-11.589325000$ $-12.936904000$ $-12.459343000$ $-11.673846000$ $-11.792934000$ $-9.842425000$ $-8.952520000$ $-8.133317000$ $-7.779534000$ $-7.083991000$ $-6.952534000$ $-7.612504000$ $-8.441401000$ $-6.038702000$ .508958000
$1.635141000-13.977341000$ $-0.957286000-14.005434000$ $-0.090278000 \quad-12.124761000$ $2.330694000-14.859828000$ $1.385736000-14.549194000$ $2.286483000-13.146182000$ $3.394952000-14.984724000$ $2.125498000-14.133549000$ $1.880388000-15.855959000$ $2.244564000-15.315755000$ $3.457287000-13.664035000$ $1.551472000-11.784320000$ $-2.960002000-11.952177000$ $-3.265915000 \quad-12.985681000$ $-3.728695000-11.476226000$ $-2.955326000 \quad-11.437335000$ $-1.944373000-13.869270000$ $-1.307287000-14.646997000$ $-2.535060000-13.444812000$ $-2.643876000-14.348531000$ $0.899782000-12.855476000$ $1.944328000-12.531694000$ $0.474895000-12.528702000$ $0.887645000-13.949006000$ $1.520015000-10.093076000$ $1.803421000 \quad-9.496261000$ $1.222130000 \quad-9.400223000$ $2.414305000-10.625375000$ $-0.880631000 \quad-9.527484000$ $-1.470560000 \quad-9.707491000$ $-1.411927000$ 0.072995000 $-0.550737000$ $-0.689176000$

$-1.444313000$ $-1.588205000$ $-2.837865000$ $-0.696555000$ 0.597875000 $-0.619035000$ $-1.296156000$ $-2.798000000$ $-3.560032000$ $-3.546131000$ 0.380405000 2.401736000 1.099334000 1.090922000 0.535311000 0.683136000 0.153344000 1.135674000 $-0.909279000$

\section{d. $1_{t}$ protonation by HFIP}

syn-TS $\quad \mathrm{E}=-2154.35231606$

$6-7.213656000-0.657265000$

$6 \quad-7.213656000 \quad-0.657265000$

$\begin{array}{llll}6 & -6.851128000 & -0.034747000\end{array}$

$\begin{array}{llll}6 & -7.797374000 & -0.475478000\end{array}$

$6-8.741486000$

$6 \quad-8.402101000$

$\begin{array}{ll}76 & -8.908066000\end{array}$

$15-11.114200000$

$6-11.425266000$

$1-11.727787000$

$1-12.136812000$

$6-10.290237000$

$1-12.408657000$

$1-11.416665000$

$1-10.212975000$

$15 \quad-8.653702000$

$1-10.461505000$

$1 \quad-8.003896000$

$1-7.902605000$

$1-9.600396000$

$6-9.821229000$

$1-10.224806000$

$1-9.425480000$

$1-10.650356000$

$6 \quad-7.686130000$

$1-7.249633000$

$-7.042267000$

$-8.662014000$

$6 \quad-5.605275000$

$1 \quad-5.346400000$

$-4.759528000$

$-5.708597000$

$-6.409777000$

$-7.021548000$

$-5.595786000$

$-5.974539000$

$-9.039630000$

$-10.072351000$

$-8.487257000$

$-9.056145000$

$-8.486445000$

$-8.045316000$

$-7.912120000$

$-7.890630000$

$-6.569629000$

$-9.092833000$

$-10.292609000$

$-9.090469000$

$-9.137572000$

$-6.367453000$

$-6.409304000$

$-5.535720000$

$-9.714186000$

$9-11.336378000$

$6-10.110227000$

$9-10.307691000$

6

$-1.358667000$

$-1.462028000$

0.741819000

1.196612000

3.039469000

0.790692000

0.722324000

3.742166000

3.276750000

3.335408000

4.795326000

2.872769000

3.695701000

2.996460000

3.859611000

0.925796000

$-2.126370000$

$-1.575689000$

$-3.078299000$

$-2.360575000$

$-0.209802000$

0.773557000

$-0.956757000$

$-0.243931000$

0.760419000

1.364056000

0.091482000

1.435091000

$-0.618249000$

$-0.849304000$

$-1.354465000$

0.367721000

$-2.366497000$

$-2.604459000$ 


$\begin{array}{ll}8 & -9.049386000 \\ 1 & -8.628543000 \\ 1 & -9.503593000 \\ 6 & -7.731473000 \\ 9 & -6.908111000 \\ 9 & -7.776166000 \\ 9 & -7.112635000\end{array}$

\section{syn-1 $\mathbf{1} \mathbf{I P}$}

$6-7.073433000$

$6-6.682831000$

$6-7.736035000$

$6 \quad-8.771075000$

$6 \quad-8.381176000$

$76-8.515344000$

$15-10.766167000$

$6-11.145844000$

$1-11.629626000$

$1-11.438263000$

$6 \quad-10.196040000$

$1-12.197498000$

$1-10.954745000$

$1-10.133026000$

$15-8.487972000$

$1-10.524355000$

$1 \quad-7.966671000$

$1 \quad-7.725181000$

$1 \quad-8.855080000$

$6 \quad-9.999712000$

$1-10.333632000$

$1-9.802360000$

$1-10.830904000$

$6-7.680588000$

$1 \quad-7.137405000$

$1-7.161314000$

$1-8.679727000$

$6 \quad-5.340076000$

$1 \quad-4.895582000$

$1-4.650578000$

$1-5.400069000$

$6-6.219788000$

$1-6.825290000$

$1 \quad-5.628918000$

$1 \quad-5.526089000$

$6 \quad-9.091426000$

$1-10.162718000$

$1 \quad-8.689158000$

$1-8.980745000$

$1 \quad-7.663705000$

$8 \quad-8.959628000$

$1-9.283815000$

$6 \quad-7.240744000$

$6-9.126999000$

$9-10.476706000$

$9 \quad-8.943041000$

$9-6.879112000$

$6 \quad-8.715629000$

$9 \quad-8.448269000$

$9-6.383126000$

$9-6.965680000$

$1 \quad-9.634558000$

$8 \quad-10.291119000$

$6 \quad-9.845470000$
$-0.020803000$

0.869722000

$-1.143208000$

$-0.082513000$

$-1.037902000$

$-0.341854000$

1.144802000

\section{$E=-2154.36795874$}

$-1.614726000 \quad-11.372198000$

$-0.549406000-12.280649000$

$-0.406756000 \quad-13.274632000$

$-1.350223000 \quad-12.969017000$

$-2.091764000-11.781174000$

$0.082558000-11.095972000$

$0.481289000-10.711677000$

$2.267917000-10.358771000$

$0.177166000-11.811250000$

$-0.219105000 \quad-9.680694000$

$3.163288000-11.162799000$

$2.483843000-10.572887000$

$2.408443000 \quad-9.291226000$

$4.161407000-10.721424000$

$2.397585000-11.201957000$

$3.260590000-12.205103000$

$2.938774000-12.418259000$

$3.127716000-10.266138000$

$-0.346014000 \quad-9.575902000$

$-1.599747000-13.784299000$

$-0.696969000 \quad-14.303817000$

$-2.366384000-14.545340000$

$-1.957880000-13.170026000$

$0.487722000-14.472622000$

$1.413890000-14.262550000$

$-0.013650000-15.300468000$

$0.758810000-14.825452000$

$0.111483000-12.328685000$

$0.183975000-11.332963000$

$-0.461500000 \quad-12.963361000$

$1.124877000-12.736034000$

$-2.222371000-10.304253000$

$-2.610374000 \quad-9.482069000$

$-3.051890000-10.714984000$

$-1.491625000 \quad-9.880865000$

$-3.277858000-11.205909000$

$-3.253598000-11.424358000$

$-4.208973000$

$-3.320711000$

0.615380000

2.406395000

3.165742000

3.263209000

4.721289000

4.725501000

5.712118000

4.187912000

3.329129000

5.127751000

3.444595000

2.006854000

1.392801000

0.519203000

$-0.152500000$
$-11.627254000$

$-10.119960000$

$-9.833501000$

$-8.184024000$

$-6.269334000$

$-6.802138000$

$-7.677835000$

$-8.004577000$

$-6.728065000$

$-5.832930000$

$-7.201861000$

$-8.823788000$

$-7.875702000$

$-6.274931000$

$-7.777308000$

$-7.530263000$

$-6.413680000$
$1 \quad-8.819730000$

$6-9.823772000$

$6-10.733268000$

$9-9.562107000$

$9-8.814802000$

$9-11.002865000$

$9-10.259988000$

$9-12.038156000$

$9-10.763443000$

0.113868000

$-1.650212000$

0.187940000

$-2.427339000$

$-1.935872000$

$-2.108121000$

$-0.349640000$

$-0.235829000$

1.564758000

anti-TS $\quad \mathrm{E}=-2154.35689154$

$\begin{array}{lll}6 & -8.766250000 & 0.397065000\end{array}$

$6 \quad-8.014832000$

$6 \quad-8.474180000$

$6-9.533222000$

$6-9.717759000$

$\begin{array}{ll}76 & -10.273142000\end{array}$

$15-12.496109000$

$6 \quad-13.158394000$

$1-13.044491000$

$-13.395300000$

$-12.109264000$

$-14.077906000$

$-13.412423000$

$-12.323539000$

$15-10.365474000$

$-12.116425000$

$-9.581432000$

$-10.077935000$

$-11.045197000$

$-10.172947000$

$-10.279723000$

$-9.563222000$

$-11.167509000$

$-7.796806000$

$-7.321164000$

$-7.014265000$

$-8.488946000$

$-6.854543000$

$-6.900534000$

$-5.910142000$

$-6.822301000$

$-8.501260000$

$-9.399816000$

$-7.728153000$

$-8.151476000$

$-10.567015000$

$-11.463697000$

$-10.010355000$

$-10.894710000$

$-10.348358000$

$-10.030737000$

$-10.693227000$

$-10.045901000$

$-11.045762000$

$-11.917101000$

$-11.583526000$

$-12.967488000$

$-12.424262000$

$-11.785848000$

$-11.767408000$

$-9.891393000$

$-9.010401000$
0.085632000

$-1.188455000$

$-1.657275000$

$-0.681700000$

0.329382000

0.079264000

1.658823000

$-0.945490000$

2.321558000

1.446626000

2.319170000

3.387313000

2.101740000

1.857008000

2.185931000

3.403799000

1.516924000

$-3.008614000$

$-3.356301000$

$-3.744199000$

$-3.005467000$

$-1.984389000$

$-1.343717000$

$-2.610539000$

$-2.641510000$

0.860090000

1.912262000

0.450418000

0.815435000

1.541463000

1.827443000

1.270508000

2.425690000

$-0.860048000$

$-1.447958000$

$-1.384285000$

0.101454000

$-0.322062000$

$-0.606635000$

$-1.388297000$

$-1.581412000$

$-2.774423000$

$-0.674710000$

0.612847000

$-0.554478000$

$-1.308894000$

$-2.741081000$

$-3.528141000$

$-3.487309000$

0.308111000
$-0.063280000$

$-6.114032000$

$-6.708495000$

$-5.214618000$

$-5.591136000$

$-7.627459000$

$-7.263031000$

$-4.025888000$

$-5.369342000$

$-5.040710000$

$-11.130443000$

$-12.321410000$

$-12.827142000$

$-11.962473000$

$-10.902524000$

$-12.833295000$

$-13.263246000$

$-14.037749000$

$-14.079326000$

$-12.162042000$

$-14.949162000$

$-14.593073000$

$-13.199767000$

$-15.082756000$

$-14.281102000$

$-15.937694000$

$-15.463407000$

$-13.766081000$

$-12.019891000$

$-12.026360000$ 


$\begin{array}{lr}9 & -8.528010000 \\ 6 & -7.972255000 \\ 9 & -7.214251000 \\ 6 & -7.123815000 \\ 8 & -7.765466000 \\ 1 & -8.645668000 \\ 1 & -6.233838000 \\ 6 & -6.609397000 \\ 9 & -5.700245000 \\ 9 & -5.966570000 \\ 9 & -7.622081000\end{array}$

\section{anti-1.IIP}

$6 \quad 1.039167000$

$6 \quad 0.267688000$

$6 \quad 0.484054000$

$6 \quad 1.379030000$

$6 \quad 1.735373000$

$76-0.473352000$

$15-1.230016000$

$6 \quad-3.025052000$

$1 \quad-0.612478000$

$1-1.233357000$

$6 \quad-3.336240000$

$1-3.300769000$

$1 \quad-3.586542000$

$1-4.414651000$

$15-2.468255000$

$1-2.983110000$

$1 \quad-2.465494000$

$1-3.441048000$

$1-0.266568000$

$6 \quad 1.986956000$

$1 \quad 1.300115000$

$1 \quad 2.895418000$

$1 \quad 2.264472000$

$6-0.035853000$

$1 \quad-1.005286000$

$1 \quad 0.659582000$

$1-0.150939000$

$6-0.519067000$

$1-0.974893000$

$1 \quad 0.139684000$

$1-1.325948000$

$6 \quad 1.151196000$

$1 \quad 1.588434000$

$1 \quad 1.792189000$

$1 \quad 0.160466000$

$6 \quad 2.789633000$

$1 \quad 2.804975000$

13.783390000

12.629956000

$1-1.716190000$

$8-3.839901000$

$6 \quad-5.029872000$

$1 \quad-5.287301000$

$6 \quad-4.932420000$

$6-6.158797000$

$9-6.206573000$

$9 \quad-5.991384000$

$9 \quad-7.403787000$

$9-4.631987000$

$9 \quad-6.097886000$
$2.316750000 \quad-18.210986000$

$1.132626000-18.648389000$

$1.421885000-19.769355000$

$0.510752000-17.538620000$

$0.513656000-16.308632000$

$-0.001856000-16.285801000$

$1.145563000-17.457930000$

$-0.883401000-17.895350000$

$-1.298257000 \quad-16.940998000$

$-0.913019000-19.119598000$

$-1.828881000 \quad-17.932961000$

\section{$\mathrm{E}=-2154.37020262$}

$2.059888000 \quad 4.576798000$

$1.680253000 \quad 5.745989000$

$2.672376000 \quad 6.774489000$

$3.676449000 \quad 6.247055000$

$3.298282000 \quad 4.882620000$

$3.705371000 \quad 4.917086000$

$4.156367000 \quad 2.787507000$

$4.657232000 \quad 2.874931000$

$5.200133000 \quad 2.038725000$

$3.111613000 \quad 1.832032000$

$5.410365000 \quad 4.182490000$

$5.254873000 \quad 2.000240000$

$3.717286000 \quad 2.851094000$

$5.421044000 \quad 4.366771000$

$4.627843000 \quad 5.647592000$

$6.447985000 \quad 4.131709000$

$5.696253000 \quad 6.589478000$

$3.784649000 \quad 6.233579000$

$5.328581000 \quad 4.792462000$

$4.799907000 \quad 7.026816000$

$5.183664000 \quad 7.785966000$

$4.458203000 \quad 7.541134000$

$5.634835000 \quad 6.378602000$

$2.606872000 \quad 8.175479000$

$2.104005000 \quad 8.222116000$

$2.044406000 \quad 8.812866000$

$3.603378000 \quad 8.610636000$

$0.415941000 \quad 5.880047000$

$0.126555000 \quad 4.930026000$

$-0.398601000 \quad 6.210984000$

$0.512332000 \quad 6.609180000$

$1.238201000 \quad 3.332358000$

$1.813902000 \quad 2.511455000$

$0.363613000 \quad 3.503465000$

$0.889679000 \quad 3.019633000$

$3.949757000 \quad 4.043774000$

$5.033903000 \quad 4.185008000$

$3.561784000 \quad 4.305033000$

$3.758468000 \quad 2.979212000$

$2.717387000 \quad 4.550622000$

$1.931866000 \quad 4.290370000$

$1.307661000 \quad 4.613356000$

$0.478099000 \quad 3.942972000$

$0.709462000 \quad 6.015566000$

$2.325952000 \quad 4.490935000$

$2.835107000 \quad 3.206837000$

$3.415268000 \quad 5.341871000$

$1.787342000 \quad 4.764342000$

$1.657105000 \quad 6.987120000$

0.076542000
$9-3.922440000$

$6-3.586964000$

$6-2.525549000$

$1-1.648222000$

$6-2.903252000$

$8-2.247268000$

$1-3.209190000$

$9 \quad-3.178389000$

$9-4.819100000$

$9-3.802536000$

$9-4.044209000$

$9-3.121788000$

$9-1.873578000$

$-0.234467000$

0.649802000

0.062179000

$-0.107555000$

$-1.337127000$

0.902130000

1.357072000

1.905468000

0.820381000

$-0.110302000$

$-1.343946000$

$-2.244330000$

$-1.847718000$

6.055985000

0.826837000

1.761621000

1.109722000

2.259461000

2.800219000

3.583665000

0.394528000

1.441393000

$-0.312546000$

3.051711000

1.231565000

3.030868000

\section{e. Hydrogen bonded complexes and protonation of $\mathbf{2}_{t}$} with HFIP

syn-Cp*FeH(dhpe $) \cdot(\mathrm{HFIP})_{2} \quad \mathrm{E}=-2186.69011339$

$6 \quad-7.018993000 \quad-0.458562000 \quad-10.683333000$

$\begin{array}{lllll}6 & -6.691532000 & 0.133023000 & -11.954175000\end{array}$

$6 \quad-7.662091000 \quad-0.343418000 \quad-12.921747000$

$6 \quad-8.603552000 \quad-1.174767000 \quad-12.240011000$

$\begin{array}{lllll}6 & -8.212446000 & -1.237927000 & -10.841590000\end{array}$

$\begin{array}{lllll}26 & -8.622395000 & 0.779580000 & -11.383352000\end{array}$

$\begin{array}{lllll}15 & -10.697456000 & 0.937090000 & -10.799726000\end{array}$

$\begin{array}{lllll}6 & -11.315212000 & 2.689642000 & -11.062654000\end{array}$

$\begin{array}{llll}1 & -11.723228000 & 0.182814000 & -11.464417000\end{array}$

$\begin{array}{lllll}1 & -11.179544000 & 0.691792000 & -9.475334000\end{array}$

$\begin{array}{lllll}6 & -10.696454000 & 3.231299000 & -12.362612000\end{array}$

$\begin{array}{lllll}1 & -12.409477000 & 2.727684000 & -11.084282000\end{array}$

$\begin{array}{lllll}1 & -10.975145000 & 3.273308000 & -10.200903000\end{array}$

$\begin{array}{lllll}1 & -10.736477000 & 4.324520000 & -12.410054000\end{array}$

$\begin{array}{llll}15 & -8.924495000 & 2.599011000 & -12.508285000\end{array}$

$\begin{array}{lllll}1 & -11.238669000 & 2.838387000 & -13.232212000\end{array}$

$1 \quad-8.755669000 \quad 2.670590000 \quad-13.930240000$

$\begin{array}{lllll}1 & -8.181578000 & 3.785543000 & -12.216201000\end{array}$

$\begin{array}{lllll}1 & -8.364764000 & 1.784276000 & -10.279091000\end{array}$

$\begin{array}{lllll}6 & -9.721006000 & -1.945484000 & -12.868920000\end{array}$

$1-10.100010000 \quad-1.449344000 \quad-13.768227000$

$\begin{array}{lllll}1 & -9.388738000 & -2.951308000 & -13.162238000\end{array}$

$\begin{array}{lllll}1 & -10.565567000 & -2.072525000 & -12.183139000\end{array}$

$6 \quad-7.617747000 \quad-0.093366000 \quad-14.396215000$

$1 \quad-7.142172000 \quad 0.863484000 \quad-14.634393000$

$1 \quad-7.038556000 \quad-0.877747000 \quad-14.902792000$

$\begin{array}{lllll}1 & -8.618531000 & -0.085021000 & -14.840392000\end{array}$

$\begin{array}{lllll}6 & -5.472330000 & 0.948418000 & -12.252621000\end{array}$

$1 \quad-5.194714000 \quad 1.576259000 \quad-11.400794000$

$1 \quad-4.610789000 \quad 0.307935000 \quad-12.490068000$

$\begin{array}{llll}1 & -5.630107000 & 1.613007000 & -13.108672000\end{array}$

$6 \quad-6.194454000 \quad-0.359399000 \quad-9.439213000$

$1 \quad-6.796334000 \quad-0.468233000 \quad-8.533984000$

$\begin{array}{lllll}1 & -5.435292000 & -1.154271000 & -9.426555000\end{array}$

$\begin{array}{llll}1 & -5.669063000 & 0.596251000 & -9.374794000\end{array}$

$6 \quad-8.845491000 \quad-2.101972000 \quad-9.795019000$

$1 \quad-9.911771000 \quad-2.258663000 \quad-9.990811000$

$\begin{array}{lllll}1 & -8.371793000 & -3.093838000 & -9.768637000\end{array}$

$\begin{array}{llll}1 & -8.758724000 & -1.667997000 & -8.795087000\end{array}$

$\begin{array}{rrrr}1 & -8.758724000 & -1.667997000 & -8.795087000 \\ 1 & -8.219970000 & 1.828270000 & -8.940951000\end{array}$

$\begin{array}{llll}8 & -8.205623000 & 1.889933000 & -7.927506000\end{array}$

$\begin{array}{lllll}6 & -7.813358000 & 3.145271000 & -7.448998000\end{array}$

$\begin{array}{llll}1 & -7.888046000 & 3.113859000 & -6.358974000\end{array}$

$\begin{array}{llll}6 & -6.347716000 & 3.420229000 & -7.775900000\end{array}$

$\begin{array}{llll}6 & -8.757329000 & 4.253166000 & -7.912687000\end{array}$

$\begin{array}{llll}9 & -10.068998000 & 3.863628000 & -7.712195000\end{array}$ 


$\begin{array}{ll}9 & -8.624250000 \\ 9 & -8.557515000 \\ 9 & -6.085591000 \\ 9 & -5.951088000 \\ 9 & -5.548338000 \\ 9 & -9.787209000 \\ 9 & -11.740932000 \\ 6 & -10.392342000 \\ 9 & -10.228151000 \\ 6 & -9.834924000 \\ 8 & -9.982563000 \\ 1 & -9.366853000 \\ 1 & -10.442706000 \\ 6 & -8.395736000 \\ 9 & -7.911794000 \\ 9 & -8.305806000 \\ 9 & -7.545553000\end{array}$

4.549066000

5.423075000

3.357023000

4.667743000

2.481187000

2.295076000

1.229369000

1.091601000

0.916116000

$-0.075769000$

0.159737000

0.868543000

$-0.949430000$

$-0.431115000$

$-1.396513000$

$-0.935032000$
0.661985000

TS syn-Cp*FeH(dhpe) $\cdot(\mathrm{HFIP})_{2} \quad \mathrm{E}=-2186.67804531$$$
1
$$

$0.069027000-11.791931000$

$-0.211352000-12.843406000$

$-1.003214000 \quad-12.297663000$

$-1.276897000 \quad-10.909974000$

$0.830038000-11.221993000$

$0.916638000-10.260275000$

$2.556634000-10.595909000$

$0.007293000-10.771579000$

$0.707059000 \quad-8.877299000$

$2.965101000-12.046251000$

$2.503364000-10.412352000$

$3.270035000-9.885276000$

$4.031022000-12.217717000$

$2.511370000-12.433988000$

$2.401355000-12.746984000$

$2.457602000-13.861047000$

$3.779522000-12.329016000$

$1.956352000-10.475305000$

$-1.613824000-13.069756000$

$-1.000859000-13.932300000$

$-2.607494000-13.450004000$

$-1.742137000-12.452611000$

$0.177830000-14.279709000$

$1.124124000-14.395174000$

$-0.589922000-14.818742000$

$0.275110000-14.783831000$

$0.812963000-11.924609000$

$\begin{array}{ll}0.372152000 & -11.014579000\end{array}$

$0.122693000-12.117637000$

$1.531421000-12.749587000$

$-0.703625000 \quad-9.303123000$

$-0.802644000 \quad-8.449004000$

$-1.577176000 \quad-9.310377000$

$0.180475000-9.127134000$

$-2.173508000 \quad-9.985668000$

$-2.250731000 \quad-10.269070000$

$-3.189796000$

$-1.817121000$

1.800876000

2.072610000

3.195595000

3.216539000

$-10.012808000$

$-8.952661000$

$-9.663903000$

$-8.238105000$

$-7.656276000$

$-6.567383000$

$-7.849493000$
$-0.615230000-10.597137000$

3.251603000
$-9.260837000$

$-7.208472000$

$-9.133336000$

$-7.329492000$

$-7.158345000$

$-5.004877000$

$-4.908268000$

$-4.663551000$

$-3.302924000$

$-5.477074000$

$-6.842440000$

$-7.143801000$

$-5.221758000$

$-5.105749000$

$-5.965126000$

$-3.822370000$

$-5.185908000$

$6 \quad-8.604196000$

$9-9.955028000$

$9 \quad-8.530737000$

$9-8.102779000$

$9-6.017399000$

$9 \quad-5.804282000$

$9 \quad-5.811091000$

$9-10.162898000$

$9 \quad-11.579875000$

$6-10.513368000$

$9 \quad-10.977414000$

$6 \quad-9.370272000$

$8 \quad-9.044659000$

$1 \quad-8.758666000$

$1-9.744266000$

$6 \quad-8.138644000$

$9-7.181750000$

$9 \quad-8.431209000$

$9 \quad-7.561525000$

\section{syn-2 $\mathbf{t} \cdot \mathrm{IP}$}

$\begin{array}{ll}6 y n-2 t & -7.245880000\end{array}$

$6-6.411796000$

$6-7.083836000$

$6 \quad-8.342572000$

$6 \quad-8.414770000$

$26-8.281929000$

$15-10.153789000$

$6 \quad-10.885133000$

$1-11.226379000$

$1-10.250656000$

$6 \quad-10.674165000$

$1-11.943841000$

$1-10.334638000$

$1-10.618864000$

$15-9.079152000$

$1-11.493056000$

$1 \quad-9.472015000$

$1 \quad-8.295208000$

$1-7.435106000$

$6-9.296436000$

1

1

1

6
1

1
1

1
1

6

6
1

1
1

6

1

1
4.447711000

4.408340000

4.555251000

5.625798000

3.378661000

4.302806000

2.088171000

2.181832000

0.623922000

0.847703000

0.660620000

$-0.105447000$

$-0.058268000$

0.879466000

$-1.109824000$

0.088187000

$-0.850115000$

$-0.071094000$

1.339086000

$-8.189329000$

$-7.875892000$

$-9.575368000$

$-7.665282000$

$-9.183308000$

$-7.164052000$

$-7.380270000$

$-5.518738000$

$-6.248274000$

$-5.395212000$

$-4.104902000$

$-5.741764000$

$-7.086796000$

$-7.430698000$

$-5.507802000$

$-4.857145000$

$-5.184310000$

$-3.512572000$

$-5.007146000$

$E=-2186.68149712$

$-0.966132000-10.461154000$

$-0.133435000 \quad-11.301226000$

$0.061877000-12.551519000$

$-0.662436000-12.500127000$

$-1.321174000 \quad-11.225467000$

$0.804297000-10.962707000$

$0.940364000 \quad-9.806546000$

$2.649282000-9.907723000$

$0.120391000-10.280946000$

$0.614821000 \quad-8.427518000$

$3.216739000-11.324087000$

$2.638525000 \quad-9.628551000$

$3.236626000-9.167625000$

$4.307986000-11.299756000$

$2.549111000-12.063032000$

$2.923795000 \quad-11.991337000$

$2.310398000-13.415445000$

$3.706908000-12.286359000$

$1.927902000-10.276863000$

$-0.843333000-13.637763000$

$0.025214000-14.303632000$

$-1.714039000-14.247007000$

$-1.002602000 \quad-13.288895000$

$0.781852000-13.740821000$

$1.609794000-13.444786000$

$0.098205000-14.360512000$

$1.189992000-14.378451000$

$0.399605000-10.927581000$

$0.575556000-9.851568000$

$-0.315412000-11.208511000$

$1.347102000-11.428004000$

$-1.484322000 \quad-9.105481000$

$-1.774511000 \quad-8.534281000$

$-2.369942000 \quad-9.185189000$

$-0.733992000 \quad-8.515854000$

$-2.282015000-10.797939000$

$-2.069157000-11.272160000$

$-3.304780000-11.080642000$

$-2.275558000 \quad-9.713735000$

$1.523282000 \quad-9.611792000$

$4.273453000 \quad-9.709358000$

$5.400693000 \quad-9.569026000$ 
$-7.028579000$

$6-6.127773000$

$6-8.222344000$

$9-9.233254000$

$9 \quad-8.829342000$

$9-7.486641000$

$9-6.408335000$

$9 \quad-5.216371000$

$9 \quad-5.483475000$

$9 \quad-8.307092000$

$9-10.023882000$

$6 \quad-8.647910000$

$9-8.338292000$

$6 \quad-7.986961000$

$8 \quad-8.378752000$

$1 \quad-8.171497000$

$1 \quad-8.291799000$

$6 \quad-6.459525000$

$9 \quad-5.920181000$

$9-6.001298000$

$9 \quad-5.893538000$

anti-Cp*FeH(dhpe) $(\mathrm{H}$

\section{1}

\section{6}

1$$
1
$$

5.560541000

5.268369000

6.616599000

6.789307000

6.478040000

7.790178000

5.261980000

6.284840000

4.074647000

5.044934000

3.691440000

3.805597000

3.839008000

2.642619000

2.613894000

3.648893000

1.740225000

2.672650000

1.567491000

2.622892000

3.794670000
$-8.542509000$

$-10.434311000$

$-9.939700000$

$-9.015471000$

$-11.180276000$

$-9.972680000$

$-11.796774000$

$-10.212430000$

$-10.158423000$

$-6.434974000$

$-6.004291000$

$-5.910031000$

$-4.557678000$

$-6.657269000$

$-7.961589000$

$-8.833807000$

$-6.094784000$

$-6.540788000$

$-7.189879000$

$-5.233398000$

$-7.128681000$ $\begin{array}{lr}1 & -11.183083000 \\ 1 & -10.361424000\end{array}$

$-8.915207000$

$-8.101524000$

$-8.421463000$

$-9.453258000$

$-9.780133000$

$-10.154431000$

$-12.265877000$

$-12.917543000$

$-12.969489000$

$-13.123517000$

$-11.879126000$

$-13.883968000$

$-13.070580000$

$-12.016664000$

$-10.131909000$

$-11.980307000$

$-9.436672000$

$-9.682781000$

$-10.807400000$

$-10.001529000$

$-9.834211000$

$-9.512894000$

$-11.077695000$

$-7.635863000$

$-7.279469000$

$-6.749905000$

$-8.216335000$

$-7.002470000$

$-7.211062000$

$-6.048096000$

$-6.854165000$

$-8.836624000$

$-9.791833000$

$-8.076962000$

$-8.569687000$

$-10.736067000$

$-11.554869000$

$-10.234879000$
$0.392628000-10.911872000$

$0.331525000-12.092280000$

$-0.893887000-12.801558000$

$-1.561085000-12.068992000$

$-0.759616000-10.907828000$

$0.393439000-12.624327000$

$0.172775000-12.968473000$

$1.778294000-13.697661000$

$-0.801976000-13.753069000$

$0.046732000-11.828558000$

$2.364577000-14.672232000$

$1.624465000-14.189207000$

$2.454189000-12.848698000$

$3.443232000-14.804893000$

$1.978823000-14.081160000$

$\begin{array}{ll}1.899206000 & -15.657684000\end{array}$

$2.034888000 \quad-15.334120000$

$3.266018000-13.639770000$

$1.546906000-11.928454000$

$-2.925227000-12.349301000$

$-3.228426000-13.384472000$

$-3.670875000-11.706154000$

$-2.986084000-12.157038000$

$-1.447552000-13.948872000$

$-0.661084000-14.619278000$

$-1.984467000-13.579518000$

$-2.152139000-14.548894000$

$1.282011000-12.454536000$

$2.296341000-12.098737000$

$0.968294000-12.008223000$

$1.333708000-13.538020000$

$1.437444000 \quad-9.842945000$

$1.550088000 \quad-9.321944000$

$1.171571000 \quad-9.094412000$

$2.415919000-10.253430000$

$-1.144381000 \quad-9.823272000$

$-1.759875000-10.210776000$

$-1.726083000 \quad-9.036406000$

$-0.264536000-9.348949000$

$-0.613804000 \quad-15.167653000$
$8-10.009353000$

$6-10.819712000$

$1-10.230026000$

$6-11.140428000$

$6 \quad-12.054865000$

$9-11.680409000$

$9-12.965291000$

$9-12.713746000$

$9-11.849123000$

$9-11.877771000$

$9 \quad-9.968062000$

$9-9.143894000$

$9 \quad-8.409630000$

$6 \quad-8.000510000$

$9-7.346581000$

$6 \quad-7.108593000$

$8 \quad-7.724280000$

$1 \quad-8.508297000$

$1-6.215673000$

$6-6.628632000$

$9 \quad-5.742200000$

$9 \quad-5.988716000$

$9 \quad-7.682368000$

TS anti-Cp*FeH(dhpe) $(\mathrm{HFIP})_{2} \quad \mathrm{E}=-2186.65798079$

$6 \quad-8.851550000 \quad 0.456915000 \quad-11.218832000$

$\begin{array}{lllll}6 & -8.077358000 & 0.148651000 & -12.389598000\end{array}$

$6-8.490961000$

$6-9.529791000$

$6-9.758410000$

$26-10.164088000$

$15-12.268430000$

$6 \quad-12.964592000$

$1-12.880122000$

$1-13.094636000$

$6 \quad-11.924753000$

$1-13.886503000$

$1-13.215049000$

$1-12.133566000$

$15-10.181884000$

$1-11.948321000$

$1-9.411740000$

$1 \quad-9.851387000$

$1-10.906100000$

$6 \quad-10.166010000$

$1-10.240895000$

$1-9.573981000$

$1-11.174743000$

$6 \quad-7.775015000$

$1-7.337972000$

$1-6.957252000$

$1-8.431086000$

$6 \quad-6.955190000$

$1 \quad-7.047880000$

$1 \quad-5.991148000$

$1-6.919095000$

$6 \quad-8.677965000$

$1 \quad-9.598111000$

$1 \quad-7.890792000$

$1-8.390886000$

$6-10.683010000$

$1-11.563492000$

$1-10.177778000$

$-0.749305000 \quad-16.084448000$

$-1.510914000-16.941869000$

$-1.693301000-17.843148000$

$-2.877932000-16.349201000$

$-0.732706000 \quad-17.391080000$

$0.515791000-17.846221000$

$-0.534877000-16.364282000$

$-1.375666000-18.417598000$

$-2.782796000 \quad-15.164327000$

$-3.651594000-17.221695000$

$-3.555715000-16.075355000$

$-0.064715000-19.292445000$

$2.036696000-19.144888000$ 


$\begin{array}{ll}1 & -11.037386000 \\ 1 & -10.288201000 \\ 8 & -10.031803000 \\ 6 & -10.698943000 \\ 1 & -10.074228000 \\ 6 & -10.992650000 \\ 6 & -11.958873000 \\ 9 & -11.663492000 \\ 9 & -12.973714000 \\ 9 & -12.499341000 \\ 9 & -11.721369000 \\ 9 & -11.697008000 \\ 9 & -9.810084000 \\ 9 & -9.121425000 \\ 9 & -8.548628000 \\ 6 & -8.044422000 \\ 9 & -7.325637000 \\ 6 & -7.170805000 \\ 8 & -7.772192000 \\ 1 & -8.664194000 \\ 1 & -6.267185000 \\ 6 & -6.691518000 \\ 9 & -5.771212000 \\ 9 & -6.075549000 \\ 9 & -7.722845000\end{array}$

0.192222000

$-0.332837000$

$-0.598581000$

$-1.371507000$

$-1.517923000$

$-2.787442000$

$-0.677376000$

0.619971000

$-0.584575000$

$-1.308061000$

$-2.822935000$

$-3.536919000$

$-3.464986000$

0.381481000

2.356101000

1.167615000

1.462098000

0.498672000

0.479035000

$-0.021063000$

1.115698000

$-0.892765000$

$-1.355025000$

$-0.893575000$

$-1.817755000$
$-9.463787000$

$-14.514476000$

$-15.868259000$

$-16.806448000$

$-17.699247000$

$-16.310971000$

$-17.331091000$

$-17.715410000$

$-16.381446000$

$-18.435947000$

$-15.130144000$

$-17.239459000$

$-16.068343000$

$-19.036352000$

$-18.168431000$

$-18.655020000$

$-19.799846000$

$-17.593715000$

$-16.344090000$

$-16.291890000$

$-17.525206000$

$-18.005155000$

$-17.084812000$

$-19.243531000$

$-18.052635000$

anti-2 $\mathbf{t} \cdot \mathrm{IP} \quad \mathrm{E}=-2186.67193130$

$6-8.627421000$

$6 \quad-7.981841000$

$6-8.580628000$

$6-9.579529000$

$6 \quad-9.620149000$

$26-10.049297000$

$15-12.002202000$

$-12.648737000$

$-12.169682000$

$-13.065274000$

$-11.490832000$

$-13.354214000$

$-13.190715000$

$-11.808098000$

$15-10.013885000$

$-11.141277000$

$-8.934186000$

$-10.096375000$

$-11.024501000$

$-10.372989000$

$-10.565968000$

$-9.824118000$

$-11.335723000$

$-8.146492000$

$-7.825877000$

$-7.307952000$

$-8.950807000$

$-6.866552000$

$-6.729634000$

$-5.920233000$

$-7.068482000$

$-8.271075000$

$-9.140685000$

$-7.512783000$

$-7.860539000$

$-10.449761000$
0.548358000

0.011319000

$-1.270157000$

$-1.535145000$

$-11.148847000$

$-11.609481000$

$-0.409693000-10.711490000$

$0.259630000-12.661716000$

$-0.266488000-13.421140000$

$1.210043000-14.362351000$

$-1.370086000-14.293031000$

$-0.527402000-12.506150000$

$2.003061000-15.000248000$

$0.879255000-15.129755000$

$1.825366000-13.634034000$

$3.011735000-15.282192000$

$1.481643000-15.896518000$

$2.284986000-14.757214000$

$3.332057000-13.229489000$

$1.166325000-12.002205000$

$-2.796356000-11.478348000$

$-3.255113000 \quad-12.452245000$

$-3.531412000-10.874561000$

$-2.624202000 \quad-10.987589000$

$-2.196771000-13.704462000$

$-1.646680000 \quad-14.592657000$

$-2.816794000-13.358519000$

$-2.867466000 \quad-14.014339000$

$0.620406000-13.106851000$

$1.678894000-12.865112000$

$0.107903000-12.889775000$

$0.529920000-14.181155000$

$1.820069000-10.448352000$

$2.270107000 \quad-9.960906000$

$1.636938000 \quad-9.675414000$

$2.560548000-11.141028000$

$-0.311134000 \quad-9.471366000$
$2.057670000 \quad-13.868644000$
$-11.424370000$

$-9.942448000$

$-10.628716000$

$-9.941339000$

$-10.510037000$

$-10.889675000$

$-10.214033000$

$-10.885736000$

$-12.258844000$

$-12.211148000$

$-13.240360000$

$-12.707661000$

$-11.710028000$

$-11.289152000$

$-9.609821000$

$-9.325208000$

$-8.738898000$

$-8.242049000$

$-7.420493000$

$-7.521415000$

$-8.336493000$

$-9.504387000$

$-6.648577000$

$-6.906376000$

$-6.211727000$

$-6.005313000$

$-7.855884000$
$-0.792137000$

$-0.803799000$

0.729268000

$-0.099897000$

$-0.755746000$

$-1.476385000$

$-1.348449000$

$-2.966555000$

$-0.982247000$

0.373368000

$-1.155645000$

$-1.612568000$

$-3.277274000$

$-3.758945000$

$-3.368282000$

0.997249000

2.698844000

1.599240000

2.096110000

0.668641000

0.295270000

$-0.326880000$

1.255367000

$-0.547698000$

$-1.310891000$

$-0.207020000$

$-1.379307000$
$-9.594954000$

$-8.630943000$

$-9.187403000$

$-14.084917000$

$-16.252688000$

$-17.371061000$

$-18.225596000$

$-17.037835000$

$-17.826342000$

$-18.097503000$

$-16.854276000$

$-18.972646000$

$-15.962453000$

$-18.099821000$

$-16.689162000$

$-18.760896000$

$-17.447574000$

$-18.136501000$

$-19.136226000$

$-17.156314000$

$-16.128489000$

$-16.333085000$

$-16.812444000$

$-17.856549000$

$-16.934542000$

$-18.855833000$

$-18.437278000$

\section{f. $C p * M(d p p e) H$ and their protonation products $(M=$}

$\mathrm{Fe}, \mathrm{Ru}, \mathrm{Os}$ )

$\mathrm{Cp} * \mathrm{Fe}($ dppe) $\mathrm{H}$

$6 \quad-0.795107000$

$6 \quad 0.616163000$

$6 \quad 1.247855000$

$6 \quad 0.207316000$

$6-1.059075000$

$26 \quad 0.045302000$

$15-1.520916000$

$15 \quad 1.512812000$

$6 \quad 0.674009000$

$1 \quad-1.375067000$

$1-0.841384000$

$1 \quad 1.249041000$

$6-0.778971000$

$1 \quad 0.710956000$

$1 \quad 0.179212000$

$1-1.514811000$

$6 \quad 0.405507000$

$1 \quad 1.356134000$

$1 \quad 0.412212000$

$1-0.392568000$

$6 \quad 2.711685000$

$1 \quad 3.317191000$

$1 \quad 2.968515000$

$1 \quad 3.029441000$

$6 \quad 1.314785000$

$1 \quad 0.779108000$

$1 \quad 1.393887000$

$1 \quad 2.328238000$

$6-1.819619000$

$1-2.782426000$

$1 \quad-1.987717000$

\section{$\mathrm{E}=-1531.67297438$}

$0.892813000 \quad 2.514308000$

$1.082570000 \quad 2.481946000$

$-0.215428000 \quad 2.626921000$

$-1.196864000 \quad 2.760392000$

$-0.525621000 \quad 2.662328000$

$-0.234534000 \quad 0.862546000$

$-0.095418000 \quad-0.639033000$

$0.098382000-0.701020000$

$-0.173369000 \quad-2.369144000$

$-0.150387000 \quad-3.126911000$

$1.392684000-2.457744000$

$0.301741000-3.173215000$

$0.306826000-2.328912000$

$-1.257250000 \quad-2.530733000$

$-1.590191000 \quad 0.248881000$

$-2.826164000 \quad 0.404537000$

$-2.650303000 \quad 3.061303000$

$-3.021266000 \quad 2.665893000$

$-2.826004000 \quad 4.146794000$

$-3.266142000 \quad 2.634540000$

$-0.445839000 \quad 2.840281000$

$0.291520000 \quad 2.304317000$

$-0.364527000 \quad 3.906835000$

$\begin{array}{ll}-1.435337000 & 2.500335000\end{array}$

$2.405320000 \quad 2.472099000$

$3.139370000 \quad 1.862468000$

$2.812734000 \quad 3.490902000$

$2.331784000 \quad 2.069518000$

$1.979186000 \quad 2.588205000$

$1.667531000 \quad 2.175031000$

$2.271845000 \quad 3.635328000$ 
$6-2.405805000$

$-2.434660000$

$-2.681846000$

2.409110000

2.931914000

$-2.876186000$

1.823532000

2.453106000

3.682959000

4.278529000

3.648659000

0.870617000

1.984161000

4.173162000

5.236984000

4.134078000

3.964882000

4.963254000

4.945906000

3.921454000

2.921159000

3.992493000

5.752766000

5.723551000

3.898006000

2.110115000

$-4.203648000$

$-5.170994000$

$-4.830909000$

$-3.511546000$

$-2.544006000$

$-4.487109000$

$-6.190431000$

$-5.583112000$

$-3.233608000$

$-1.515404000$

$-3.458762000$

$-4.150315000$

$-3.904247000$

$-2.962019000$

$-2.267368000$

$-3.669031000$

$-4.879763000$

$-4.441856000$

$-2.762066000$
$-3.187622000$

$-2.506739000$
2.874010000

$-1.135519000$

$-2.189664000$

$-1.082189000$

$-0.618903000$

1.720393000

$-1.095985000$

1.184302000

$-1.624815000$

2.771574000

4.014693000

4.235804000

3.202731000

1.959437000

2.622291000

4.807723000

5.200910000

3.361153000

1.160701000

$-0.862614000$

$-1.816840000$

$-3.021143000$

$-3.267660000$

$-2.312960000$

0.069711000

$-1.620637000$

$-3.761364000$

$-4.202742000$

$-2.502296000$

0.864447000

1.866296000

3.205807000

3.540135000

2.541056000

$-0.171943000$

1.595804000

3.982400000

4.579734000

2.823272000

$-1.626089000$

$-2.792194000$

$-3.978812000$

$-3.991201000$

$-2.822737000$

$-0.709116000$

$-2.775444000$

$-4.885717000$

$-4.909657000$
2.043177000

2.899777000

2.607328000

3.963429000

2.333824000

$-0.936660000$

$-0.920980000$

$-0.546219000$

$-1.066041000$

$-1.664640000$

$-1.771303000$

$-1.145531000$

$-0.416634000$

$-0.313721000$

$-2.161452000$

$-2.346537000$

$-1.227821000$

0.068926000

0.238236000

$-1.848313000$

$-2.058600000$

$-1.347596000$

$-0.430382000$

$-0.221668000$

$-2.403528000$

$-2.778174000$

$-1.510565000$

0.121557000

0.473780000

$-0.210601000$

$-0.076304000$

$-0.277860000$

$-0.599288000$

$-0.720385000$

$-0.061815000$

0.182602000

$-0.179395000$

$-0.745869000$

$-0.926309000$

$-2.104345000$

$-2.438518000$

$-1.738947000$

$-0.708330000$

$-0.377158000$

$-2.647598000$

$-3.242978000$

$-1.999070000$

$-0.164365000$

$\left[\mathrm{Cp} * \mathrm{Fe}(\mathrm{dppe})\left(\eta^{2}-\mathrm{H}_{2}\right)\right]^{+}$

$6-1.072975000$

$6 \quad 0.194789000$

$6 \quad 1.232271000$

$6 \quad 0.601345000$

$6-0.831700000$

$26 \quad 0.010083000$

$15-1.569250000$

$15 \quad 1.565581000$

6.700331000

$-1.310981000$

$-0.705209000$

1.302679000

$-0.714024000$
$E=-1532.09666700$

$0.450322000 \quad 2.516125000$

1.094164000

0.112677000

$-1.134621000$

$-0.935312000$

$-0.505283000$

$-0.078358000$

$-0.073895000$

$-0.296978000$

$-0.120914000$

1.372405000

0.133846000

0.285564000
2.290448000

2.541532000

2.838253000

2.795152000

0.869096000

$-0.713900000$

$-0.722108000$

$-2.370682000$

$-3.173494000$

$-2.476749000$

$-3.178504000$

$-2.351160000$
0.664541000

$-1.381929000$

$-0.424570000-1.946821000$

$0.449353000-1.938589000$

$1.278988000-2.388309000$

2.343410000

1.203752000

0.824689000

2.693224000

2.974267000

2.947606000

3.315846000

0.419090000

$-0.452839000$

0.608780000

1.278117000

$-2.398111000$

$-3.223041000$

$-2.578176000$

$-2.445085000$

$-1.858714000$

$-1.546621000$

$-2.021763000$

$-2.825096000$

2.429064000

2.971130000

$-2.726331000$

$-2.708103000$

1.797703000

2.450069000

3.743877000

4.385427000

3.737361000

0.800036000

1.949556000

4.250656000

5.395829000

4.262211000

3.862488000

4.883459000

5.035700000

4.163035000

3.136072000

3.767010000

5.560808000

5.831703000

4.279073000

2.462097000

$-4.111086000$

$-4.948755000$

$-4.417706000$

$-3.039242000$

$-2.199601000$

$-4.541010000$

$-6.016824000$

$-5.070688000$

$-2.619024000$

$-1.129526000$

$-3.485511000$

$-4.332603000$

$-4.426080000$

$-3.675253000$

$-2.824117000$

$-3.446682000$

$-2.393893000$

$-2.472708000$

$-3.289523000$

0.401147000

1.308672000

0.555572000

$-0.419146000$

2.562930000

3.058329000

3.030239000

2.777989000

1.126349000

0.494127000

1.362347000

2.062135000

$-1.934739000$

$-2.961318000$

$-1.868067000$

$-1.766869000$

1.559631000

$-1.261498000$

1.359625000

$-1.472038000$

2.667924000

3.899725000

4.049578000

2.956607000

1.721478000

2.577868000

4.738226000

5.005986000

3.059053000

0.877246000

$-1.132311000$

$-2.064302000$

$-3.133117000$

$-3.266102000$

$-2.335379000$ 


\begin{tabular}{|c|c|c|c|c|c|c|c|}
\hline & -4.921021000 & -2.381625000 & -3.603941000 & 1 & 5.241091000 & -4.170925000 & -1.578928000 \\
\hline 1 & -5.083294000 & -4.402999000 & -2.163359000 & 1 & 3.350614000 & -4.433238000 & 0.013498000 \\
\hline 1 & -3.749244000 & -4.535550000 & -0.069433000 & 1 & 1.791875000 & -2.547338000 & 0.408892000 \\
\hline \multirow[t]{2}{*}{1} & -2.253636000 & -2.681415000 & 0.567397000 & 6 & -4.315634000 & 0.642568000 & -0.133279000 \\
\hline & & & & 6 & -5.378681000 & 1.533941000 & 0.042098000 \\
\hline \multicolumn{4}{|c|}{ trans $-\left[\mathrm{Cp} * \mathrm{Fe}(\mathrm{dppe})(\mathrm{H})_{2}\right]^{+} \quad \mathrm{E}=-1532.10155981$} & 6 & -5.187283000 & 2.904425000 & -0.148948000 \\
\hline 6 & -0.812030000 & 1.063229000 & 2.509112000 & 6 & -3.923484000 & 3.385051000 & -0.506154000 \\
\hline & 0.620539000 & 1.255500000 & 2.473031000 & 6 & -2.857021000 & 2.499538000 & -0.670018000 \\
\hline & 1.244983000 & -0.035587000 & 2.571541000 & 1 & -4.485251000 & -0.420283000 & 0.000403000 \\
\hline & 0.201093000 & -1.027907000 & 2.635171000 & 1 & -6.356128000 & 1.153726000 & 0.320276000 \\
\hline & -1.069051000 & -0.348119000 & 2.611476000 & 1 & -6.015123000 & 3.593656000 & -0.020380000 \\
\hline & 0.012092000 & 0.095481000 & 0.805233000 & 1 & -3.767374000 & 4.448749000 & -0.653585000 \\
\hline & -1.606253000 & -0.028787000 & -0.674954000 & 1 & -1.877371000 & 2.896601000 & -0.918471000 \\
\hline & 1.564180000 & 0.155787000 & -0.744997000 & 6 & -3.339 & -1.726512000 & -2.128131000 \\
\hline 6 & 0.630134000 & -0.014796000 & -2.364900000 & 6 & 7000 & -2.957877000 & 8984000 \\
\hline 1 & -1.405421000 & 0.115520000 & -3.129040000 & 6 & -3.470819000 & -4.129602000 & 2967000 \\
\hline 1 & -0.852950000 & 1.587944000 & -2.326220000 & 6 & -2.515 & -4.065884000 & -0.836638000 \\
\hline 1 & 1.188885000 & 0.480302000 & -3.167 & 6 & -1.96 & 1000 & 26000 \\
\hline & -0.815868000 & 0.494281000 & -2.286911000 & 1 & -3.676 & -0.823952000 & -2.629400000 \\
\hline 1 & 0.636740000 & -1.090259000 & -2.5792 & 1 & -4.62 & -3.003391000 & 04000 \\
\hline 1 & 0.141005000 & -1.238813000 & 0.187 & 1 & -3.85 & -5.085546000 & +2709000 \\
\hline 1 & -0.094667000 & 271000 & 0.11 & 1 & -2.19 & -4.9723 & 39000 \\
\hline 6 & 866000 & -2.48 & 2.92 & 1 & -1.21 & 000 & 24000 \\
\hline , & 000 & -2.8 & 2.57 & & & & \\
\hline 1 & & -2.6 & & \multicolumn{2}{|c|}{$\mathrm{Cp} * \mathrm{Ru}(\mathrm{dppe}) \mathrm{H}$} & \multicolumn{2}{|c|}{$E=-1502.18871699$} \\
\hline 1 & -0.383660000 & -3.10 & 2.48 & 6 & -1.0082760 & 501025000 & 000 \\
\hline 6 & 2.707253000 & -0.290883000 & 2.750 & 6 & 0.31 & 3000 & 3000 \\
\hline 1 & 3.309583000 & 0.536920000 & 2.368 & 6 & & 1000 & 9000 \\
\hline 1 & 2.939079000 & 512000 & 3.81 & 6 & 0.49 & -1.166376000 & 5000 \\
\hline 1 & 3.036822000 & -1.205686000 & 2.251 & 6 & -0.91 & -0.8336 & 5800 \\
\hline 6 & 1.31 & 2.5 & 2.50 & 44 & 000 & 000 & 7000 \\
\hline 2 & 0.724910000 & 3.35 & 2.02 & 15 & -1.5 & 8000 & 53000 \\
\hline 1 & 1.501231000 & 2.88538 & 3.53 & & 7000 & 3000 & 540000 \\
\hline 1 & 2.285792000 & 2.54 & 1.99 & 6 & 0.6 & 00 & 2000 \\
\hline 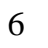 & -1.828059000 & 2.151103000 & 2.622 & 1 & -1.35 & -0.2843 & 3000 \\
\hline 1 & -2.809777000 & 1.8 & 2.26 & 1 & 000 & 00 & 5000 \\
\hline 1 & -1.938252000 & 2.44 & 3.67 & 1 & 1.27 & 0.1569 & 6000 \\
\hline 1 & -1.539198000 & 3.042189000 & 2.060416000 & 6 & -0.757201000 & 0.193199000 & 92000 \\
\hline 6 & -2.40 & -0.9 & 2.8 & 1 & & 00 & 2000 \\
\hline 1 & -2.455951000 & -1.9932 & 2.40 & 1 & 0.1 & 000 & 000 \\
\hline 1 & -2.616176000 & -1.062 & 3.90 & 1 & & -2 & 1000 \\
\hline 1 & -3.211063000 & -0.395662000 & 2.37 & 6 & & -2.5026 & 000 \\
\hline 6 & 2.572082000 & 1.693949000 & -0.890 & 1 & & -2.634402000 & 000 \\
\hline . & 2.80 & -1.19 & -0.9 & 1 & 1.1 & 00 & 1000 \\
\hline 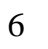 & -3.042229000 & 1.115197000 & -0.49 & 1 & 0.4 & 22300000 & 3000 \\
\hline 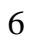 & & & & 6 & & & \\
\hline 6 & 2.029754000 & 2.834084000 & -1.50 & 1 & 3.105972000 & 1.0849 & 7000 \\
\hline 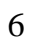 & 2.759395000 & 4.022936000 & -1.57 & 1 & & 0.2457 & 1000 \\
\hline 6 & & & & 1 & & -0.6743 & 000 \\
\hline 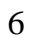 & 4.583476000 & 2.970333000 & -0.386 & 6 & 0.677528000 & 2.594523000 & 2.534279000 \\
\hline & 3.858206000 & 1.776811000 & -0.32 & 1 & -0.118626000 & 3.181269000 & 72000 \\
\hline 1 & 1.037171000 & 2.801242000 & -1.947 & 1 & 0.84 & 3.013179000 & 8000 \\
\hline 1 & 2.332383000 & 4.890611000 & -2.066708000 & 1 & 1.588907000 & 2.757984000 & 84000 \\
\hline 1 & & & & 6 & & & \\
\hline 1 & 5.576901000 & 3.017043000 & 0.047 & 1 & -3.127029000 & 0.822767000 & 65000 \\
\hline 1 & 4.304560000 & 0.906031000 & 0.14 & 1 & -2.51 & & 23000 \\
\hline 6 & 3.873236000 & -1.062753000 & -1.840457000 & 1 & -2.215839000 & 2.319304000 & 2.180503000 \\
\hline 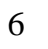 & 4.743787000 & -2.130132000 & -2.069523000 & 6 & -2.049580000 & -1.745397000 & 3.213532000 \\
\hline 6 & 4.561459000 & -3.344371000 & -1.400079000 & 1 & -1.811207000 & -2.788287000 & 2.981211000 \\
\hline 6 & 3.499848000 & -3.491218000 & -0.504183000 & 1 & -2.294776000 & -1.696559000 & 4.285255000 \\
\hline & 2.625370000 & -2.425235000 & -0.274063000 & 1 & -2.955176000 & -1.484902000 & 2.656800000 \\
\hline 1 & 4.028087000 & -0.126791000 & -2.366997000 & 6 & 2.391666000 & 1.600114000 & -1.026806000 \\
\hline & 5.562302000 & -2.013657000 & -2.772212000 & 6 & 2.977902000 & -1.197459000 & -1.030081000 \\
\hline
\end{tabular}




$\begin{array}{lr}6 & -2.728054000 \\ 6 & -2.697165000 \\ 6 & 1.844586000 \\ 6 & 2.462725000 \\ 6 & 3.640462000 \\ 6 & 4.198524000 \\ 6 & 3.582218000 \\ 1 & 0.933765000 \\ 1 & 2.025453000 \\ 1 & 4.120950000 \\ 1 & 5.119029000 \\ 1 & 4.039691000 \\ 6 & 3.984254000 \\ 6 & 5.017673000 \\ 6 & 5.063165000 \\ 6 & 4.069523000 \\ 6 & 3.032528000 \\ 1 & 3.964502000 \\ 1 & 5.786853000 \\ 1 & 5.868490000 \\ 1 & 4.098633000 \\ 1 & 2.243177000 \\ 6 & -4.110121000 \\ 6 & -4.927460000 \\ 6 & -4.379166000 \\ 6 & -3.001770000 \\ 6 & -2.184517000 \\ 1 & -4.553143000 \\ 1 & -5.993700000 \\ 1 & -5.015417000 \\ 1 & -2.563370000 \\ 1 & -1.110206000 \\ 6 & -3.594400000 \\ 6 & -4.423077000 \\ 6 & -4.371032000 \\ 6 & -3.486442000 \\ 6 & -2.654030000 \\ 1 & -3.654902000 \\ 1 & -5.108470000 \\ 1 & -5.015223000 \\ 1 & -3.438948000 \\ & \\ & \\ 1\end{array}$

1.294551000 $-1.549138000$ 2.636598000 3.888466000 4.132213000 3.111907000 1.859540000 2.471357000 4.670428000 5.104185000 3.286830000 1.069483000 $-0.976643000$ $-1.900789000$ $-3.056641000$ $-3.284954000$ $-2.361402000$ $-0.076932000$ $-1.719190000$ $-3.773099000$ $-4.181183000$ $-2.531644000$ 1.154357000 2.280349000 3.563218000 3.716715000 2.593619000 0.165210000 2.150484000 4.435587000 4.709896000 2.722463000 $-1.489758000$ $-2.573047000$ $-3.732873000$ $-3.802544000$ $-2.718071000$ $-0.589603000$ $-2.512529000$ $-4.575248000$ $-4.701075000$
$-0.666353000$

$-1.194940000$

$-1.804204000$

$-1.873449000$

$-1.162150000$

$-0.386376000$

$-0.321254000$

$-2.369928000$

$-2.487456000$

$-1.215828000$

0.162792000

0.265184000

$-1.988744000$

$-2.158729000$

$-1.371463000$

$-0.416364000$

$-0.248535000$

$-2.596549000$

$-2.903715000$

$-1.503596000$

0.196379000

0.477499000

$-0.459498000$

$-0.307113000$

$-0.362339000$

$-0.555343000$

$-0.693911000$

$-0.417976000$

$-0.146413000$

$-0.248682000$

$-0.587758000$

$-0.796528000$

$-2.278770000$

$-2.578547000$

$-1.797311000$

$-0.718665000$

$-0.421155000$

$-2.884210000$

$-3.418859000$

$-2.030984000$

$-0.110625000$

$\left[\mathrm{Cp} * \mathrm{Ru}(\mathrm{dppe})\left(\eta^{2}-\mathrm{H}_{2}\right)\right]^{+}$

$6-1.075404000$

$6 \quad 0.203281000$

$6 \quad 1.239396000$

$6 \quad 0.596787000$

$6-0.841872000$

$44 \quad 0.011990000$

$15-1.580265000$

$15 \quad 1.579377000$

$6 \quad 0.710775000$

$1-1.302496000$

$1-0.735108000$

1.302116000

$-0.718053000$

0.702003000

$-0.441674000$

0.478761000

1.271794000

2.303775000

1.303792000

0.744893000

\section{$E=-1502.60913259$}

0.462032000

1.094600000

0.110598000

$-1.127224000$

$-0.916178000$

$-0.584751000$

$-0.132602000$

$-0.110928000$

$-0.302112000$

$-0.172095000$

1.333947000

0.166653000

0.246539000

$-1.382490000$

$-2.143433000$

$-2.120724000$

$-2.369310000$

$-2.439937000$

$-2.370389000$

$-3.275992000$
2.620707000

2.377027000

2.660155000

2.988605000

2.949426000

0.842451000

$-0.832110000$

$-0.841598000$

$-2.492469000$

$-3.290073000$

$-2.587363000$

$-3.287492000$

$-2.464779000$

$-2.683641000$

0.393047000

0.319222000

3.480180000

3.126837000

4.578016000

3.169241000

2.698995000

3.001403000

2.928153000

3.321880000

0.436157000

$-0.423098000$

0.602519000

1.312368000

$-2.394359000$

$-3.225910000$

$-2.561078000$

$-2.441490000$

$-1.873634000$

$-1.578424000$

$-2.018354000$

$-2.844368000$

2.416068000

3.010400000

$-2.706052000$

$-2.756778000$

1.798961000

2.432309000

3.691069000

4.318574000

3.690119000

0.830062000

1.945698000

4.182971000

5.303541000

4.204624000

3.888691000

4.944608000

5.146209000

4.288968000

3.226029000

3.756058000

5.611341000

5.969533000

4.444870000

2.560351000

$-4.091793000$

$-4.907694000$

$-4.353737000$

$-2.973803000$

$-2.155463000$

$-4.539002000$

$-5.977000000$

$-4.990081000$

$-2.536258000$

$-1.083698000$

$-3.490476000$

$-4.377553000$

$-4.557402000$

$-3.854191000$

$-2.961243000$

$-3.387804000$

$-4.929974000$

$-5.245343000$

$-3.997556000$

$-2.423170000$

0.401332000

1.254340000

0.649578000

$-0.453902000$

2.561218000

3.051159000

3.042024000

2.762508000

1.156249000

0.500510000

1.491560000

2.036214000

$-1.896310000$

$-2.928460000$

$-1.813273000$

$-1.721264000$

1.537556000

$-1.264509000$

1.322965000

$-1.496199000$

2.643823000

3.888744000

4.052288000

2.960205000

1.712156000

2.541283000

4.726796000

5.018821000

3.073823000

0.867131000

$-1.119378000$

$-2.013677000$

$-3.056598000$

$-3.201314000$

$-2.309843000$

$-0.302916000$

$-1.895742000$

$-3.748887000$

$-4.005203000$

$-2.423763000$

1.175607000

2.299764000

3.581672000

3.739195000

2.618929000

0.187978000

2.170007000

4.451863000

4.732396000

2.758095000

$-1.455022000$

$-2.482169000$

$-3.559830000$

$-3.600001000$

$-2.573936000$

$-0.614379000$

$-2.439266000$

$-4.358450000$

$-4.427450000$

$-2.609145000$

2.799329000

2.188737000

3.844776000

2.521913000

2.199508000

1.735434000

3.173386000

1.577460000

2.702649000

2.432826000

3.735737000

2.059017000

3.413611000

3.203920000

4.499363000

2.941599000

$-0.927266000$

$-1.036367000$

$-0.645254000$

$-1.269503000$

$-1.538925000$

$-1.571187000$

$-0.986590000$

$-0.381202000$ 


\begin{tabular}{|c|c|c|c|c|c|c|c|}
\hline 6 & 0.628698000 & 1.227754000 & 2.691905000 & 6 & -2.857225000 & 2.509193000 & -0.708929000 \\
\hline 6 & 1.250185000 & -0.069485000 & 2.796371000 & 1 & -4.519208000 & -0.409358000 & -0.115209000 \\
\hline 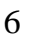 & 0.202068000 & -1.060966000 & 2.854388000 & 1 & -6.369897000 & 1.178288000 & 57179000 \\
\hline 0 & -1.071263000 & -0.380477000 & 2.809561000 & 1 & -5.999525000 & 3.622391000 & -0.015274000 \\
\hline 44 & 0.020740000 & 0.070689000 & 0.830298000 & 1 & -3.743336000 & 4.467788000 & -0.630925000 \\
\hline 15 & -1.642299000 & -0.036448000 & -0.778594000 & 1 & -1.873121000 & 2.900866000 & -0.948778000 \\
\hline 15 & 1.591554000 & 0.143385000 & -0.877929000 & 6 & -3.362465000 & -1.698751000 & -2.273549000 \\
\hline 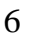 & 0.612675000 & -0.059078000 & -2.468210000 & 6 & -3.939637000 & -2.913584000 & -2.644398000 \\
\hline 1 & -1.417575000 & 0.140162000 & -3.230186000 & 6 & -3.600890000 & -4.088927000 & -1.964391000 \\
\hline 1 & -0.828033000 & 1.583627000 & -2.398678000 & 6 & 2781000 & 06000 & -0.913279000 \\
\hline 1 & 1.161129000 & 0.394487000 & -3.302246000 & 6 & -2.100163000 & -2.829107000 & -0.541716000 \\
\hline 6 & -0.821536000 & 0.488333000 & -2.379276000 & 1 & -3.647342000 & -0.791797000 & -2.798785000 \\
\hline 1 & 0.589961000 & -1.141420000 & -2.646335000 & 1 & -4.653453000 & -2.943326000 & -3.460978000 \\
\hline 1 & 0.141022000 & -1.384466000 & 647000 & 1 & 724000 & -5.032300000 & -2.254074000 \\
\hline 1 & -0.094570000 & 1.498847000 & 0.10 & 1 & 0000 & 3000 & -0.383603000 \\
\hline 6 & 0.401436000 & -2.518609000 & .000 & 1 & 4000 & 76000 & 8116000 \\
\hline 1 & 1.348817000 & -2.885 & & & & & \\
\hline 1 & 0.419495000 & -2.696095000 & .000 & \multicolumn{2}{|c|}{$\mathrm{Cp} * \mathrm{Os}(\mathrm{dppe}) \mathrm{H}$} & \multicolumn{2}{|c|}{$E=-1499.36609161$} \\
\hline 1 & -0.404126000 & -3.129706000 & 2.712830000 & 6 & -0.646639000 & 1.088815000 & 2.5883 \\
\hline 6 & 2.711009000 & -0.326920000 & 94000 & 6 & 63000 & 4000 & 2.540865000 \\
\hline 1 & 3.316392000 & 0.48 & 2.58 & 6 & 5000 & 000 & 3000 \\
\hline 1 & 2.944770000 & -0.40 & 4.05 & 6 & 00 & -1.0 & 000 \\
\hline 1 & 3.034256000 & -1.2 & 2.5 & 6 & & & 000 \\
\hline 6 & 1.337066000 & 2.5 & 2.76 & 76 & 2000 & 2000 & 9000 \\
\hline 1 & 0.746673000 & & & & & & \\
\hline 1 & 1.522714000 & 2.8 & 3.8 & 15 & 5000 & 000 & 3000 \\
\hline 1 & 2.301846000 & 2.51 & 2.25 & 6 & 00 & 5000 & 6000 \\
\hline 6 & -1.838397000 & 2.11 & & 1 & & 1000 & 5000 \\
\hline 1 & -2.784090000 & 000 & 2.3 & 1 & 3000 & 000 & 0000 \\
\hline 1 & & & & 1 & & & \\
\hline 1 & -1.50 & 3.0 & 2.3 & 6 & & & 000 \\
\hline 6 & -2.414429000 & -1.00 & 3.0 & 1 & 000 & 000 & 5000 \\
\hline 1 & -2.445126000 & -2.037 & 2.6 & 1 & 1000 & 000 & 0.348201000 \\
\hline 1 & -2.668275000 & -1.03 & 4.0 & 1 & 00 & -2. & 8000 \\
\hline 1 & -3.200829000 & -0.445813000 & $2.4 \mathrm{C}$ & 6 & & -2.5 & 3000 \\
\hline 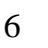 & 2.5 & 1.6 & 0 & 1 & 00 & -3. & 000 \\
\hline 6 & 2.862729000 & -1.18 & -1.0 & 1 & 00 & -2.5 & 000 \\
\hline 6 & & & & 1 & & & \\
\hline 6 & -2.43 & -1.6 & & 6 & & & 000 \\
\hline 6 & 334000 & 2.76 & -1.8 & 1 & 3.4 & & 000 \\
\hline 6 & 2.82 & 3.95 & -1.9 & 1 & 00 & 00 & 3000 \\
\hline 6 & 4.028639000 & 4.092 & -1.22 & 1 & 2.91 & 2000 & 0000 \\
\hline 6 & & & -0.44 & 6 & & & \\
\hline 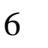 & 3.7 & 1.8 & -0.3 & 1 & 1.1 & 00 & 000 \\
\hline 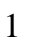 & 1.173558000 & & -2.4 & 1 & & 00 & 000 \\
\hline 1 & & & & 1 & & & \\
\hline 1 & 4.59358 & & -1.2 & 6 & -1.5 & 77000 & 000 \\
\hline 1 & 5.43798 & & 0.05 & 1 & -2.5 & 26000 & 000 \\
\hline 1 & 4.168693000 & 1.0 & 0.22 & 1 & -1.7 & 00 & 6000 \\
\hline 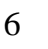 & 3.908552000 & -1.040 & -1.97 & 1 & 254000 & 3.103925000 & 2.017200000 \\
\hline 6 & 4.825247000 & -2.07 & & 6 & -2.448004000 & -0.74 & 689000 \\
\hline 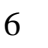 & 4.713172000 & -3.25 & -1.43 & 1 & 20000 & -1.80 & 2.910656000 \\
\hline 6 & 3.678555000 & 7000 & -0.50 & 1 & -2.701917000 & -0.602870000 & 4.207740000 \\
\hline 6 & & & & 1 & & & \\
\hline 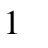 & 4.011123000 & -0.1229 & -2.54 & 6 & 2.433807000 & 1.692005000 & -0.963828000 \\
\hline 1 & 5.626080000 & -1.95 & & 6 & 2.912724000 & -1.128981000 & -1.186029000 \\
\hline 1 & 5.428985000 & -4.06 & -1.58 & 6 & -2.951753000 & 1.030852000 & -0.525353000 \\
\hline 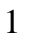 & 3.587842000 & -4.325927000 & 0.067464000 & 6 & -2.477967000 & -1.696019000 & -1.254880000 \\
\hline 1 & & & & 6 & & & -1.291739000 \\
\hline 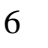 & -4.338130000 & 0.654778000 & -0.220962000 & 6 & 2.349753000 & 4.104395000 & -1.321335000 \\
\hline 6 & -5.389004000 & & & 6 & 3.707257000 & & -1.001255000 \\
\hline 6 & -5.180995000 & 2.926815000 & -0.167364000 & 6 & 4.425190000 & 3.065584000 & -0.654042000 \\
\hline 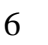 & -3.912171000 & 3.402176000 & -0.514618000 & 6 & 3.795898000 & 1.815885000 & -0.638713000 \\
\hline
\end{tabular}


$2.791719000 \quad-1.510234000$

$4.990669000 \quad-1.588411000$

$5.180521000-1.018691000$

$3.139203000 \quad-0.398005000$

$0.932634000 \quad-0.380683000$

$\begin{array}{ll}-0.990356000 & -2.297745000\end{array}$

$-1.938335000-2.554665000$

$-3.037171000-1.702574000$

$-3.183488000-0.596189000$

$-2.235846000-0.342357000$

$-0.135142000-2.958913000$

$-1.820616000-3.417729000$

$-3.773543000-1.903218000$

$\begin{array}{ll}-4.036101000 & 0.066428000\end{array}$

$\begin{array}{ll}-2.343582000 & 0.499945000\end{array}$

$0.598561000 \quad-0.114264000$

$1.517196000 \quad 0.121886000$

$\begin{array}{ll}2.884719000 & -0.056993000\end{array}$

$3.329676000 \quad-0.457363000$

$2.412508000 \quad-0.677231000$

$\begin{array}{ll}-0.461431000 & 0.012461000\end{array}$

$\begin{array}{ll}1.160654000 & 0.439415000\end{array}$

$3.597180000 \quad 0.118386000$

$\begin{array}{ll}4.391371000 & -0.590246000\end{array}$

$2.779375000-0.946099000$

$\begin{array}{ll}-1.676868000 & -2.326989000\end{array}$

$-2.836373000 \quad-2.708585000$

$-4.034773000 \quad-2.019567000$

$-4.064276000 \quad-0.948790000$

$-2.902143000 \quad-0.570513000$

$-0.748270000 \quad-2.856217000$

$-2.805241000 \quad-3.539376000$

$-4.936835000 \quad-2.316774000$

$-4.990783000$
2.415168000

$-1.713597000$

$-2.706205000$

$-1.814414000$

$-1.385883000$

$-2.383217000$

$-2.479237000$

$-2.520852000$

$-3.199719000$

2.647086000

2.550453000

$-3.214232000$

$-2.195669000$

2.266826000

3.183054000

4.488437000

4.875892000

3.964647000

1.256916000

2.878381000

5.200075000

5.891308000

4.288482000

3.174635000

4.021051000

4.270573000

3.672438000

2.816199000

3.010521000

4.488428000

4.930366000

3.868196000

2.353887000

$-4.210499000$

$-5.424266000$

$-5.662281000$

$-4.682931000$

$-3.464478000$

$-4.044980000$

$-6.186968000$

$-6.608029000$

$-4.866001000$

$-2.722330000$

$-3.285992000$

$-3.683878000$

$-2.998972000$

$-1.913005000$

$-1.511182000$

$-3.833659000$

$-4.530047000$

$-3.312965000$

$-1.377933000$

$-0.668082000$
2.592498000

2.556407000

2.202691000

3.095161000

3.278531000

$-0.332167000$

$-1.420585000$

$-0.004723000$

0.088461000

1.374457000

$-1.435377000$

0.809881000

$-1.560195000$

2.659811000

3.714269000

3.503386000

2.230780000

1.171026000

2.848788000

4.697662000

4.322134000

2.056859000

0.180343000

$-1.404116000$

$-2.439514000$

$-3.512925000$

$-3.543660000$

$-2.511303000$

$-0.568758000$

$-2.406492000$

$-4.316531000$

$-4.369335000$

$-2.546504000$

0.095129000

0.704962000

2.034448000

2.749352000

2.142834000

$-0.944426000$

0.140574000

2.505347000

3.777053000

2.717839000

$-1.479936000$

$-2.599900000$

$-3.811723000$

$-3.898326000$

$-2.778661000$

$-0.548938000$

$-2.528611000$

$-4.682292000$

$-4.835430000$

$-2.850858000$
1.664627000

2.396529000

2.110121000

3.348621000

1.644436000

3.559079000

3.539607000

4.598231000

2.967935000

$-0.767103000$

$-1.270553000$

$-0.289192000$

$-1.560138000$

$-1.191338000$

$-1.174594000$

$-0.721275000$

$-0.292029000$

$-0.318822000$

$-1.540215000$

$-1.517905000$

$-0.710662000$

0.048821000

$-0.017041000$

$-2.533583000$

$-2.930777000$

$-2.068978000$

$-0.807876000$

$-0.410727000$

$-3.206734000$

$-3.909401000$

$-2.378802000$

$-0.131580000$

0.570048000

0.403620000

0.726328000

0.360188000

$-0.333011000$

$-0.656085000$

0.670514000

1.252909000

0.606658000

$-0.629226000$

$-1.198990000$

$-2.448165000$

$-3.179217000$

$-3.037107000$

$-2.163579000$

$-1.427981000$

$-2.557936000$

$-3.854753000$

$-3.603525000$

$-2.049842000$

$-0.749965000$
0.365624000
1.271853000

0.435597000

$-0.480812000$

2.738130000

3.359098000

3.015300000

2.995142000

1.435469000

0.891726000

1.594891000
$-1.908006000$

$-2.430473000$

$-1.744058000$

$-2.574513000$

0.034612000

0.573411000

0.384463000

$-1.026133000$

2.788675000

3.449106000

3.339228000
3.953663000

3.637619000

5.036913000

3.770584000

3.050320000

2.331554000

4.053822000

2.989734000

2.102581000

1.422755000

3.040121000 trans $-\left[\mathrm{Cp} * \mathrm{Os}(\mathrm{dppe})(\mathrm{H})_{2}\right]^{+} \quad \mathrm{E}=-1499.80661031$

$\begin{array}{llll}6 & -0.811444000 & 1.046005000 & 2.703513000\end{array}$

$6 \quad 0.637347000$

$6 \quad 1.257846000$

$6 \quad 0.205721000$

$6 \quad-1.071088000$

$\begin{array}{ll}76 & 0.020220000\end{array}$

$15-1.639488000$

$15 \quad 1.585850000$
1.235894000

$-0.063078000$

$-1.051548000$

$-0.372501000$

0.071804000

$-0.034393000$

0.137316000
2.690465000

2.813365000

2.881635000

2.826865000

0.839907000

$-0.783964000$

$-0.885045000$ 


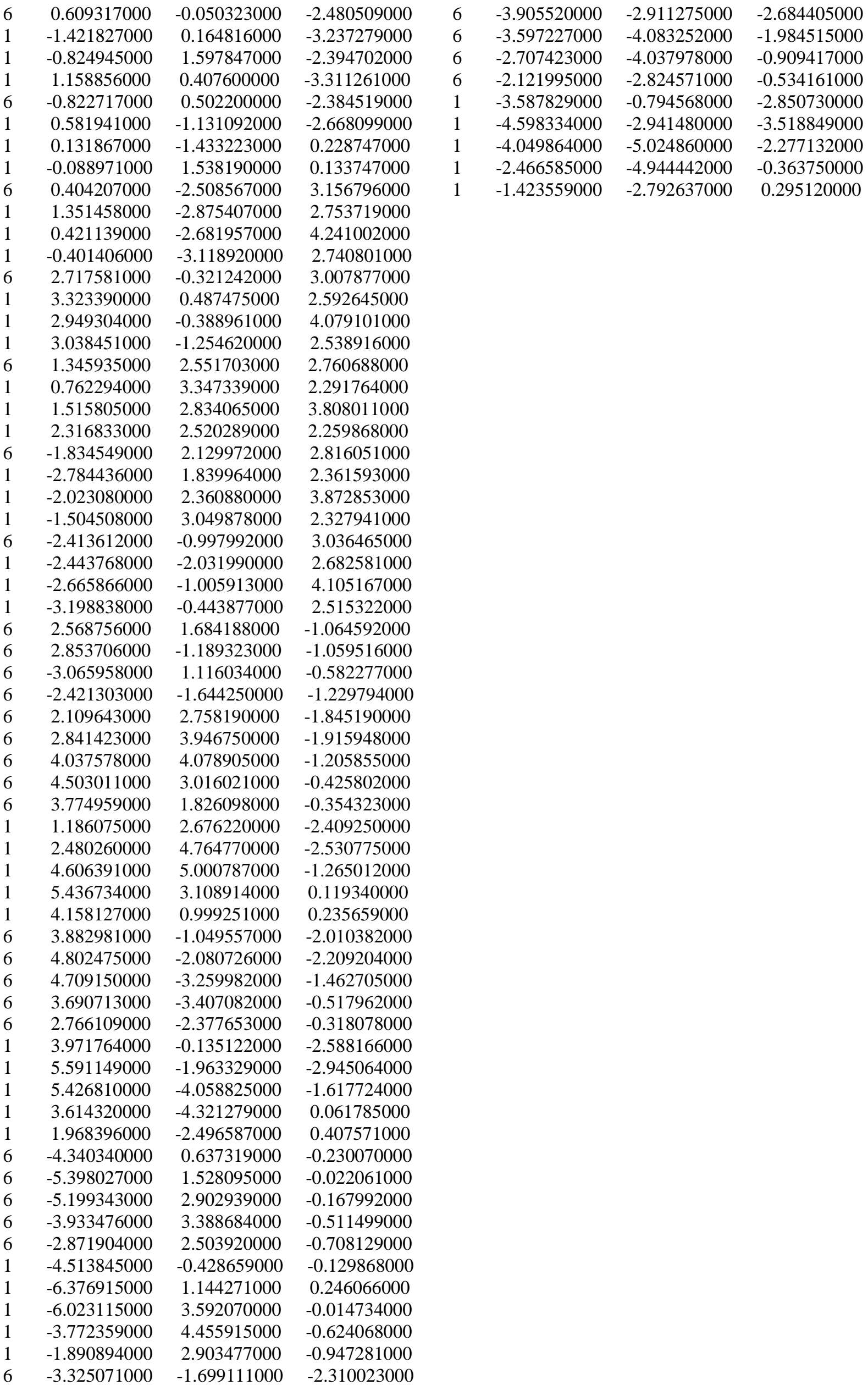


